\title{
A Network Filter for Social Learning Evidence from Equity Research
}

\author{
Jose Nicolas Uribe
}

Submitted in partial fulfillment of the requirements for the degree of Doctor of Philosophy

under the Executive Committee of the Graduate School of Arts and Sciences

\section{COLUMBIA UNIVERSITY}


(c) 2015

Jose N. Uribe

All rights reserved 


\section{ABSTRACT}

\section{A Network Filter for Social Learning Evidence from Equity Research}

\section{Jose Nicolas Uribe}

When are decision makers able to learn from others? I argue that actors occupying network positions that enable social learning gain a competitive advantage. I show that the accuracy of security analysts' earnings forecasts improves when the coverage network readily conveys information about competitors’ decision-making context. The benefits of social learning are most pronounced in unstable environments, measured by firms’ forecast dispersion. Causality is established using a natural experiment: surviving analysts’ network positions -along with their forecasting accuracy -deteriorated to the extent that their coverage overlapped with analysts who perished in the 9/11 attacks on the World Trade Center. The importance of social learning in the analyst profession goes well beyond improving forecasting accuracy. I show that analysts’ clients recognize narrow expertise on those stocks where the analyst is ideally positioned for social learning. This article contributes to organizational theory by specifying network positions providing a superior view of competitors' information environment and to strategy research by identifying conditions under which these positions confer a competitive advantage. 


\section{TABLE OF CONTENTS}

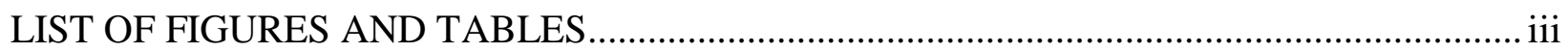

ACKNOWLEDGMENTS ........................................................................................ iv

Chapter 1: INTRODUCTION......................................................................................... 1

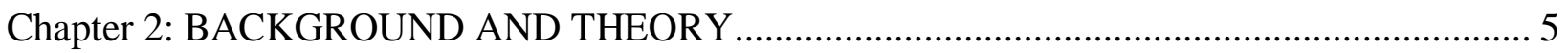

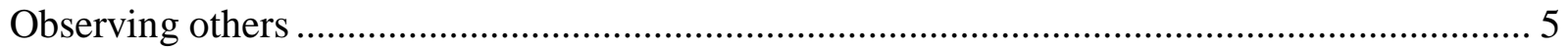

Imitation, rational herding and social learning ……….......................................................... 5

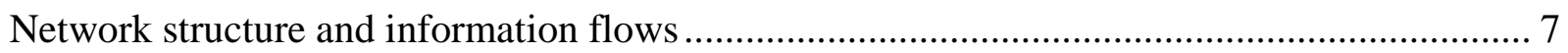

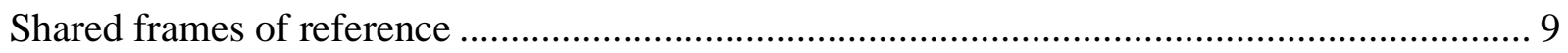

Audience closure as a measure of shared frames of reference in bipartite networks ................ 11

The role of environmental uncertainty ................................................................................ 14

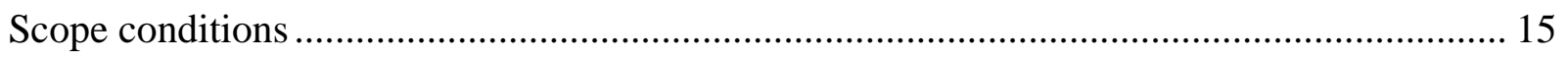

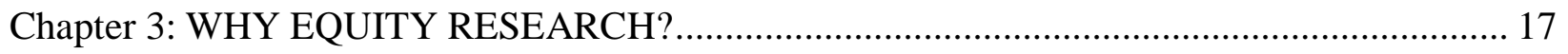

Analysts' task complexity ................................................................................................ 17

Earnings forecasts and forecasting accuracy ......................................................................... 18

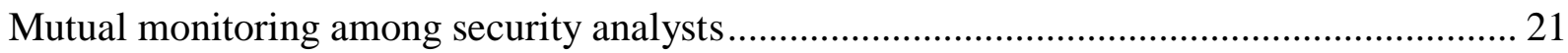

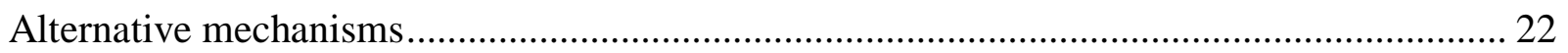

Forecasting under uncertainty …………………………..................................................... 23

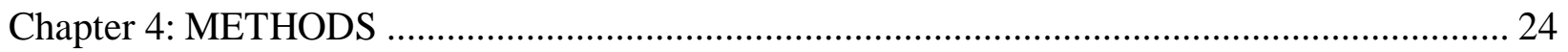

Data and sample......................................................................................................... 24 
Dependent variable

Audience closure in analyst context .......................................................................... 25

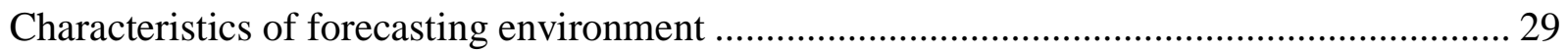

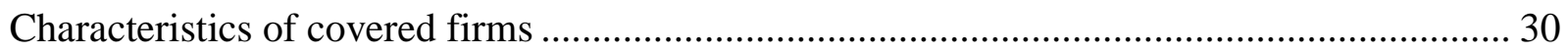

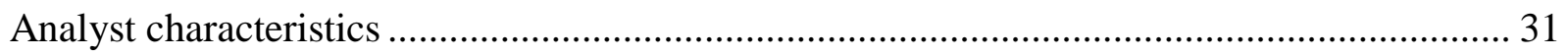

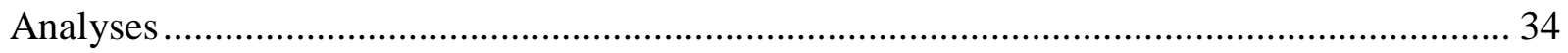

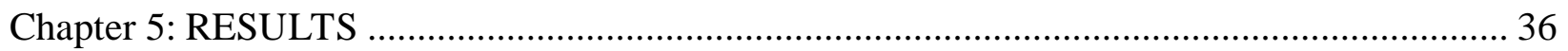

Testing a scope condition: observing others ............................................................. 42

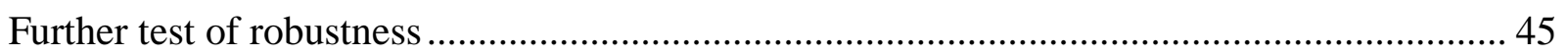

Chapter 6: A NATURAL EXPERIMENT TO ESTABLISH CAUSALITY ............................. 47

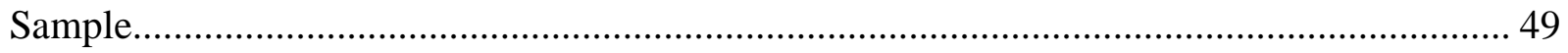

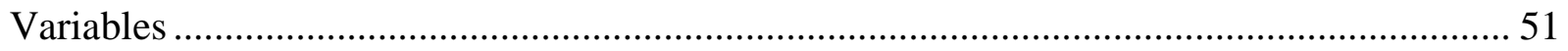

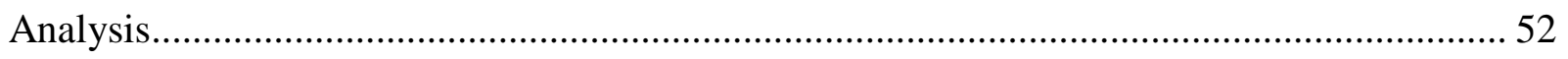

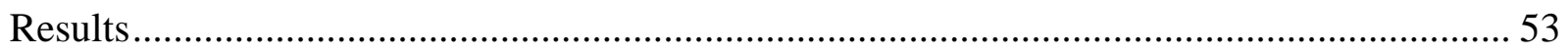

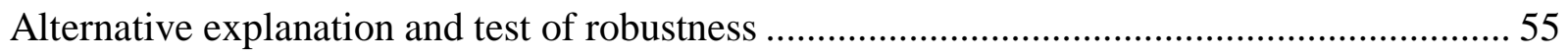

Chapter 7: STOCK-SPECIFIC EXPERTISE ................................................................. 57

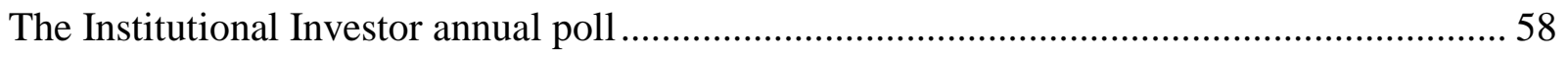

Investors' recognition of stock-specific expertise ........................................................ 58

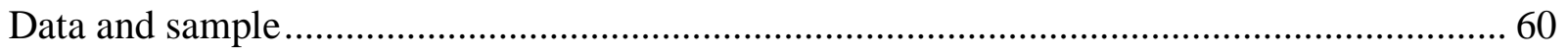

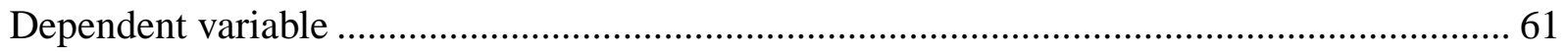


Relative scores for measures that vary within stock-years ......

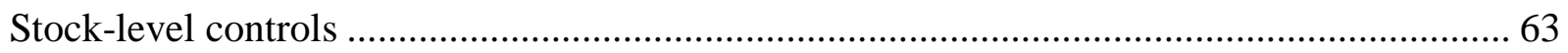

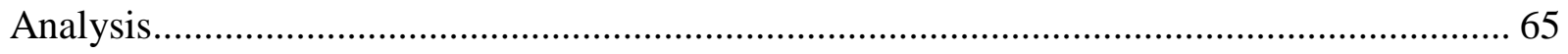

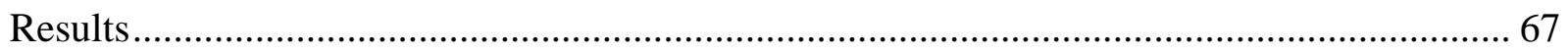

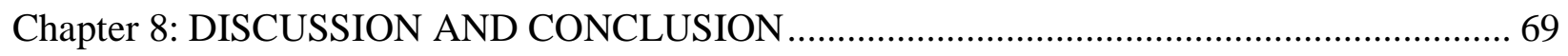

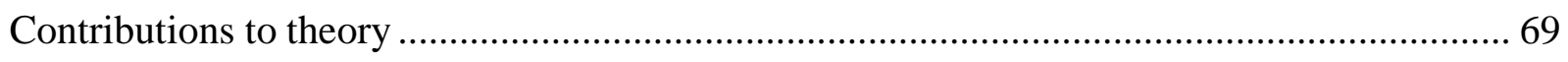

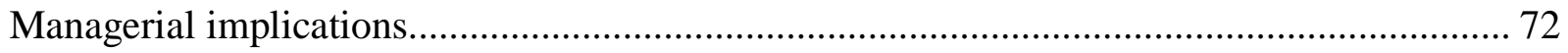

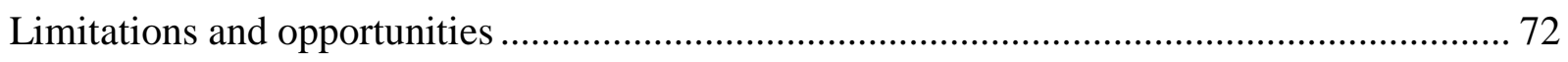

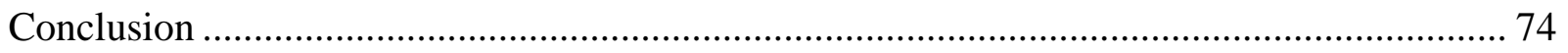

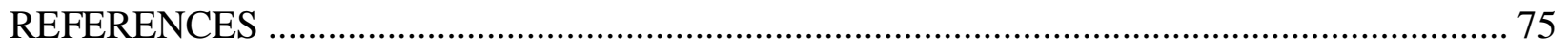

APPENDIX 1: CONSTRUCTING AUDIENCE CLOSURE ................................................. 91

APPENDIX 2: AUDIENCE CLOSURE AND OTHER NETWORK MEASURES.................. 93

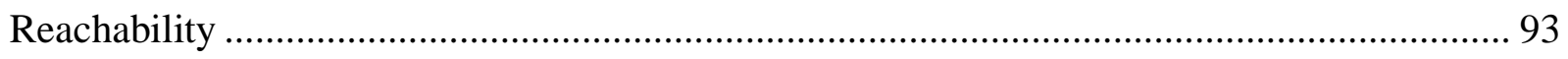

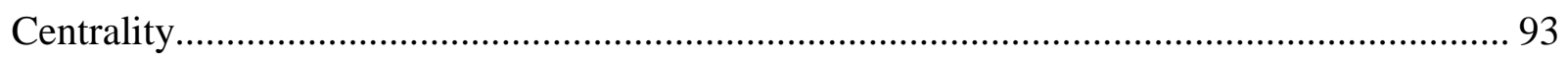

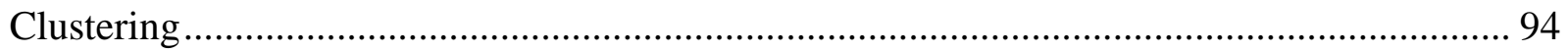

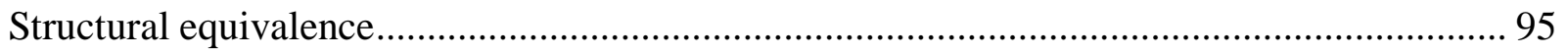

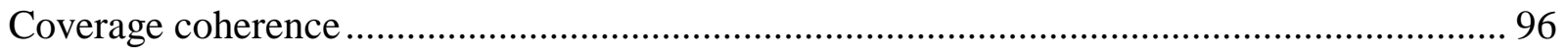

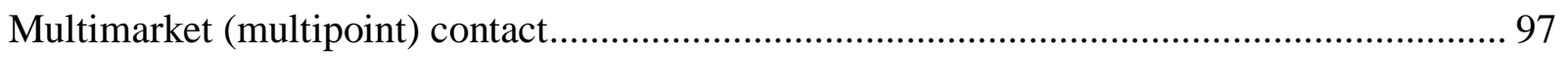

APPENDIX 3: PRODUCER CLOSURE EQUALS AUDIENCE CLOSURE.......................... 98 


\section{LIST OF FIGURES AND TABLES}

Figure 2.1: Producers (squares) as shared frames of reference .............................................. 13

Figure 4.1: Wolleben's coverage universe and those firms' analyst coverage.......................... 26

Figure 4.2: Comparison of two firms with equal analyst coverage ....................................... 27

Figure 4.3: Co-coverage of Wolleben's other firms by Peets and BEF analysts....................... 28

Figure 5.1: Effect of audience closure on forecasting error at three levels of uncertainty .......... 42

Figure 6.1: Loss of audience closure from an exogenous shock .......................................... 48

Figure 6.2: 9/11 sample selection, treatment and control groups (3,121 forecasts) .................. 50

Figure 6.3: Predicted increase in forecast error due to lost audience closure............................ 51

Figure 7.1: Effect of audience closure on the probability that firm $k$ is mentioned ................... 68

Table 3.1: Importance of accuracy in I.I’s analyst rankings, 2009-2013 ................................. 19

Table 4.1: Accuracy - descriptives and correlations (401,198 observations) ........................... 33

Table 5.1: Which conditions minimize forecasting error? (Test of H1)................................. 37

Table 5.2: Interactive effect of dispersion and AC on forecasting error (Test of H2)................ 40

Table 5.3: Audience closure and speed of forecast.......................................................... 44

Table 5.4: Determinants of error on forecasts of industry leaders’ EPS ................................. 46

Table 6.1: Effect on forecasting error of audience closure lost on 9/11 ................................. 54

Table 7.1: Investors’ recognition of analyst's stock-specific expertise................................. 61

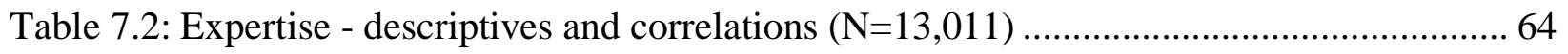

Table 7.3: Conditional probability that firm $k$ is mentioned in connection to analyst $i$.............. 66 


\section{ACKNOWLEDGMENTS}

I would like to express my deep gratitude to my advisor, Paul Ingram, for the excellent suggestions on this work and for his guidance throughout my time as a PhD student. Paul's sage advice and uncompromising standards of scholarship supported and inspired me through the many ups and downs of the research and writing process.

The other members of my dissertation committee also deserve much credit. I learned from Peter Bearman that the biggest roadblocks often represent the richest opportunities. Damon Phillips taught me much about how to transform amorphous ideas into a compelling theoretical armature. Kathy Phillips helped me elucidate my proposed mechanisms, and her insistence on "why should we care” greatly enhanced my writing. Working with David Ross improved my understanding of the importance of developing alternative hypotheses and of careful econometric analysis.

Finally, I would like to thank Jerry Kim, Ko Kuwabara, Stephan Meier, Hyung Il Oh, Evan Rawley, Oded Rozenbaum and Dan Wang for reading various parts of this work and for their invaluable expert advice. 
I dedicate this work to Autumn-Grace Dougherty, my life companion and a fountain of love and support. 


\section{CHAPTER 1: INTRODUCTION}

A Latin proverb alludes to the advantages of social learning by claiming that "a wise man learns by the mistakes of others.” ${ }^{\text {A }}$ Absent propitious conditions, however, even a wise person will be hard pressed to learn much from anyone. Making correct inferences about the actions of others -mistaken or not-requires an accurate understanding of their decision making context. Without contextual understanding, observing others may be of little or no benefit, could lead to incorrect inferences, or degenerate into blind imitation. Contextual understanding enables firms and decision-makers to distill the right lessons from the actions, reactions and outcomes of their competitors. What then, are the prerequisite conditions to contextual understanding? More specifically, what is the role of social structure in learning from others and under what conditions can specific network positions improve the performance of organizations and decision makers?

Answering these questions requires a shift away from the traditional focus on nodes, or actors in a network, to a focus on relative positions. An actor-centered focus misses structural properties encompassing higher-order dynamics. The result is a proliferation of research describing various seemingly independent phenomena, even when their source is one and the same. For example, research on learning from others (Baum, et al., 2000;Ferrier, 2001;Smith, et al., 2001;Beckman, and Haunschild, 2002;Srinivasan, et al., 2007;Greve, 2009;Tsai, et al., 2011) has developed virtually independently from research on herding and information cascades (e.g. Haveman, 1993;Greve, 1998;Mizruchi, and Fein, 1999;Rao, et al., 2001;Clement, and Tse, 2005;Watts, and Dodds, 2007;Pollock, et al., 2008;Jegadeesh, and Kim, 2010), even though both learning and herding emerge from the same underlying process -observing others. Juxtaposing these two research streams reveals dramatic variation in the predicted outcomes of observing

\footnotetext{
${ }^{1}$ The phrase "A fool learns from his own mistakes. A truly wise man learns from the mistakes of others." is also attributed to the $19^{\text {th }}$ century Prussian statesman Otto von Bismarck.
} 
others. A rapprochement of findings is however possible by studying the puzzle from the perspective of social structure.

One’s position in a network dramatically influences opportunities to observe and understand others' information environment, understood as the choice set of alternatives framing decision making. Absent a solid grasp on others’ information environment, actors may end up trapped in the herd even as they try to learn. Conversely, plentiful access to others' information environment permits filtering out relevant insights from noise, improving information quality. In this connection, I construct a simple measure called audience closure to quantify access to others' information environment. Audience closure can be used to detect influential positions across a variety of bipartite networks including firms joining alliances (Doz, 1996;Stuart, 1998;Gulati, and Gargiulo, 1999;Gulati, and Higgins, 2003;Gimeno, 2004), producers entering new markets (Baum, and Korn, 1999;Haveman, and Nonnemaker, 2000), or competitors choosing a technological position (Stuart, and Podolny, 1996). I provide empirical evidence that positions characterized by high audience closure in a network of competitors enable occupants to filter information more effectively.

This research makes three major contributions. First, learning from others is not just a node-level characteristic or the result of individual agency. Rather, network positions are differentially endowed with capacity to funnel and filter observed information. Second, the benefits to social learning are moderated by environmental uncertainty. While past work has argued that social learning is most advantageous in complex and uncertain environments (Greve, 1998;Srinivasan, et al., 2007;Terlaak, and Gong, 2008), other research has found environmental uncertainty to have harmful behavioral consequences (Milgram, et al., 1969;Rao, et al., 2001; Cialdini, 2009). The structural turn proposed in this paper helps reconcile these seemingly 
discrepant perspectives. Uncertain environments are characterized by noisy, nebulous information, which increases the riskiness of learning from others. Uncertainty often results in mindless imitation, negative information cascades and bad decisions. At the same time, uncertainty also increases the potential payoff of filtering information effectively. When uncertainty is high, occupants of positions characterized by audience closure can better filter observed information and gain a performance advantage. Conversely, there is little to be gained from a better filter in stable environments where all parties have full access to relevant decision factors. The third contribution of this research is an empirical substantiation of causality. By employing the advantages of a natural experiment (Mouw, 2006), I address the profound selection and causality challenges plaguing most network studies (e.g. Emirbayer, 1997;Sampson, et al., 2002). I investigate exogenous structural changes in the network of analysts whose coverage overlapped with victims of the 9/11 terrorist attacks and estimate the impact of these changes on forecasting accuracy.

The theory is developed by examining the forecasting performance and the development of stock-specific expertise amongst security analysts. The equity research profession is characterized by complexity and uncertainty, two conditions known to increase reliance on observing others (Aldrich, and Ruef, 2006). While the analyst setting has been exploited to test theories of herding and information cascades, (i.e. Hong, et al., 2000;Cooper, et al., 2001;Rao, et al., 2001;Clement, and Tse, 2005;Jegadeesh, and Kim, 2010), herding-based theories cannot account for systematic drivers of individual performance (they are concerned with changes in a group's performance variability). Therefore, previous studies have overlooked whether analysts differ in how effectively they use observed information. I find that network positions of audience closure improve forecasting accuracy, and that audience closure's filtering benefits are 
most pronounced in uncertain environments, measured by firms' forecast dispersion. I address endogeneity concerns by studying how the sudden deaths of sixteen publishing analysts in the 9/11 attacks affected the forecasting performance of surviving competitors. The random, exogenous removal of analysts from the stock evaluation network causally lowered forecasting accuracy on those stocks that survivors had co-covered with the victims. Beyond improving forecasting performance, social learning enables the development of narrow yet valuable expertise. I examine justifications made by the investment clients of top-ranked analysts, and find that expertise is more readily recognized on those stocks where the analyst is exceptionally positioned for social learning.

Chapter 2 reviews the contemporary scholarship on social learning and network positions, highlighting major gaps in this literature. Also in chapter 2, I lay out the social learning mechanism and propose the concept of "audience closure" as a general measurement strategy for studying audiences and producers in an evaluation network. Chapter 3 provides important characteristics of the equity research profession and states the hypotheses regarding the impact of analysts' network position on forecasting accuracy. The data and methods used to test these hypotheses are described in chapter 4 . Chapter 5 reports the results of the analysis, including several checks of robustness. In chapter 6, I discuss endogeneity concerns and provide support for a causal interpretation of audience closure by studying how the sudden deaths of sixteen publishing analysts in the 9/11 attacks affected the forecasting performance of surviving competitors. Chapter 7 further validates the importance of audience closure: clients of topranked analysts tend to recognize expertise on those specific stocks with which the analyst has exceptional audience closure. Finally, Chapter 8 discusses contributions to the literature and implications for practitioners. 


\section{CHAPTER 2: BACKGROUND AND THEORY}

\section{Observing others}

Most human behavior is learned from observing others (Bandura, 1977). By observing others, individuals can gain information about a larger number of options than could be directly evaluated without carrying the full cost of exploration and experimentation (Terlaak, and Gong, 2008; Wisdom, et al., 2013). A robust stream of research in evolutionary biology (Giraldeau, et al., 2002;Kameda, and Nakanishi, 2003;McElreath, et al., 2005;Mesoudi, 2008) and cognitive science (Goldstone, and Janssen, 2005;Rendell, et al., 2010; Theiner, et al., 2010;Wisdom, and Goldstone, 2011;Wisdom, et al., 2013) has identified several conditions that enhance learning from others. However, attending to the actions of others can have negative consequences. For instance, Rao and colleagues (2001) show that relying on social proof to infer the value of an action often leads to disappointment. Information cascades, where decision-makers act exclusively on information inferred from others with complete disregard for their private information, also call into question the benefits of attending to the actions of others (Gaba, and Terlaak, 2013). The benefits of learning and the risks of herding have been extensively investigated, but each body of research has remained largely self-contained.

\section{Imitation, rational herding and social learning}

In the imitation (e.g. Milgram, et al., 1969;DiMaggio, and Powell, 1983) and herding traditions observers follow others based on a variety of decision rules including "follow similar others", "follow high status” or "follow the majority”. In its original formulation (Banerjee, 1992), rational herders ignore their own information and follow the majority, even when the majority is wrong. Once a rational herder follows the majority, their private information is 
invisible to other observers. New observers have even more reason to follow the growing majority, forming information cascades. More sophisticated formulations (i.e. "rational” herding) take into account individual preferences, payoffs and information accuracy (i.e. Bikhchandani, et al., 1998) as well as the complexity of what is being observed (Munshi, 2004). Despite the insights gained from this research, rational herders and imitators ultimately engage in some form of aping legitimated action (DiMaggio, and Powell, 1983), leaving little room for learning from others.

In contrast to studies based on imitation or rational herding, social learning theory ${ }^{2}$ focuses on a critical step between observation and action; the interpretation of third party behavior. The importance of accurate interpretation of others' actions is implicit in extant research. Social learners who masterfully incorporate cues from others into their decision framework are more adept at interpreting rivals’ moves as well as predicting their possible future moves. For example, firms can take advantage of geographically dispersed inter-firm networks to learn about competitors and draw more value from observing their actions (Greve, 2009). Similarly, firms enjoy a competitive advantage from “understanding their rivals” (e.g. Ferrier, 2001;Smith, et al., 2001;Tsai, et al., 2011). I go beyond the general call to understand competitors and collaborators by pointing to what exactly needs to be understood: others’ information environment.

Ideally, social learning requires a thorough review of similarities and differences between a context " $A$ ", where some information is observed and context " $B$ " where the observed information is to be applied. While similarities provide a quick check that the information can be easily adopted, differences between contexts $A$ and $B$ will increasingly hamper social learning

\footnotetext{
2 I use "social learning” throughout, but some studies in the organizational learning literature use the equivalent term "vicarious learning”.
} 
because an observer must adjust for each different characteristic. Without contextual understanding, inferences from others' actions may lead to acting on inappropriate or outdated information (Rendell, et al., 2010). The advantages of understanding others' information environment have been documented in laboratory and field studies. Experimental subjects in a multiplayer game performed better when allowed to observe the actions of peers in similar information environments because this condition enabled subjects to quickly make improvements to their own solutions (Wisdom, et al., 2013). In Rogers' studies of innovation diffusion (1995), similar information environments enabled building up from earlier discoveries by preserving backwards compatibility with previous knowledge. This research, however, has yet to incorporate the role of structure in constraining and enabling social learning. Next I discuss how positions in a network differentially affect the understanding of others' information environment, thus uncovering a structural source of competitive advantage.

\section{Network structure and information flows}

A large body of work links network structure to information advantages and performance (e.g. Burt, 1992;Burt, 1997;Reagans, and Zuckerman, 2001;Cummings, and Cross, 2003;Cummings, 2004;Burt, 2007). One driver of information advantages is a party’s position in the relevant network structure. Central positions are typically associated with access to more information (Strang, and Tuma, 1993), while positions spanning disconnected groups (i.e. positions of brokerage) confer more diverse information (Burt, 1992). Although positions of brokerage can speed up detection and development of rewarding opportunities (Burt, 2005;Burt, 2007;Burt, 2010), brokers spanning many otherwise disconnected others can also receive a broad spectrum of relatively superficial information. Evans’ (2010) study of industrial and 
government-funded academic science suggests that network structures characterized by brokerage produce more expansive and speculative knowledge, while dense clusters of collaboration generate deeper and more focused knowledge. An interface replete with structural holes hampers the ability to develop finely-meshed information filters, required to filter out noise while capturing nuance. A network broker with insufficient contextual knowledge will therefore be unable to understand or derive much value from novel information (Aral, and Van Alstyne, 2011).

While scholars have convincingly demonstrated that direct social ties increase the ability to learn from others (Darr, et al., 1995;Ingram, and Simons, 2002), few studies have investigated how network positions hinder or enables social learning. Research on structural equivalence has shown that individuals similarly positioned in the flow of information attend to each other and tend to converge in their judgments, "even if they have no direct communication with each other”(Burt, 1987, p. 1293). Just like herding, however, structural equivalence can predict convergence in outcomes, but not superior performance. However, other research implies that some network positions enable occupants to learn more effectively from their competitors. For example, Greve (2009) found that networks facilitating comparison of information from multiple sources enabled shipping firms to quickly adopt a novel container ship. Similarly, shipbuilders with access to the decision criteria of competitors were able to avoid an innovation that had disseminated in their market but subsequently proved disappointing (Greve, 2011). This article builds upon and extends this research by specifying the concept of "shared frames of reference" as the theoretical mechanism enabling occupants of some network positions to engage in social learning more effectively. 


\section{Shared frames of reference}

Frames of reference denote a set of units that identify a coordinate system with respect to which properties of objects are gauged (Levinson, 2003). When applied to social learning, frames of reference designate the set of objects that inform others' actions or opinions. Decision makers may share some, all or none of their frames of reference with each other. An essential tool for making sense of complex offerings is the ability to carry out diagnostic comparisons (Gilbert, et al., 1995), and shared frames of reference between evaluators enable such diagnostic comparisons (Clark, and Brennan, 1991;Kashima, et al., 2007). More shared frames of reference denote fuller cognitive access and understanding of others' decision criteria, and enable better use by ego of information inferred from observing alters' actions. The following example illustrates the ubiquity of frames of reference in evaluation tasks.

Imagine having to choose a hotel using the TripAdvisor website for an overnight stay at an unfamiliar destination. One of the hotels being considered (call it $K$ ) has received two reviews, from users $i$ and $j$ respectively. Reviewer $i$ "loved the hotel”, while reviewer $j$ "would not recommend this hotel”. Suppose that $i$ has reviewed a number of places that the decision maker is well familiar with. ${ }^{3}$ These reviews comprise shared frames of reference. Each additional shared frame improves the decision maker's ability to use i's evaluation of hotel $K$ to meet her goals. The intuition here is that i's evaluation of hotel $K$ would be discounted if reviews of familiar places diverged wildly from the decision maker's private views. If opinions converged, $i$ 's evaluation of $K$ would tend to be more influential. In contrast to $i$, user $j$ reviewed hotels which the decision maker is not familiar with (or wrote the other reviews in a foreign

\footnotetext{
${ }^{3}$ TripAdvisor and other services based on user-generated content permit access to reviewers' history by clicking on their profiles.
} 
language). Without shared frames of reference, $j$ 's opinion about hotel $K$ constitutes "flat" information, which is less helpful for the decision maker.

High overlap in frames of reference between decision makers conveys more of the different dimensions of information known to each party, while also conveying information about the source. Two distinct but interdependent processes are at play here. First, more shared frames enable untangling characteristics about the source from information about the target under evaluation. For example, information from a known pessimist (optimist) can be adjusted upward (downward). Second, shared frames also enable better contextualizing because the focal evaluator is more familiar with the choice set of alternatives framing others' behavior and opinions. For example, other hotels reviewed by $i$ in the previous example could overwhelmingly attract a particular type of clientele, which would be difficult to know (or very time-consuming to learn) without first-hand experience because most reviews would be written from the perspective of the dominant clientele. In other words, shared frames convey information about other evaluators (the untangling process) as well as information about others' information environment (the contextualizing process). Both the untangling and contextualizing processes inherent in shared frames improve an evaluator's ability to learn from others. ${ }^{4}$ The usefulness of the shared frames of reference concept can be empirically tested in evaluation networks populated by audiences and producers. ${ }^{5}$

A "producer" refers to any actor whose offerings are consumed or evaluated by one or more "audiences”. Audiences include actual and potential consumers, investors, employees,

\footnotetext{
${ }^{4}$ Untangling and contextualizing are theoretically distinct but empirically inseparable because basic comparison processes in the brain seem to always carry out both tasks jointly. The usefulness of studying these two processes in isolation is not immediately apparent.

${ }^{5}$ A "producer" refers to any actor whose offerings are consumed or evaluated by one or more "audiences". Audiences include actual and potential consumers, investors, employees, certification agencies, government institutions, critics, and analysts (Hsu, et al., 2009).
} 
certification agencies, government institutions, critics, and analysts (Hsu, et al., 2009). Without one or more actual or potential audiences, the "producer” designation would be meaningless. Likewise, an "audience” emerges only when a set of evaluators attend to the same or similar producers. This ontological interdependence is often overlooked in empirical studies of audience and producers. Consider the well-studied interface of security analysts providing guidance on the stocks of publicly traded firms (e.g. Zuckerman, 1999;Zuckerman, 2000;Rao, et al., 2001;Zuckerman, 2004;Beunza, and Garud, 2007;Burt, 2007;Bowers, et al., 2013;Washburn, and Bromiley, 2014). A newly listed company will seek coverage from analysts specializing in firms similar to it. At the same time, a rookie analyst will focus attention on those firms covered by competitors with similar coverage responsibilities. An exclusive focus on the network of firms or on the network of analysts would miss the fact that shared frames of reference in evaluation networks arise interdependently. ${ }^{6}$ I attend to this interdependence and develop the concept of shared frames of reference as a characteristic of positions in a bipartite network of audiences evaluating producers.

\section{Audience closure as a measure of shared frames of reference in bipartite networks}

Structure in a traditional social network typically refers to patterns of ties between actors of the same general type. ${ }^{7}$ In bipartite networks, two types of actors (i.e. evaluators and producers) are linked exclusively to each other (Borgatti, and Everett, 1997). An advantage of bipartite networks over traditional networks is that the necessary data for the former can come

\footnotetext{
${ }^{6}$ For example, the overlap between different customers' past purchases and their browsing activity is at the heart of Amazon.com's algorithm for recommending products (Zhou, et al., 2010).

${ }^{7}$ While useful for many research questions, interviews and questionnaires capture not actual patterns of interaction but actors' perception and recollection of their networks.
} 
from any source identifying links between two types of agents, such as lists of groups and members, firms and markets, actors and movies or buyers and sellers. A challenge of analyzing bipartite networks is that most traditional network measures such as reach (Wasserman, and Faust, 1994, pgs. 159-161) and different types of centrality (Freeman, 1979;see Borgatti, 2006 for a review) describe properties of single-node networks. Measures created specifically for bipartite networks usually summarize a node’s overall position (Borgatti, and Everett, 1997;Lind, et al., 2005;Latapy, et al., 2008;Opsahl, 2011), for example a firm’s average position relative to all analysts that cover it (Zuckerman, 2004). Capturing shared frames of reference in the audience producer interface requires a measure that uniquely describes the relative positions of each node relative to each other node in the opposite network. I define "audience closure" as a measure specifically designed for bipartite networks, which captures the number of frames of reference readily available to a specific evaluator about a specific producer. ${ }^{8,9}$

The audience closure for an evaluator $i$ and a producer $k$ is the number of shortest possible indirect paths between them, or the total number of three-step paths. ${ }^{10}$ Compare the positions of the four evaluators (Ali, Ben, Cal and Deb) in figure 2.1 attending to the focal producer, $\mathrm{p}_{\mathrm{F}}$. Ali does not have any indirect paths to $\mathrm{p}_{\mathrm{F}}$, and audience closure is therefore zero. There is a single three-step path between Ben and $\mathrm{p}_{\mathrm{F}}$ (through $\mathrm{p}_{1}$ - Deb), so audience closure for $\mathrm{p}_{\mathrm{F}}$ and Ben is one. Audience closure for $\mathrm{p}_{\mathrm{F}}$ and Cal is two because they are connected by two

\footnotetext{
${ }^{8}$ Appendix 1 contains detailed steps of how to construct audience closure starting from raw data. Stata code to calculate audience closure and related measures is available from the author upon request.

${ }^{9}$ See appendix 2 for a detailed description of the relationship and differences between audience closure and several extant network measures.

10 Ties in bipartite networks connect nodes of different types, meaning that the minimum distance between two nodes of the same type (i.e. evaluator-evaluator or producer-producer) is two.
} 
distinct three-step paths (through $\mathrm{p}_{2}-$ Deb and $\mathrm{p}_{3}-\mathrm{Deb}$ ). Deb has the highest audience closure with $\mathrm{p}_{\mathrm{F}}(3)$, since three three-step paths connect them (through $\mathrm{p}_{1}-\mathrm{Ben}, \mathrm{p}_{2}-\mathrm{Cal}$, and $\mathrm{p}_{3}-\mathrm{Cal}$ ).

Figure 2.1: Producers (squares) as shared frames of reference

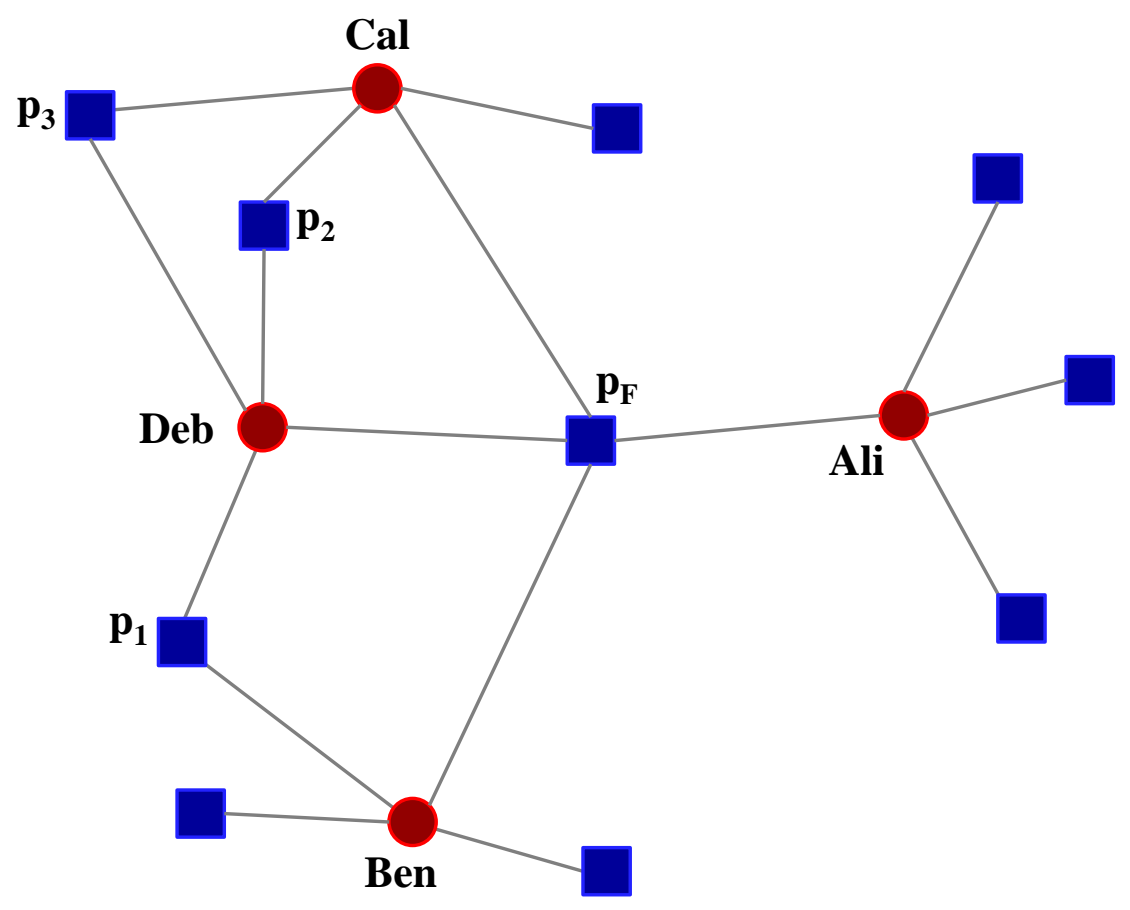

Audience closure captures the extent to which an observer has ready access to others’ frames of reference (i.e. she knows where others' "are coming from”), and can thus better calibrate her own cognitive map about a specific target of evaluation. For example, in figure 2.1, Deb is familiar with Ben's evaluation of $\mathrm{p}_{1}$ and Cal's evaluation of $\mathrm{p}_{2}$ and $\mathrm{p}_{3}$. She can use this information to improve her interpretation of Ben's and Cal's evaluations of the focal producer and in turn calibrate her own assessment.

Higher audience closure between Deb and the focal producer is sensitive not only to the extent that $\mathrm{p}_{\mathrm{F}}$ connects Deb’s most similar alters (Zuckerman, 2004), but also to the extent that Deb interfaces with $\mathrm{p}_{\mathrm{F}}$ 's most comparable producers. In social networks terminology, Deb and 
$\mathrm{p}_{\mathrm{F}}$ form more dually cohesive structures (Borgatti, and Everett, 1997). This is another desirable characteristic of audience closure; it incorporates the interdependence of audiences and producers by not reducing information from the producer side of the network when studying audience-side dynamics (and vice-versa). ${ }^{11}$ Each unique three-step path provides a focal evaluator with an additional shared frame of reference to calibrate and update her knowledge about a focal producer. One could of course define audience closure to include the number of unique paths of any length connecting evaluators and producers. However the "scope of the social frame of reference” influencing an evaluation operates only over very short distances (Burt, 1987). For example, once direct links and three-step paths are taken into account, it is unlikely that Ben's evaluation of $\mathrm{p}_{\mathrm{F}}$ in figure 2.1 will be influenced by the fact that Deb and Cal share producers $\mathrm{p}_{2}$ and $\mathrm{p}_{3}$.

\section{The role of environmental uncertainty}

Managing uncertainty is a central aspect of organizational life. According to Oliver Williamson (1985, pg. 57), “interesting problems of economic organization arise only in conjunction with uncertainty:”. Environmental uncertainty reflects a lack of information clarity, and hampers the accurate assessment of current and future decision-making situations (Beckman, et al., 2004;Gaba, and Terlaak, 2013). A long research tradition finds that in such ambiguous situations, people tend to turn to each other for cues as to the structure of the situation (Coleman, et al., 1957;Burt, 1987;Davis, and Greve, 1997). The effectiveness of social learning under conditions of uncertainty, however, remains an unsettled question. Another departure of this research from previous studies is an examination of how environmental uncertainty influences

\footnotetext{
${ }^{11}$ This statement implies symmetric treatment of both node sets. In other words, audience closure for evaluator $i$ and producer $k$ is equal to "producer closure" for producer $k$ and audience $i$. Appendix 3 contains a mathematical proof of this equivalence.
} 
the impact of social learning on performance, and how networks funnel and filter this relationship.

Some scholars find that social learning can be especially advantageous in complex and uncertain environments (Greve, 1998;Srinivasan, et al., 2007;Terlaak, and Gong, 2008). At the same time, other research finds that uncertainty can also trigger bandwagons and information cascades (Rao, et al., 2001). When uncertainty is high, uninformed actors are more likely to follow each other and can perpetuate a wrong course of action as those observed undertaking the same action increase in number (Milgram, et al., 1969;Cialdini, 2009). I propose that these divergent findings can be reconciled by considering actors' shared frames of reference. Fuller access to others' frames of reference increases the ability to incorporate good information and discard bad information. The extent to which an observer knows others' frames of reference determines whether uncertainty will help or hinder. Uncertain environments can increase the advantage of those better positioned to interpret complex, noisy signals (i.e. individuals occupying positions of high audience closure). Rather than blindly herding, a social learner from a position that exposes others' frames can better differentiate useful signals from "background noise”. Therefore, environmental uncertainty should increase the value of social learning from high audience closure positions. When uncertainty is high, Deb should have a greater advantage in evaluating the focal producer in figure 2.1 than when the environment is easily predictable.

\section{Scope conditions}

Social learning requires mutual awareness -but not acquaintanceship -among individuals (Bandura, 1977). This means that my theory does not apply to audiences who do not know about each other or who are unable to observe one another's actions. More specifically, one could not 
calculate audience closure for retail investors and the stocks they trade through anonymous electronic exchanges. The benefits from social learning generally increase when evaluated objects are complex or unique (Tucci, and Lojo, 1994) and when the problem space is too large for a single individual to cover (Wisdom, and Goldstone, 2011). To this point, a study of e-mail communications at an executive recruiting firm found that network bandwidth between contacts (a close construct to audience closure in single-mode networks) increased access to novel information more than network diversity when contacts were aware of a larger number of topics and operating in fast changing information environments (Aral, and Van Alstyne, 2011). The theory I propose here applies to tasks where information is abundant but interpretation is difficult. I do not predict a competitive advantage from overlapping frames of reference for tasks of information discovery, where detection of opportunities and diverse points of view represent crucial resources (such situations benefit more from positions that can reach diverse and distant others rather than from positions of audience closure). For example, a venture capitalist's search for diversified targets for funding would benefit more from positions of brokerage than from audience closure. Finally, testing audience closure as a source of competitive advantage requires audiences with a strong motivation for observing the behaviors, opinions and outcomes of others. A direct implication is that the performance of audiences unconcerned with the actions and outcomes of others should not be affected by changes in audience closure. The world of equity analysts meets these scope conditions and provides an interesting organizational context in which to test the theory. 


\section{CHAPTER 3: WHY EQUITY RESEARCH?}

Sell-side analysts’ stock recommendations and forecasts of companies' future earnings constitute "two of the most anxiously anticipated, solicited, and dissected news items on Wall Street” (Cohen, et al., 2010). ${ }^{12}$ Not surprisingly, much research has been devoted to understanding analysts' forecasts of firms' future earnings. ${ }^{13}$ In addition to its critical role in financial markets, the analyst setting provides an important empirical advantage for understanding audience-producer dynamics. Audiences are frequently a more diffuse group than producers and their boundaries harder to identity. Scholars acknowledging this empirical challenge have left the task of modeling the implications of the coexistence of multiple audiences to future research (e.g. Hannan, et al., 2007). The analyst setting provides visible links between multiple audiences and producers. Published research reports for individual firms are typically signed by a single "head analyst", and thousands of research reports connect firms to the analysts who cover them.

\section{Analysts' task complexity}

In financial markets the difficulty of interpreting and framing information justifies the costly activities of analysts (Grossman, and Stiglitz, 1980). More than in most other professions, analysts must allocate their attention "efficiently among the overabundance of information

\footnotetext{
${ }^{12}$ Security analysts are categorized as either "sell-side” or "buy-side.” In this study, I examine sell-side analysts who produce research reports mainly for the consumption of investors outside the firms that employ them. Usually they work for a brokerage firm that aims to attract clients by issuing reports. Buy-side analysts produce research to advise investment decisions that are internal to their firms which are money managers such as mutual funds, pension funds, or hedge funds. Buy-side analysts' research is not visible to all audience members, so they do not meet the scope condition of my theory.
}

${ }^{13}$ Among other topics, analysts have been studied in connection to reputational and career concerns, conflicts of interest, geographic location, and herding behavior. For a review, see Mehran and Stulz (2007), Ljungqvist, Malloy and Marston (2009a) and Groysberg (2010). 
sources that might consume it" (Simon, 1997, pgs. 40-41). Constructing a firm’s earnings forecasts requires interpretation of enormous amounts of information on accounting and economic fundamentals, business strategy, operations and corporate governance (Beunza, and Garud, 2007). Analysts’ ability to masterfully combine and interpret this information is valuable to their clients. For example, an analyst appearing in Institutional Investor (I.I.) magazine’s analyst ranking was praised for "always confirming what she hears with other sources. She puts the information together and interprets its impact on the stocks” (October 1998, emphasis added). Analysts seem to be neither mindless herders nor atomistic calculators, but rather information interpreters who "combine mental models and social cues in their calculations" (Beunza, and Garud, 2007).

\section{Earnings forecasts and forecasting accuracy}

Security analysts’ earnings forecasts are commonly used in the finance literature as a measure of market expectations (Ramnath, et al., 2008). Earnings forecasts embed analysts’ knowledge and insight about a firm, and are also the source for their recommendations and price targets (Loh, and Mian, 2006). The accuracy of earnings forecasts is a valid and convenient measure of information advantage because forecasts are observable, their accuracy is easy to evaluate and because forecasting accuracy represents a professional imperative that analysts need in order to build and maintain their reputation (Ljungqvist, et al., 2007). Forecast accuracy matters for analysts because it matters to their clients. Nowhere is this clearer than in Institutional Investor (I.I.) magazine's annual poll, which cites from institutional investors and buy-side money managers explaining their vote for a particular analyst. Table 3.1 provides 
sample quotes extracted from the last few editions of I.I.'s “All-American Research Team” issue to illustrate the importance given to accuracy in the work of sell-side analysts.

Table 3.1: Importance of accuracy in I.I's analyst rankings, 2009-2013

\begin{tabular}{|c|c|c|c|}
\hline Cite from Institutional Investor magazine & Sector \& year & Analyst \& employer & Attributed to \\
\hline $\begin{array}{l}\text { [produces] "the most rigorous financial models out } \\
\text { there," which "fully illustrate the accuracy of earnings } \\
\text { estimates" }\end{array}$ & $\begin{array}{l}\text { Cable \& Satellite } \\
\text { (2011) }\end{array}$ & $\begin{array}{l}\text { Benjamin Swinburne } \\
\text { (Morgan Stanley) }\end{array}$ & clients \\
\hline "consistently accurate on stock calls" & $\begin{array}{l}\text { Internet } \\
\text { (2011) }\end{array}$ & $\begin{array}{l}\text { Justin Post } \\
\text { (Bofa/Merrill Lynch) }\end{array}$ & a fan \\
\hline "extreme accuracy in stock calls" & $\begin{array}{l}\text { Computer Services \& } \\
\text { IT Consulting } \\
\text { (2011) }\end{array}$ & $\begin{array}{l}\text { Roderick Bourgeois } \\
\text { (Sanford C Bernstein) }\end{array}$ & a buy-side fan \\
\hline $\begin{array}{l}\text { "accurately predicted an upward rerating of the } \\
\text { entertainment group...I trust his numbers more than any } \\
\text { of his peers"' }\end{array}$ & $\begin{array}{l}\text { Media } \\
(2013)\end{array}$ & $\begin{array}{l}\text { Douglas Mitchelson } \\
\text { (Deutsche Bank) }\end{array}$ & an advocate \\
\hline $\begin{array}{l}\text { "Michael's valuation work is finely tuned and invariably } \\
\text { the most accurate of the group" }\end{array}$ & $\begin{array}{l}\text { Homebuilders \& } \\
\text { Building Products } \\
\text { (2013) }\end{array}$ & $\begin{array}{l}\text { Michael Rehaut } \\
\text { (JP Morgan) }\end{array}$ & a loyalist \\
\hline $\begin{array}{l}\text { "Bill's recommendations and estimates are accurate and } \\
\text { reliable" }\end{array}$ & $\begin{array}{l}\text { Airfreight \& Surface } \\
\text { Transportation } \\
\text { (2013) }\end{array}$ & $\begin{array}{l}\text { William Greene Jr } \\
\text { (Morgan Stanley) }\end{array}$ & a backer \\
\hline
\end{tabular}

Forecast accuracy represents a clear information advantage for analysts because of the reputational, economic, and career incentives tied to producing accurate estimates, and the high costs associated with inaccuracy (Hong, et al., 2000). Irvine (2004) found a positive association between forecast accuracy and compensation, while Stickel (1992) found that highly rated “AllAmerican” analysts are more accurate earnings forecasters than other analysts. Hong and Kubik (2003) showed that relatively accurate forecasters are more likely to experience favorable job 
separations, either remaining or moving up to a higher status brokerage house. In turn, the probability that an analyst will leave her current position increases if her forecasts are less accurate than those of her peers (Irvine, 2004). Because short-term earnings forecasts are easily verifiable, more so than investment recommendations and other activities, analysts face quick reputational costs for missing actual results by wide margins.

As with any source of competitive advantage, forecast accuracy is hard to come by. ${ }^{14}$ Cohen et al. (2010) found no significant differences in relative forecast accuracy between analysts with school ties to management and those without, even though analysts with ties to managers capitalized on their private information advantage by making more profitable stock recommendations. Similarly, Ljungqvist and colleagues (2007) did not find evidence that investment banking or brokerage pressures affected analysts’ forecast accuracy. Cowen et al. (2006) find that, regardless of the type of firm they work for, more accurate earnings forecasters also tend to issue less optimistic stock recommendations. Given the difficulty of making accurate forecasts, analysts gaining a reputation for accuracy can more credibly make bolder recommendations (Ljungqvist, et al., 2007) and tend to issue more profitable stock recommendations (Loh, and Mian, 2006). ${ }^{15}$

\footnotetext{
${ }^{14}$ In contrast, virtually any analyst can issue a bold forecast (i.e. far away from consensus) without any regard to the accuracy of his estimate. Being bold and inaccurate is a risky proposition that is easily exposed once firms' actual earnings are published. Low-status analysts with little reputation at risk may sometimes engage in such a strategy (i.e. Bowers, et al., 2013), but the large body of literature on analyst behavior indicates that the dominant strategy for rookies and non-experts is to engage in safe herding and follow the consensus.

${ }^{15}$ Loh et al. (2006) report that the average factor-adjusted return associated with the recommendations of analysts in the highest accuracy quintile exceeds the corresponding return for analysts in the lowest accuracy quintile by $1.27 \%$ per month.
} 


\section{Mutual monitoring among security analysts}

Several studies document that analysts observe each other (Hong, and Kubik, 2003; Wansleben, 2012). By observing each other, analysts engage in an indirect, or mediated form of sociality (Beunza, and Stark, 2012) that does not require direct interpersonal ties in order to be keenly and mutually aware. Analysts need to be sharply attuned to each other's coverage universe (Rao, et al., 2001) and opinions (Cooper, et al., 2001) because clients will often reference the opinions of other analysts (Barker, 1998) or question why their position on a stock differs from that of a competitor (Bowers, et al., 2013). For example, when analyst Meredith Whitney raised the alarm on Oct. 31, 2007 that Citigroup would need to take drastic measures to avoid bankruptcy, Bear Stearns' analyst David Hilder, went on record saying that “concerns about Citigroup's capital position and dividend policy, raised by a competitor, are overstated" (Lewis, April 9 2008, emphasis added).

In sum, analysts have ample opportunities and institutionalized incentives to cross-check and update private information by observing the actions of other analysts. However, analysts' ability to interpret and infer accurate meaning from these observations depends on shared frames of reference. More shared frames of reference provide superior information filtering because actions and opinions of competitors are both readily accessible and more relevant for calibrating information about a particular firm. ${ }^{16}$ Audience closure uniquely characterizes each analyst's frames of reference shared with the set of competitors co-covering each stock. The superior information filtering inherent in positions of high audience closure improves the analyst's ability to accurately forecast a firm's future earnings, leading to the first hypothesis.

\footnotetext{
${ }^{16}$ On the issue of information access, an analyst is obviously free to read any reports published by other analysts. However, the time pressures and cognitive demands of the job make it unlikely that an analyst will develop deep knowledge about firms not in her portfolio.
} 
H1: Higher audience closure improves forecasting accuracy.

\section{Alternative mechanisms}

In addition to testing the social learning mechanism, the audience closure variable implicitly tests an alternative hypothesis based on the structural holes literature (Burt, 1992). If diverse and unique information is what benefits performance, then audience closure would in fact be a measure of information constraints, resulting in lower forecasting accuracy. Even if audience closure constitutes a positive predictor of forecasting accuracy, it may be capturing a mechanism other than social learning. For example, an analyst's high audience closure with a stock implies that the analyst's closest competitors also cover that stock. Competitors covering more of the same stocks are more relevant to each other, which is known to increase attentional focus (Bargh, 1982). In fact, research in other competitive settings ranging from knitwear manufacturers (Porac, et al., 1995) to basketball teams (Kilduff, 2010) have found that close competitors tend to focus attention on each other. Consequently, a firm covered by close competitors will tend to command a disproportionate amount of a focal analyst's attention, which in general should lead to more accurate forecasts. I address this alternative mechanism both statistically and theoretically. First, I include statistical controls for the amount of attention a focal analyst bestows on each stock. Second, there is no reason to believe that the forecasting accuracy on stocks covered by close competitors should vary according to the uncertainty in the stock's information environment. Conversely, the current theory enables clear predictions about the influence of environmental uncertainty on social learning's impact on accuracy. 


\section{Forecasting under uncertainty}

Uncertainty includes turbulent conditions across the stock market as well as the idiosyncratic turbulence of individual firms (Beckman, et al., 2004;Amiram, et al., 2013;Gaba, and Terlaak, 2013). In addition to market and firm-specific uncertainty, Gaba and Terlak (2013) defined inference uncertainty as “uncertainty stemming specifically from others’ actions, revealing inconsistent information and inhibiting the focal actor from updating its private information”. I focus on firms’ inference uncertainty because it is most consistent with the frames of reference mechanism. When others’ appraisals of future earnings become disparate, the value of better interpreting the published analyses of competitors becomes more advantageous. A good measure for inference uncertainty is forecast dispersion, which reflects noise in the private signals received by analysts and inherent difficulties in deciphering firms’ prospects (Johnson, 2004;Jackson, 2005). Forecast dispersion is associated with errors in judgment, negative information cascades, and lower overall forecast accuracy (Amiram, et al., 2013). ${ }^{17}$ If audience closure captures a social learning advantage, this advantage should be most pronounced when interpretations of a firm's signals are widely dispersed, leading to the second hypothesis:

H2: The benefits of audience closure on accuracy should operate primarily, or even exclusively, when forecast dispersion is high.

\footnotetext{
${ }^{17}$ In contrast, low variance in forecasts (i.e. high consensus) is a reliable predictor of a firm's future earnings.
} 


\section{CHAPTER 4: METHODS}

\section{Data and sample}

I extracted from the Institutional Brokers’ Estimate System (IBES) unadjusted detailed files of all available analyst forecasts between 2001 and 2013 for the subsequent annual earnings reports. I excluded "stale” forecasts, which were issued before the announcement of the previous year's actual earnings (Loh, and Mian, 2006) as well as observations where forecasts came from anonymous analysts (c.f. Fang, and Yasuda, 2009). The IBES data was merged with Compustat and CRSP to obtain accounting and financial data. The source for the institutional holdings data was the $13 \mathrm{f}$ form that investment companies and professional money managers are required to file with the SEC on a quarterly basis (Boldin, and Ding, 2008).

Following previous financial research, (c.f. Fang, and Yasuda, 2009;Cohen, and Lou, 2012), I removed observations in which the stock returns for the corresponding year were not available in CRSP. I also excluded from my sample those stocks with a price below one dollar at the time of the analyst estimate, which mitigates the impact of micro-cap stocks on calculations of forecasting accuracy. I matched the identity of analysts ranked by Institutional Investor magazine with the analyst's individual code in the IBES dataset using a translation file provided by Thomson Reuters.

The 2001-2013 time period was selected to coincide with the enactment of Regulation Fair Disclosure (Reg-FD), instated by the SEC in October 2000 to end the selective disclosure by firms to a subset of market participants (Cohen, et al., 2010). Prior to Reg-FD, early access to information constituted a type of “currency” between some firms and their favored analysts. Early information allowed favored analysts to gain an edge in forecast accuracy, usually in 
exchange for more favorable firm coverage (Bowers, et al., 2013). ${ }^{18}$ Much research on the impact of Reg-FD concludes that the law has in fact been effective in curtailing selective disclosure (see for example Cohen, et al., 2010). A second reason for selecting the 2001-2012 time period is the well-documented "anonymization" of a number of retrospectively embarrassing recommendations by star analysts from the pre Reg-FD IBES tape (Mola, and Guidolin, 2009). The improved quality of the IBES dataset after Reg-FD is thoroughly documented by Ljungqvist et al. (2009a).

\section{Dependent variable}

I capture lack of accuracy with the forecast error for analyst $i$ covering stock $k$ in year $t$ using a measure introduced by Hong and Kubik (2003). The most accurate forecast possible has a forecast error of zero. Any amount of error is scaled by the firm's lagged stock price, and multiplied by 10,000 to express forecast error in terms of basis points:

$$
F E_{i k t}=\frac{\left|F_{i k t}-A_{k t}\right|}{P_{k t-1}} \times 10,000
$$

where $F_{i k t}$ is the forecast of analyst $i$ for firm $k$ in year $t, A_{k t}$ are the actual earnings per share (EPS) of firm $k$ in year $t$ and $\mathrm{P}_{\mathrm{kt}-1}$ represents the closing stock price of firm $k$ in the previous year. I use the $\log$ of $F E_{i k t}$ as the dependent variable to reduce skewness.

\section{Audience closure in analyst context}

Audience closure (AC) in year $t$ for analyst $i$ covering firm $k$ can be written as

$$
A C_{i k t}=\sum_{i \neq j}\left(y_{i j t}-\sigma_{i k t}\right) \sigma_{j k t},
$$

\footnotetext{
${ }^{18}$ Under Reg-FD, companies must reveal any material information to all investors and analysts simultaneously in the case of intentional disclosures, or within 24 hours in the case of unintentional disclosures.
} 
where $y_{i j t}$ is the number of firms in year $t$ that analyst $i$ co-covers with every other analyst $j$. The indicator $\sigma_{i k t}\left(\sigma_{i j t}\right)$ is equal to one if in year $t$ analyst $i(j)$ covered the focal firm $k$, and zero otherwise. I use the log of Audience Closure ${ }_{i k t}$ to reduce skewness. Audience closure captures the focal analyst's ( $i$ ) shared frames reference with competitors $(j)$ relevant to forecasts of a focal firm $(k)$ on year $t$. Changes in audience closure arise based on a number of factors, including changes in coverage for the focal analyst or competitors, as well as firms' entries and exits from different industries.

The following example illustrates the logic and calculation of audience closure for Michael Wolleben, an analyst from Sidoti \& Co., and two of the firms he covered in 2011. That year, Wolleben covered a total of 11 firms, including Bob Evans Farms (BEF) and Peets Coffee (Peets). Collectively, these 11 firms received coverage from 51 analysts (Wolleben and 50 other analysts). Figure 4.1 displays Wolleben's covered firms in 2011 and patterns of analyst coverage for these firms in 2011.

Figure 4.1: Wolleben's coverage universe and those firms' analyst coverage

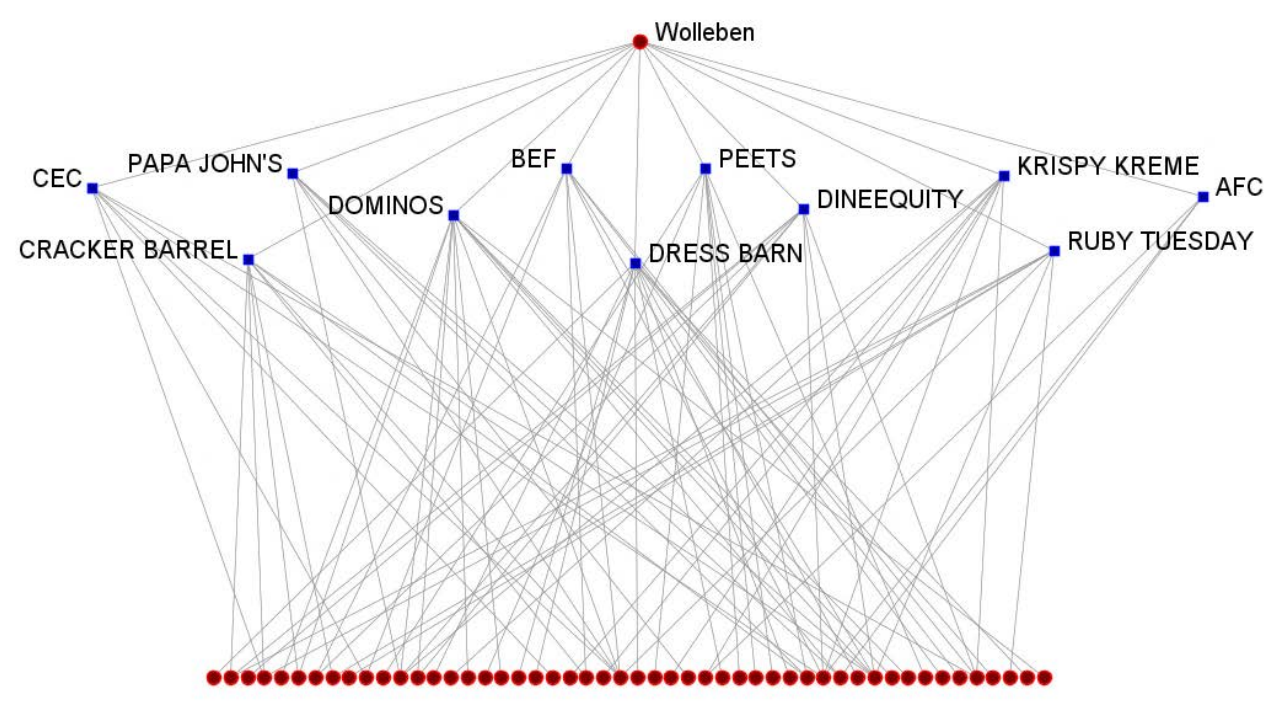


Despite significant overall overlap in figure 4.1, Wolleben was the only analyst in 2011 covering both Peets and $B E F$, each of which received coverage by eight additional analysts (Figure 4.2).

Figure 4.2: Comparison of two firms with equal analyst coverage

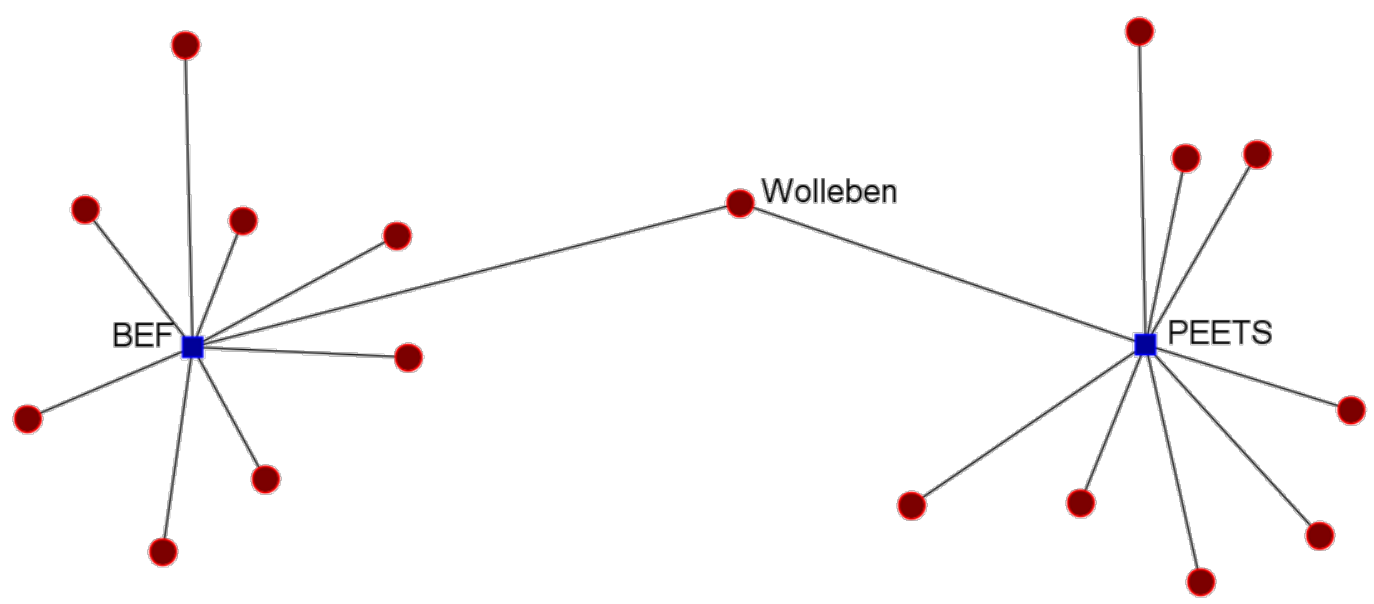

Access to competitors' frames of reference relevant to evaluating Peets and BEF depends on the overall co-coverage pattern between Wolleben and each set of competitors. Figure 4.3 illustrates coverage of Wolleben's other firms by BEF analysts (to the right) and Peets analysts (to the left). Each link connecting a firm to an analyst in figure 4.3 represents a distinct shared frame of reference that is readily accessible to Wolleben to improve, update or simply doublecheck forecasts for either BEF or Peets. 
Figure 4.3: Co-coverage of Wolleben's other firms by Peets and BEF analysts

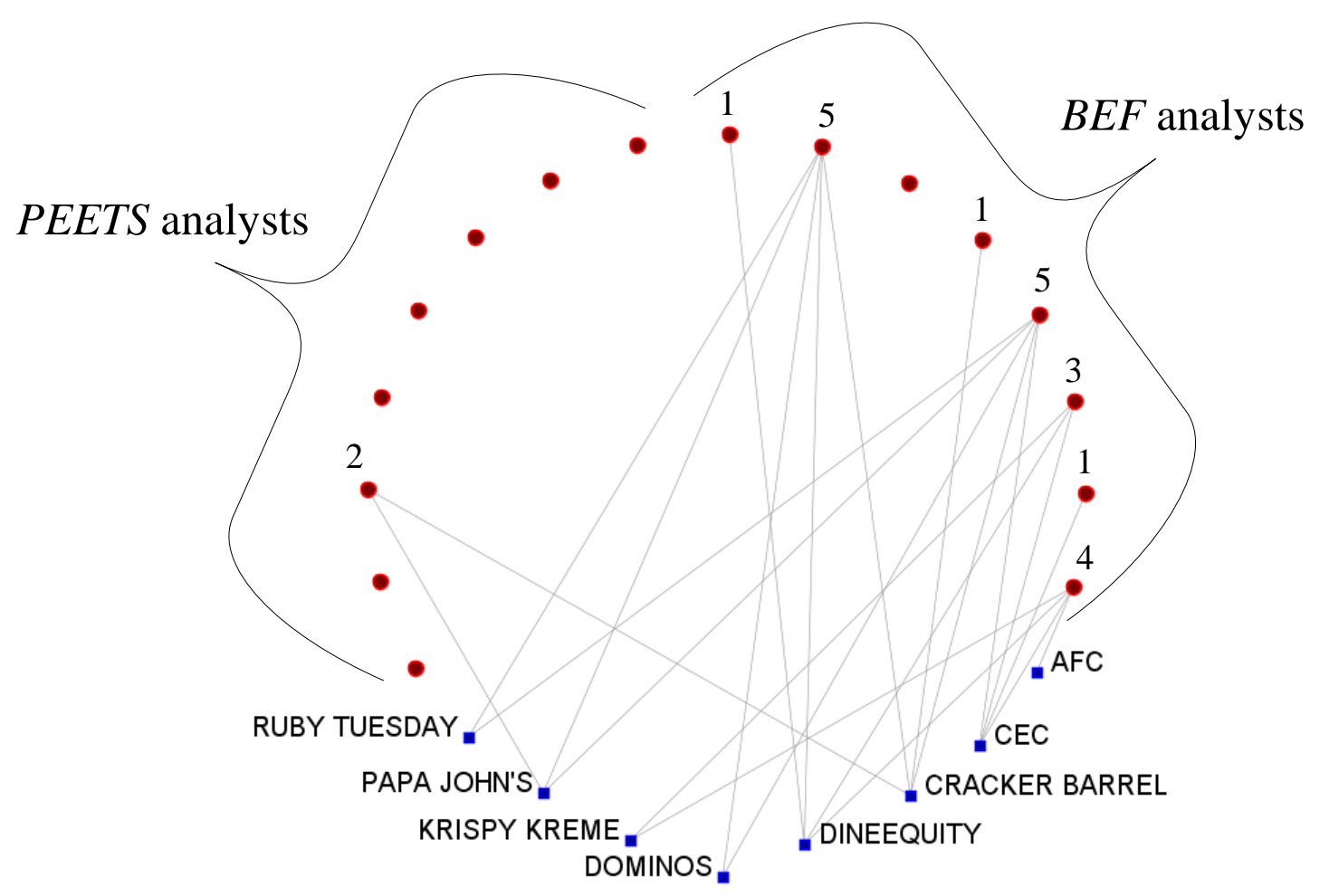

A simple count of the links connecting analysts covering $B E F$ to Wolleben's other firms indicates that audience closure between BEF and Wolleben is 20 (i.e. seven competitors cocovering 20 other firms, or shared frames of reference). ${ }^{19}$ Conversely, audience closure between Peets and Wolleben is two, since only one analyst from the Peets group covered two of Wolleben's other firms that year (Papa John's and Cracker Barrel).

Decision makers generally use heuristics that reduce search costs while increasing accuracy (Rao, et al., 2001). Without extending his coverage universe, Wolleben can elicit twenty reports from seven other analysts when forecasting BEF's future earnings. In contrast, Wolleben can easily summon only two reports from one analyst when thinking about Peets' future earnigns. Wolleben can calibrate his forecasts for $B E F$ with information from others much more effectively than for Peets. In line with my predictions, Wolleben was the least accurate

\footnotetext{
${ }^{19}$ From left to right, Wolleben's shared frames with each $B E F$ analyst are 1, 5, 0, 1, 5, 3, 1 and 4.
} 
forecaster for Peets in 2011, although he ranked around the $60^{\text {th }}$ percentile in accuracy amongst $B E F$ analysts.

\section{Characteristics of forecasting environment}

I test all models using several controls - described below -known to affect forecast accuracy. These include characteristics of the forecasting environment as well as heterogeneity in firms and analysts.

Forecast dispersion is computed according to work in finance (e.g. Avramov, et al., 2009;Berkman, et al., 2009). Dispersion $k$ is the standard deviation of EPS forecasts scaled by the absolute value of analysts' mean forecast for firm $k$.

Overall market volatility $y_{t}$ is the annualized standard deviation of daily value-weighted market returns of every stock traded in NASDAQ, NYSE and AMEX exchanges (Amiram, et al., 2013). This variable controls for cross-sectional dependence and also for the portion of environmental uncertainty that is not firm-specific.

Revision frequency has been used as a measure of interest in a particular stock (Mola, and Guidolin, 2009) and to proxy analysts’ allocation of effort and attention to it (McNichols, and O'Brien, 1997). The variable Log Forecast revisions ${ }_{i k t}$ is the logged count of the number of annual forecast revisions an analyst makes for each covered firm. ${ }^{20}$

Analysts who make their last annual forecast closer to the release of "true" earnings will often be more accurate because of the availability of more precise and up to date information (O'Brien, 1988;Clement, 1999). I therefore control for the number of days from an analyst's last forecast until the company releases its actual earnings with the variable Log Days to actuals ikt. $_{\text {. }}$

\footnotetext{
${ }^{20}$ Clement and Tse (2005) find that analysts who revise their earnings forecasts more frequently are less likely to herd. Similarly, Jegadeesh and Kim (2010) find that analysts who herd make less frequent revisions.
} 


\section{Characteristics of covered firms}

The number of analysts following a firm indicates the volume of information production about its financial prospects (Boehmer, and Kelley, 2009). A large following is usually deemed beneficial to the firm. For example, companies that are covered by more analysts receive relatively more favorable recommendations (McNichols, and O'Brien, 1997). The volume of information production is held constant with the variable No. of analysts $s_{k t}$, yearly count of the number of analysts covering firm $k$.

Analysts have less discretion with respect to covering the largest players in their sector, thus decreasing selection effects for these companies. I proxy for the size of a firm with the log of market capitalization, Log Market value ${ }_{k t}$. Firms’ annualized stock performance is captured by Cumulative returns $k_{k t}$. The variable Leverage $_{k \text { t }}$, the ratio of the book value of debt to total capital (debt plus equity), accounts for variation in a given firm's capital structure.

Institutional investors use equity analysts' research to inform their investment decisions. Consequently, a stock's institutional ownership influences the tenor of analyst recommendations (Ljungqvist, et al., 2007) trading activity (Boehmer, and Kelley, 2009) and price movements (Loh, and Stulz, 2011). I account for these influences with the variable Institut. ownership (\%) ${ }_{k t}$, the percentage of stock $k$ 's outstanding shares owned by institutional investors in year $t$. The impact of institutional investors can be concentrated or diffuse, depending on the relative size of each equity owner. I control for the concentration of institutional ownership with the variable Institut. ownership (HHI) $)_{k}$, a Herfindahl-type index of the concentration of ownership among institutional investors.

Coverage coherence $e_{k t}$ measures whether a firm's stock “occupies a clear position in the structure used by speculators to organize valuation” (Zuckerman, 2004). This control is 
important to distinguish audience closure's advantage in reading competitors from the coherence of a stock's investment community.

\section{Analyst characteristics}

Past research documents an inverse relationship between the size of an analyst's coverage universe and forecast accuracy (e.g. Mikhail, et al., 1997;Clement, 1999), presumably because covering a smaller set of firms allows greater focus and reduces an analyst's overall job complexity. I control for changes in the demands on an analyst's attention with the variable Stocks covered $_{i t}$, a measure of the number of firms covered by analyst $i$ in year $t$.

Analysts' firm-specific forecasting experience is associated with greater forecast accuracy (Clement, 1999) and negatively predicts propensity to herd (Hong, et al., 2000;Ljungqvist, et al., 2009b). I account for an analyst’s stock-specific experience with Years covering $_{i k t}$, the number of years analyst $i$ has covered stock $k$ in year $t$.

In general, the largest brokerage houses often assign “junior analysts” to work under head analysts in each sector. Junior analysts can increase the amount of research going into reports. I control for employer effects with Employer size $e_{i t}$, a measure of the total number of analysts employed in year $t$ at the same organization as focal analyst $i$.

Status is known to prompt others to follow one's actions (Bandura, 1977). Status in the analyst profession depends critically on the annual poll of money managers conducted by the Institutional Investor (I.I.) magazine (Hong, and Kubik, 2003). Ranked analysts are not only better compensated on average but are often more accurate forecasters (Stickel, 1992). High status is captured with the binary variable Ranked by II magazine $e_{i t}$, coded as 1 if analyst $i$ was 
ranked in the prior year's edition of II ( 0 otherwise). Roughly $11 \%$ of observations in the sample came from ranked analysts.

It is critical to differentiate audience closure from traditional network measures. I therefore control for an analyst's centrality in the coverage network using Degree centrality ${ }_{i t}$, the number of "direct competitors" in the bipartite network that the focal analyst can reach in two steps (Latapy, et al., 2008).

Capturing trading volume for their employers incentivizes analysts to release information before others (Cooper, et al., 2001). However, once an analyst revises her position, competitors may quickly follow suit to capture trading commissions. Log Timeliness ${ }_{i k t}$ controls for an analyst's propensity to herd on a particular stock and accounts for the propensity to issue forecasts quickly ahead or quickly behind other analysts (Cooper, et al., 2001). I constructed the variable by dividing the sum of the number of days between a current estimate and the dates of the preceding two estimates by the sum of the number of days between the current estimate and the following two estimates (Jegadeesh, and Kim, 2010). Log Timeliness ${ }_{i k t}$ increases for an analyst that is quick to issue forecasts but slow to follow others. ${ }^{21}$ Table 4.1 contains descriptive statistics and correlations for all the variables used in the analyses.

\footnotetext{
${ }^{21}$ Analysts tend to mechanically adjust their annual forecasts to reflect the surprise contained in quarterly earnings announcements, meaning that these forecast revisions are unlikely to contain new information (Cooper, et al., 2001). I control for the tendency of analysts to revise year-end forecasts following the release of quarterly earnings by eliminating forecast revisions that occur within five days of the quarterly earnings report.
} 


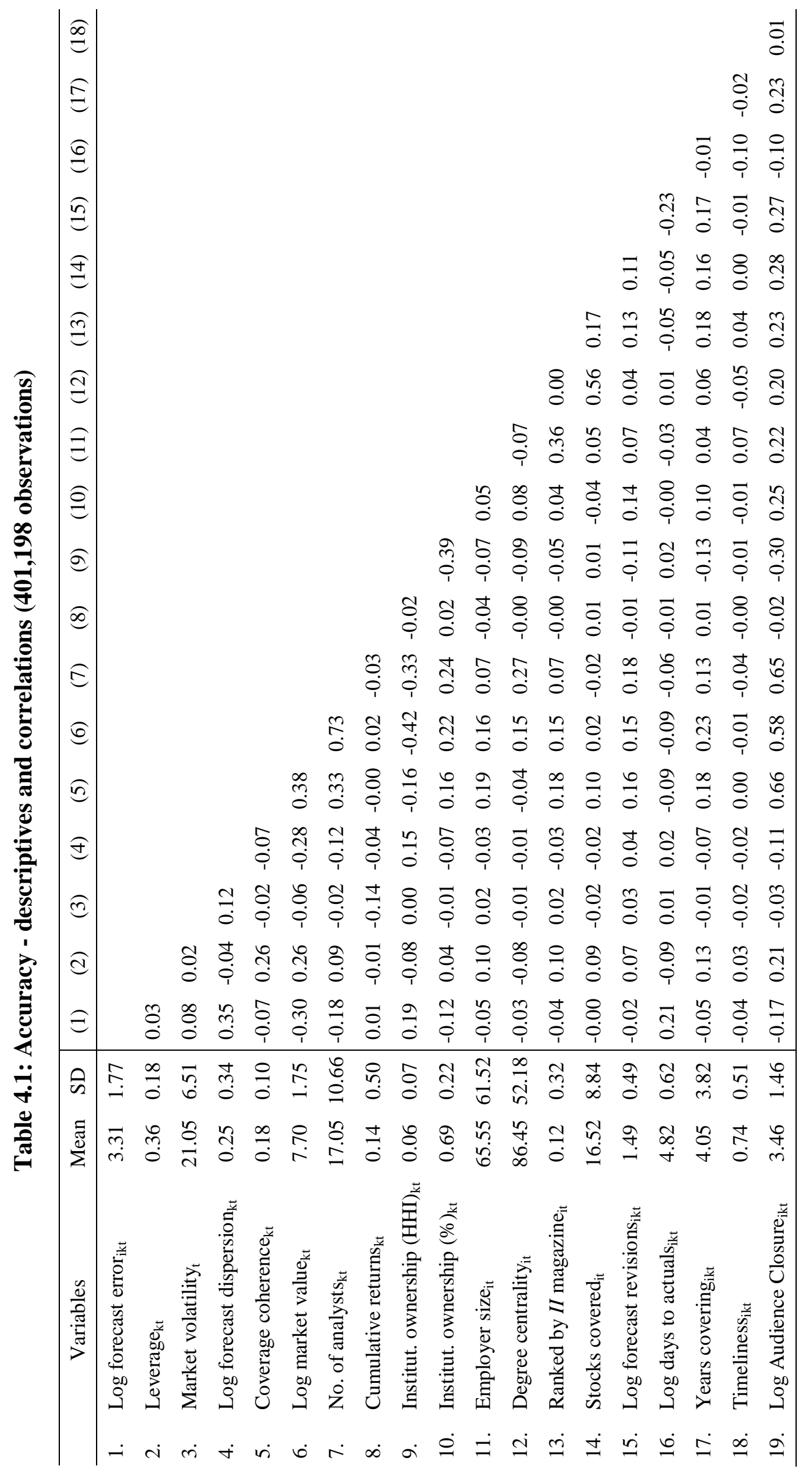




\section{Analyses}

This research’s focus on positions implies that structural advantages should hold regardless of whether one takes the perspective of the firm or the analyst. Higher audience closure should be associated with more accurate forecasts beyond firm-specific and analystspecific heterogeneity. I test hypothesis 1 using three complementary views of the data. First, I hold fixed the analyst-firm pair and observe changes in the forecasting environment in order to examine whether network positions are associated with better forecasts beyond firm-specific and analyst-specific heterogeneity. In the second specification, I hold each firm and time period constant while allowing for shifts in the characteristics of covering analysts. Such a model enables detecting analyst characteristics associated with more accurate forecasts. Finally, I examine the characteristics of firms that enable forecasters to be more accurate by holding constant the analyst and time period, while allowing for shifts in the characteristics of covered firms. The following model incorporates the aforementioned variables:

$$
F E_{i k t}=\alpha_{i}+\delta_{k}+\omega V_{t}+\lambda F_{i k t}+\beta K_{k t}+\gamma I_{i t}+\varepsilon_{i k t}
$$

where $\mathrm{FE}_{\mathrm{ikt}}$ is the log of analyst $i$ 's forecasting error on company $k$ 's earnings per share in year $t$. $F_{\mathrm{ikt}}$ is a vector of characteristics for a specific forecast of stock $k$ by analyst $i$. It includes the number of days between the last forecast and the announcement of company earnings, the number of forecast revisions during time horizon $t$ and shared frames of reference, measured by the log of audience closure, available to analyst $i$ evaluating firm $k . K_{k t}$ is a vector of firm characteristics, including market value, cumulative returns, leverage, forecast dispersion, institutional holdings and size of the analyst following. $I_{i t}$ is a vector of analyst characteristics; the number of firms followed, years of experience covering stock $k$, propensity for herding 
behavior, whether the analyst was mentioned in the I.I. rankings, and the size of the brokerage house employing the analyst. Yearly market volatility is captured by $\mathrm{V}_{\mathrm{t}}$, while $\alpha_{\mathrm{i}}$ and $\delta_{\mathrm{k}}$ respectively denote analyst and firm fixed effects. Lastly, $\epsilon_{\mathrm{ikt}}$ is an observation-specific error term.

Equation 1 reflects the data's panel structure, where the unit of analysis is an analyst $i$ forecasting the earnings of company $k$ in year $t$ (i.e. variation in the data occurs at three levels). I show the effects of audience closure using three views of the data structure. Estimating equation (1) with fixed effects for the analyst-firm pair accounts for time-invariant heterogeneity in analysts and firms, and reveals which conditions over time affect forecasting errors. Fixed effects for each firm-year reveals which analyst characteristics tend to drive forecasting error. Finally, fixed effects for each analyst-year reveals firm-level characteristics that impact forecasting accuracy within analysts’ annual coverage portfolio. I report heteroscedasticityrobust standard errors along with coefficient estimates. ${ }^{22}$

\footnotetext{
${ }^{22}$ Standard errors for the main coefficients of interest remain largely unchanged when clustering standard errors by firms or by analysts.
} 


\section{CHAPTER 5: RESULTS}

Table 5.1 displays four models testing hypothesis 1.Models one and two keep the analystfirm pair constant. Model three holds constant the firm-year pair, and model four holds the analyst-year pair constant. The first two models answer the question of which time-varying characteristics affect changes in forecasting error for specific analyst-firm pairs. Model three shows which analyst characteristics tend to drive forecasting error within firm-year observations. Model four measures characteristics of firms within an analyst's annual portfolio that have an impact on forecasting error. 
Table 5.1: Which conditions minimize forecasting error? (Test of H1)

\begin{tabular}{|c|c|c|c|c|}
\hline & Model 1 & Model 2 & Model 3 & Model 4 \\
\hline Log audience closure ${ }_{\text {ikt }}$ & $\begin{array}{l}-0.152^{* * *} \\
(0.006)\end{array}$ & $\begin{array}{l}-0.027 * * * \\
(0.007)\end{array}$ & $\begin{array}{l}-0.043^{* * *} \\
(0.003)\end{array}$ & $\begin{array}{l}-0.096^{* * *} \\
(0.005)\end{array}$ \\
\hline Log forecast revisions skt & $\begin{array}{l}0.040^{* * *} \\
(0.007)\end{array}$ & $\begin{array}{c}0.015^{*} \\
(0.006)\end{array}$ & $\begin{array}{l}-0.129^{* * *} \\
(0.005)\end{array}$ & $\begin{array}{l}0.225^{* * *} \\
(0.008)\end{array}$ \\
\hline Log days to actuals $s_{\mathrm{ikt}}$ & $\begin{array}{l}0.586^{* * *} \\
(0.005)\end{array}$ & $\begin{array}{l}0.573^{* * *} \\
(0.005)\end{array}$ & $\begin{array}{l}0.598^{* * *} \\
(0.006)\end{array}$ & $\begin{array}{l}0.582^{* * *} \\
(0.005)\end{array}$ \\
\hline Years covering $_{\text {ikt }}$ & $\begin{array}{l}0.084^{* * *} \\
(0.001)\end{array}$ & $\begin{array}{l}0.102^{* * *} \\
(0.001)\end{array}$ & $\begin{array}{l}-0.003^{* * *} \\
(0.000)\end{array}$ & $\begin{array}{l}0.008^{* * *} \\
(0.001)\end{array}$ \\
\hline Timeliness $_{\mathrm{ikt}}$ & $\begin{array}{l}-0.025^{* * *} \\
(0.006)\end{array}$ & $\begin{array}{l}-0.023^{* * *} \\
(0.005)\end{array}$ & $\begin{array}{l}-0.021^{* * * *} \\
(0.004)\end{array}$ & $\begin{array}{l}-0.002 \\
(0.005)\end{array}$ \\
\hline Forecast dispersion $_{\mathrm{kt}}$ & & $\begin{array}{l}0.479 * * * \\
(0.014)\end{array}$ & & $\begin{array}{l}1.112^{* * *} \\
(0.016)\end{array}$ \\
\hline No. of analysts ${ }_{k t}$ & & $\begin{array}{l}-0.002^{*} \\
(0.001)\end{array}$ & & $\begin{array}{l}0.009^{* * *} \\
(0.001)\end{array}$ \\
\hline Coverage coherence $\mathrm{kt}_{\mathrm{kt}}$ & & $\begin{array}{l}0.340^{* * *} \\
(0.071)\end{array}$ & & $\begin{array}{l}1.033^{* * *} \\
(0.046)\end{array}$ \\
\hline Log market value $e_{k t}$ & & $\begin{array}{l}-0.548^{* * *} \\
(0.009)\end{array}$ & & $\begin{array}{l}-0.305^{* * *} \\
(0.003)\end{array}$ \\
\hline Leverage $_{\mathrm{kt}}$ & & $\begin{array}{l}0.505^{* * *} \\
(0.035)\end{array}$ & & $\begin{array}{l}1.166^{* * *} \\
(0.018)\end{array}$ \\
\hline Cumulative returns $_{\mathrm{kt}}$ & & $\begin{array}{l}0.228^{* * *} \\
(0.006)\end{array}$ & & $\begin{array}{l}0.111^{* * *} \\
(0.008)\end{array}$ \\
\hline Inst. ownership $(\mathrm{HHI})_{\mathrm{kt}}$ & & $\begin{array}{l}0.741^{* * *} \\
(0.107)\end{array}$ & & $\begin{array}{l}0.798^{* * *} \\
(0.052)\end{array}$ \\
\hline Inst. ownership (\%) & & $\begin{array}{l}0.322^{* * *} \\
(0.035)\end{array}$ & & $\begin{array}{l}-0.597^{* * *} \\
(0.016)\end{array}$ \\
\hline Degree centrality ${ }_{\text {it }}$ & & $\begin{array}{l}-0.001^{* * *} \\
(0.000)\end{array}$ & $\begin{array}{l}0.000 * * * \\
(0.000)\end{array}$ & \\
\hline Ranked by II magazine $_{\text {it }}$ & & $\begin{array}{l}-0.040^{* *} \\
(0.013)\end{array}$ & $\begin{array}{r}0.009^{\wedge} \\
(0.005)\end{array}$ & \\
\hline Employer size $_{\text {it }}$ & & $\begin{array}{r}0.000^{\wedge} \\
(0.000)\end{array}$ & $\begin{array}{l}0.000^{* * *} \\
(0.000)\end{array}$ & \\
\hline Stocks covered $_{\text {it }}$ & & $\begin{array}{r}0.002^{*} \\
(0.001)\end{array}$ & $\begin{array}{l}0.001^{* *} \\
(0.000)\end{array}$ & \\
\hline Market volatility ${ }_{\mathrm{t}}$ & & $\begin{array}{l}0.017^{* * *} \\
(0.000)\end{array}$ & & \\
\hline $\begin{array}{l}\text { Analyst-firm fixed effects } \\
\text { Firm-vear fixed effects }\end{array}$ & $\checkmark$ & $\checkmark$ & $\checkmark$ & \\
\hline Analyst-year fixed effects & & & & $\checkmark$ \\
\hline Constant & $\begin{array}{l}0.632^{* * *} \\
(0.032)\end{array}$ & $\begin{array}{l}3.500^{* * *} \\
(0.080)\end{array}$ & $\begin{array}{l}0.737 * * * \\
(0.032)\end{array}$ & $\begin{array}{l}2.132 * * * \\
(0.039)\end{array}$ \\
\hline F statistic & 3644.403 & 1830.177 & 1497.280 & 4352.250 \\
\hline $\mathrm{R}^{2}$-within & 0.079 & 0.146 & 0.109 & 0.200 \\
\hline
\end{tabular}

Notes:

Dependent variable is the log of Forecasting Error, in basis points Includes annual EPS forecasts between 2001 and 2013 (401,059 observations)

Heteroscedasticity-robust standard errors in parentheses

$\wedge \mathrm{p}<.1,{ }^{*} \mathrm{p}<0.05,{ }^{* *} \mathrm{p}<0.01,{ }^{* * *} \mathrm{p}<0.001$ 
Hypothesis 1 is strongly supported: additional frames of reference reduce forecasting error, supporting a social learning advantage from high audience closure positions. The result holds whether the data is analyzed longitudinally (models 1 and 2) or in the cross-section (models 3 and 4). The significant, negative coefficient on audience closure in models 1 and 2 shows that even after keeping an analyst-firm pair constant, longitudinal changes in the network position increasing audience closure improve forecasting accuracy. Forecasting error within analyst-firm pairs is reduced in those years in which the analyst shares more frames of reference with competitors covering that stock. In addition to the analyst-firm fixed effects, this result is robust to the inclusion of time-varying covariates at the level of analysts and firms. The significant, negative coefficient on audience closure in model 3 means that from the perspective of a single stock in a given year, those analysts with high audience closure tend to issue more accurate estimates (i.e. lower forecasting error). The significant, negative coefficient on audience closure in model 4 means that in a given year, an analyst's forecasts tend to be more accurate on firms with high audience closure.

In model 2, the most conservative model, one standard deviation increase in audience closure leads to a decrease in forecasting error of .022 standard deviations. As a comparison, this effect is about one-third of what would be obtained if the overall market volatility decreased by one standard deviation (Beta coefficient $=.063$ ). The size of the impact of audience closure on forecasting error is comparable to increasing by two standard deviations the number of 
analysts covering the focal stock (Beta coefficient $=0.11$ ). ${ }^{23}$ The sign and strength of most control variables is similar to what has been previously found in the analyst literature. ${ }^{24}$

Models testing hypothesis 2 are presented in table 5.2 .

\footnotetext{
${ }^{23}$ This result was obtained by standardizing all observations used in the original models and re-running the same regressions using standardized variables.

${ }^{24}$ Somewhat surprisingly, a stock's increased coverage coherence is associated with an increase in an analyst's forecasting error. A possible explanation is that higher coverage coherence is associated with lower trading volume (Zuckerman, 2004), lowering commission incentives and analyst motivation to fine-tune their models.
} 
Table 5.2: Interactive effect of dispersion and AC on forecasting error (Test of H2)

\begin{tabular}{|c|c|c|}
\hline & Model 1 & Model 2 \\
\hline Log audience closure $_{\mathrm{ikt}}$ & $\begin{array}{l}-0.009 \\
(0.007)\end{array}$ & $\begin{array}{l}-0.085^{* * *} \\
(0.005)\end{array}$ \\
\hline Forecast dispersion $_{\mathrm{kt}}$ & $\begin{array}{l}0.715^{* * *} \\
(0.031)\end{array}$ & $\begin{array}{l}1.242^{* * *} \\
(0.029)\end{array}$ \\
\hline Dispersion $\times$ AC & $\begin{array}{l}-0.068^{* * *} \\
(0.009)\end{array}$ & $\begin{array}{l}-0.039 * * * \\
(0.010)\end{array}$ \\
\hline Log forecast revisions $s_{\mathrm{ikt}}$ & $\begin{array}{c}0.015^{*} \\
(0.006)\end{array}$ & $\begin{array}{l}0.225^{* * *} \\
(0.008)\end{array}$ \\
\hline Log days to actuals $s_{\mathrm{ikt}}$ & $\begin{array}{l}0.573^{* * *} \\
(0.005)\end{array}$ & $\begin{array}{l}0.582^{* * *} \\
(0.005)\end{array}$ \\
\hline Years covering ikt & $\begin{array}{l}0.101^{* * *} \\
(0.001)\end{array}$ & $\begin{array}{l}0.008^{* * *} \\
(0.001)\end{array}$ \\
\hline Timeliness $_{\mathrm{ikt}}$ & $\begin{array}{l}-0.023^{* * *} \\
(0.005)\end{array}$ & $\begin{array}{l}-0.002 \\
(0.005)\end{array}$ \\
\hline No. of analysts ${ }_{k t}$ & $\begin{array}{l}-0.002^{*} \\
(0.001)\end{array}$ & $\begin{array}{l}0.009^{* * *} \\
(0.001)\end{array}$ \\
\hline Coverage coherence $_{\mathrm{kt}}$ & $\begin{array}{l}0.347 * * * \\
(0.071)\end{array}$ & $\begin{array}{l}1.038^{* * *} \\
(0.046)\end{array}$ \\
\hline Log market value $\mathrm{e}_{\mathrm{kt}}$ & $\begin{array}{l}-0.549^{* * *} \\
(0.009)\end{array}$ & $\begin{array}{l}-0.306^{* * *} \\
(0.003)\end{array}$ \\
\hline Leverage $_{\mathrm{kt}}$ & $\begin{array}{l}0.505^{* * *} \\
(0.035)\end{array}$ & $\begin{array}{l}1.169^{* * *} \\
(0.018)\end{array}$ \\
\hline Cumulative returns $_{\mathrm{kt}}$ & $\begin{array}{l}0.229 * * * \\
(0.006)\end{array}$ & $\begin{array}{l}0.112^{* * * *} \\
(0.008)\end{array}$ \\
\hline Inst. ownership (HHI) $)_{\mathrm{kt}}$ & $\begin{array}{l}0.719 * * * \\
(0.107)\end{array}$ & $\begin{array}{l}0.788^{* * *} \\
(0.052)\end{array}$ \\
\hline Inst. ownership (\%) $)_{\mathrm{kt}}$ & $\begin{array}{l}0.332 * * * \\
(0.035)\end{array}$ & $\begin{array}{l}-0.590^{* * *} \\
(0.016)\end{array}$ \\
\hline Degree centrality $_{\text {it }}$ & $\begin{array}{l}-0.001^{* * *} \\
(0.000)\end{array}$ & \\
\hline 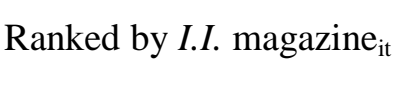 & $\begin{array}{l}-0.038^{* *} \\
(0.013)\end{array}$ & \\
\hline Employer size $_{\text {it }}$ & $\begin{array}{r}0.000^{\wedge} \\
(0.000)\end{array}$ & \\
\hline Stocks covered $_{\text {it }}$ & $\begin{array}{c}0.002^{*} \\
(0.001)\end{array}$ & \\
\hline Market volatility $_{t}$ & $\begin{array}{l}0.017^{* * *} \\
(0.000)\end{array}$ & \\
\hline Analyst-firm fixed effects & $\checkmark$ & \\
\hline Analyst-year fixed effects & & $\checkmark$ \\
\hline Constant & $\begin{array}{l}3.438 * * * \\
(0.080)\end{array}$ & $\begin{array}{l}2.096^{* * *} \\
(0.039)\end{array}$ \\
\hline F statistic & 1751.465 & 4236.100 \\
\hline $\mathrm{R}^{2}$-within & 0.146 & 0.200 \\
\hline
\end{tabular}

Dependent variable is the log of Forecasting Error, in basis points

Includes annual EPS forecasts between 2001 and 2013 (401,059 observations)

Heteroscedasticity-robust standard errors in parentheses

$\wedge \mathrm{p}<.1,{ }^{*} \mathrm{p}<0.05,{ }^{* *} \mathrm{p}<0.01,{ }^{* * *} \mathrm{p}<0.001$ 
Models 1 and 2 in table 5.2 test hypothesis 2 by adding an interaction term between audience closure and stock $k$ 's forecast dispersion. Model 1 provides a longitudinal test (i.e. using analyst-firm fixed effects) while model 2 tests the hypothesis in the cross section (i.e. using analyst-year fixed effects). Hypothesis 2 is also strongly supported: the advantages of audience closure are most evident under high environmental uncertainty, measured by a wide dispersion in forecasts about a particular stock. In the cross sectional test (model 2), adding the interaction reduces the size but not the significance of the main effect of audience closure (compare to Model 4 in table 5.1). The interpretation is that forecasting error tends to be lower for high audience closure stocks in an analyst's portfolio even when dispersion is low. In contrast, the main effect of audience closure is no longer significant in model 1, indicating that in situations where a firm's prospects are clear to most analysts, social learning does not confer an advantage. Low dispersion in a firm's earnings forecasts indicates a transparent and predictable information environment, which diminishes the effects of competitive advantages. In contrast, when uncertainty is high, such as for rapidly-changing firms, the information filter provided by shared frames of reference confers an interpretative advantage. Figure 5.1 illustrates the predictions of model 1 in table 5.2 by graphing the effect of audience closure on forecasting error at varying levels of forecast dispersion. 
Figure 5.1: Effect of audience closure on forecasting error at three levels of uncertainty

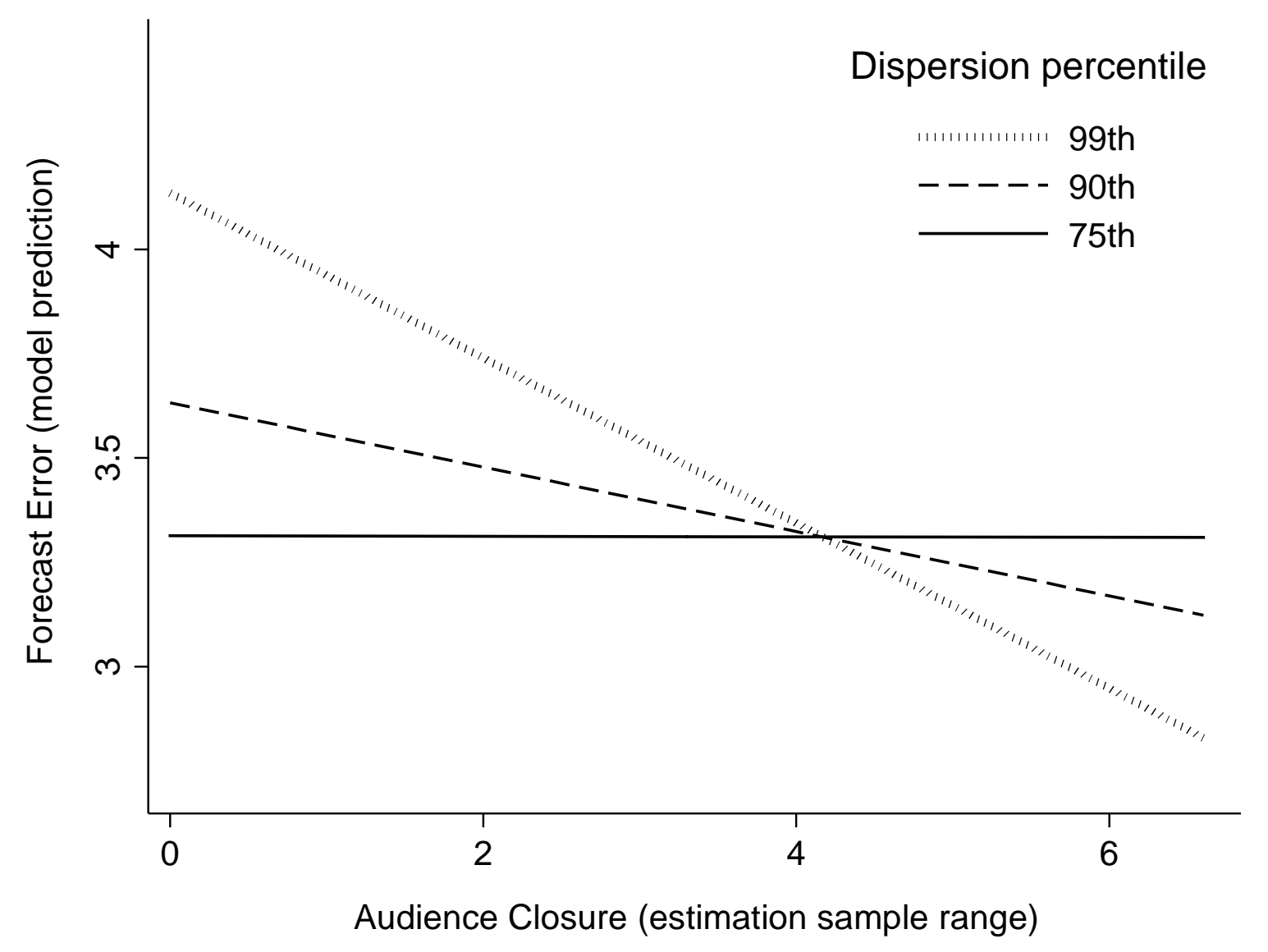

Figure 5.1 illustrates that increasing audience closure does not reduce forecasting error until the level of dispersion reaches above the $75^{\text {th }}$ percentile of observed values. The audience closure advantage is more likely to be a factor when covering firms whose prospects are inherently difficult to decipher, such as Tesla Motors or Pandora (at the $90^{\text {th }}$ and $99^{\text {th }}$ dispersion percentile, respectively).

\section{Testing a scope condition: observing others}

This dissertation began with the premise that observing others could lead to either social learning or herding. I implicitly assumed that individuals have the ability to engage in nuanced interpretation, and that the benefits of this interpretive activity are augmented when occupying 
network positions high in audience closure. In addition, I specified that the effects of audience closure are contingent on audiences motivated to infer meaning from the behavior, opinions and outcomes of others. A direct implication is that the performance of audiences unconcerned with the actions and outcomes of others should not be affected by changes in audience closure. In the analyst setting, audience closure improves the social learning mechanism, leading to more accurate forecasts. However, analysts who do not observe their competitors are, by definition, not engaged in social learning. Analysts not attempting to infer meaning from competitors will seldom change their own forecasts in response to the forecasts and restatements issued by others. The potential advantages of high audience closure with a firm will not affect the accuracy of analysts who are unresponsive to forecasts issued by their competitors. These individuals will score highly in the Timeliness variable, but the coefficient on audience closure should not be significant for such "self-directed” analysts. I define self-directed analysts as those scoring in the top quartile for Timeliness. Table 5.3 presents identical models to table 5.1 model 1; analysts above the $75^{\text {th }}$ percentile in terms of forecasting speed do not benefit from audience closure (Model 1a). Conversely, analysts at or below the $75^{\text {th }}$ percentiles see an increase in accuracy from audience closure that is significant and somewhat stronger than what I found for the full sample results displayed in table 5.1. In summary, audience closure denotes opportunities for developing a finer-grained interpretation of others' actions, but this filtering advantage only bears fruit when decision makers actually attend, and try to infer meaning from the actions of their competitors. The last two columns in table 5.3 present the interaction of audience closure and forecast dispersion, and the results reiterate hypothesis 2. The impact of audience closure depends on an information environment that is relatively uncertain (Model 2b), but the effect is small and only marginally significant for self-directed analysts (Model 2a). 
Table 5.3: Audience closure and speed of forecast

\begin{tabular}{|c|c|c|c|c|}
\hline Speed of forecast (pctl): & $\begin{array}{c}\text { Model 1a } \\
75^{+} \\
\end{array}$ & $\begin{array}{l}\text { Model 1b } \\
\quad<75\end{array}$ & $\begin{array}{r}\text { Model 2a } \\
75+\times \mathbf{D}\end{array}$ & $\begin{array}{l}\text { Model 2b } \\
<75 \times \mathbf{D}\end{array}$ \\
\hline Log audience closure ${ }_{i k t}$ & $\begin{array}{l}0.007 \\
(0.020)\end{array}$ & $\begin{array}{l}-0.030 * * * \\
(0.008)\end{array}$ & $\begin{array}{c}0.017 \\
(0.021)\end{array}$ & $\begin{array}{l}-0.011 \\
(0.009)\end{array}$ \\
\hline Forecast dispersion $_{\mathrm{kt}}$ & $\begin{array}{l}0.498^{* * *} \\
(0.040)\end{array}$ & $\begin{array}{l}0.478^{* * *} \\
(0.017)\end{array}$ & $\begin{array}{l}0.660 * * * \\
(0.097)\end{array}$ & $\begin{array}{l}0.729 * * * \\
(0.037)\end{array}$ \\
\hline Dispersion $\times$ AC & & & $\begin{array}{l}-0.044 \wedge \\
(0.026)\end{array}$ & $\begin{array}{l}-0.072^{* * * *} \\
(0.010)\end{array}$ \\
\hline $\log _{\text {forecast revisions }} \mathrm{ikt}$ & $\begin{array}{l}0.158^{* * *} \\
(0.018)\end{array}$ & $\begin{array}{l}-0.008 \\
(0.008)\end{array}$ & $\begin{array}{l}0.157^{* * * *} \\
(0.018)\end{array}$ & $\begin{array}{l}-0.009 \\
(0.008)\end{array}$ \\
\hline Log days to actuals $s_{\mathrm{ikt}}$ & $\begin{array}{l}0.537^{* * *} \\
(0.014)\end{array}$ & $\begin{array}{l}0.578^{* * *} \\
(0.006)\end{array}$ & $\begin{array}{l}0.536^{* * *} \\
(0.014)\end{array}$ & $\begin{array}{l}0.578^{* * *} \\
(0.006)\end{array}$ \\
\hline Years covering $_{\mathrm{ikt}}$ & $\begin{array}{l}0.099 * * * \\
(0.003)\end{array}$ & $\begin{array}{l}0.101^{* * *} \\
(0.002)\end{array}$ & $\begin{array}{l}0.099 * * * \\
(0.003)\end{array}$ & $\begin{array}{l}0.100^{* * *} \\
(0.002)\end{array}$ \\
\hline No. of analysts ${ }_{k t}$ & $\begin{array}{l}-0.005^{\wedge} \\
(0.003)\end{array}$ & $\begin{array}{l}-0.001 \\
(0.001)\end{array}$ & $\begin{array}{l}-0.005^{\wedge} \\
(0.003)\end{array}$ & $\begin{array}{l}-0.001 \\
(0.001)\end{array}$ \\
\hline Coverage coherence $_{\mathrm{kt}}$ & $\begin{array}{c}0.077 \\
(0.181)\end{array}$ & $\begin{array}{l}0.402^{* * *} \\
(0.084)\end{array}$ & $\begin{array}{c}0.079 \\
(0.181)\end{array}$ & $\begin{array}{l}0.410^{* * *} \\
(0.083)\end{array}$ \\
\hline Log market value $_{\mathrm{kt}}$ & $\begin{array}{l}-0.560^{* * * *} \\
(0.022)\end{array}$ & $\begin{array}{l}-0.546^{* * *} \\
(0.010)\end{array}$ & $\begin{array}{l}-0.561^{* * * *} \\
(0.022)\end{array}$ & $\begin{array}{l}-0.547^{* * *} \\
(0.010)\end{array}$ \\
\hline Leverage $_{\mathrm{kt}}$ & $\begin{array}{l}0.643^{* * *} \\
(0.096)\end{array}$ & $\begin{array}{l}0.528^{* * *} \\
(0.040)\end{array}$ & $\begin{array}{l}0.643^{* * *} \\
(0.096)\end{array}$ & $\begin{array}{l}0.527^{* * *} \\
(0.040)\end{array}$ \\
\hline Cumulative returns $_{\mathrm{kt}}$ & $\begin{array}{l}0.184^{* * *} \\
(0.016)\end{array}$ & $\begin{array}{l}0.238^{* * *} \\
(0.007)\end{array}$ & $\begin{array}{l}0.184^{* * *} \\
(0.016)\end{array}$ & $\begin{array}{l}0.239 * * * \\
(0.006)\end{array}$ \\
\hline Inst. ownership $(\mathrm{HHI})_{\mathrm{kt}}$ & $\begin{array}{l}1.133^{* * *} \\
(0.310)\end{array}$ & $\begin{array}{l}0.584^{* * *} \\
(0.125)\end{array}$ & $\begin{array}{l}1.117 * * * \\
(0.310)\end{array}$ & $\begin{array}{l}0.559^{* * *} \\
(0.125)\end{array}$ \\
\hline Inst. ownership (\%) $)_{\mathrm{kt}}$ & $\begin{array}{l}0.357^{* * *} \\
(0.090)\end{array}$ & $\begin{array}{l}0.328^{* * *} \\
(0.041)\end{array}$ & $\begin{array}{l}0.365^{* * *} \\
(0.090)\end{array}$ & $\begin{array}{l}0.338^{* * *} \\
(0.041)\end{array}$ \\
\hline Degree centrality $_{\mathrm{it}}$ & $\begin{array}{l}-0.002^{* * * *} \\
(0.000)\end{array}$ & $\begin{array}{l}-0.001^{* * *} \\
(0.000)\end{array}$ & $\begin{array}{l}-0.002^{* * * *} \\
(0.000)\end{array}$ & $\begin{array}{l}-0.001 * * * \\
(0.000)\end{array}$ \\
\hline Ranked by II magazine $_{\mathrm{it}}$ & $\begin{array}{l}-0.046 \\
(0.029)\end{array}$ & $\begin{array}{l}-0.039 * \\
(0.016)\end{array}$ & $\begin{array}{l}-0.045 \\
(0.029)\end{array}$ & $\begin{array}{l}-0.038 * \\
(0.016)\end{array}$ \\
\hline Employer size $_{\mathrm{it}}$ & $\begin{array}{r}0.000^{\wedge} \\
(0.000)\end{array}$ & $\begin{array}{c}0.000 \\
(0.000)\end{array}$ & $\begin{array}{r}0.000^{\wedge} \\
(0.000)\end{array}$ & $\begin{array}{c}0.000 \\
(0.000)\end{array}$ \\
\hline Stocks covered $_{\text {it }}$ & $\begin{array}{r}0.004 \wedge \\
(0.002)\end{array}$ & $\begin{array}{c}0.002^{*} \\
(0.001)\end{array}$ & $\begin{array}{r}0.004 \wedge \\
(0.002)\end{array}$ & $\begin{array}{c}0.002^{*} \\
(0.001)\end{array}$ \\
\hline Market volatility $y_{t}$ & $\begin{array}{l}0.016^{* * *} \\
(0.001)\end{array}$ & $\begin{array}{l}0.018^{* * *} \\
(0.001)\end{array}$ & $\begin{array}{l}0.016^{* * *} \\
(0.001)\end{array}$ & $\begin{array}{l}0.018^{* * *} \\
(0.001)\end{array}$ \\
\hline Analyst-firm fixed effects & $\checkmark$ & $\checkmark$ & $\checkmark$ & $\checkmark$ \\
\hline Constant & $\begin{array}{l}3.394^{* * * *} \\
(0.207)\end{array}$ & $\begin{array}{l}3.468^{* * *} \\
(0.093)\end{array}$ & $\begin{array}{l}3.361^{* * * *} \\
(0.207)\end{array}$ & $\begin{array}{l}3.400 * * * \\
(0.093)\end{array}$ \\
\hline F statistic & 266.425 & 1409.483 & 252.278 & 1347.377 \\
\hline $\mathrm{R}^{2}$-within & 0.132 & 0.150 & 0.132 & 0.150 \\
\hline Observations & 100,162 & 300,911 & 100,162 & 300,911 \\
\hline
\end{tabular}

Notes:

Dependent variable is the log of Forecasting Error, in basis points Includes annual EPS forecasts between 2001 and 2013

Heteroscedasticity-robust standard errors in parentheses

$\wedge^{\wedge} \mathrm{p}<.1,{ }^{*} \mathrm{p}<0.05,{ }^{* *} \mathrm{p}<0.01,{ }^{* * *} \mathrm{p}<0.001$ 


\section{Further test of robustness}

Analysts have some discretion in selecting which stocks to cover and are known to drop companies for which they are less accurate (Clarke, et al., 2007), raising selection concerns for the findings reported in table 5.1. However, analysts have relatively little discretion with respect to covering the largest companies in their sectors (Ljungqvist, et al., 2007). Following Ljungvist et al. (2007), I replicated models 1 and 2 in table 5.1 for a subsample where selection is less likely to play a role. ${ }^{25}$ I limited the analysis to the five largest firms in each of 49 Fama-French industries, ranked annually by market capitalization. Table 5.4 shows that even in the restricted subsample, with less than $10 \%$ of total firms, the coefficient on audience closure continues to be significant and in the predicted direction across both models.

\footnotetext{
${ }^{25}$ The robustness test is not appropriate for hypothesis two because forecasts for the largest firms in an industry display much lower dispersion than the average firm.
} 
Table 5.4: Determinants of error on forecasts of industry leaders' EPS

\begin{tabular}{|c|c|c|}
\hline & Model 1 & Model 2 \\
\hline Log audience closure $\mathrm{ikt}$ & $\begin{array}{l}-0.167 * * * \\
(0.015)\end{array}$ & $\begin{array}{l}-0.066^{* * *} \\
(0.017)\end{array}$ \\
\hline $\log _{\text {forecast revisions }} \mathrm{ikt}$ & $\begin{array}{l}0.107 * * * \\
(0.015)\end{array}$ & $\begin{array}{l}0.066^{* * *} \\
(0.014)\end{array}$ \\
\hline Log days to actuals $s_{\mathrm{ikt}}$ & $\begin{array}{l}0.542^{* * *} \\
(0.010)\end{array}$ & $\begin{array}{l}0.535^{* * *} \\
(0.010)\end{array}$ \\
\hline Years covering $_{\mathrm{ikt}}$ & $\begin{array}{l}0.068^{* * *} \\
(0.003)\end{array}$ & $\begin{array}{l}0.076^{* * *} \\
(0.003)\end{array}$ \\
\hline Timeliness $_{\mathrm{ikt}}$ & $\begin{array}{l}-0.016 \\
(0.012)\end{array}$ & $\begin{array}{l}-0.002 \\
(0.012)\end{array}$ \\
\hline Forecast dispersion $_{\mathrm{kt}}$ & & $\begin{array}{l}0.593^{* * *} \\
(0.038)\end{array}$ \\
\hline No. of analysts $\mathrm{kt}_{\mathrm{k}}$ & & $\begin{array}{l}-0.003 \\
(0.002)\end{array}$ \\
\hline Coverage coherence $_{\mathrm{kt}}$ & & $\begin{array}{c}0.387 * \\
(0.172)\end{array}$ \\
\hline Log market value $\mathrm{kt}$ & & $\begin{array}{l}-0.401 * * * \\
(0.023)\end{array}$ \\
\hline Leverage $_{\mathrm{kt}}$ & & $\begin{array}{c}0.370^{*} \\
(0.151)\end{array}$ \\
\hline Cumulative returns $_{\mathrm{kt}}$ & & $\begin{array}{l}0.187^{* * *} \\
(0.016)\end{array}$ \\
\hline Inst. ownership $(\mathrm{HHI})_{\mathrm{kt}}$ & & $\begin{array}{l}1.742 * * * \\
(0.425)\end{array}$ \\
\hline Inst. ownership (\%) $)_{\mathrm{kt}}$ & & $\begin{array}{l}1.516^{* * *} \\
(0.106)\end{array}$ \\
\hline Degree centrality $_{\text {it }}$ & & $\begin{array}{l}-0.001^{* * *} \\
(0.000)\end{array}$ \\
\hline Ranked by II magazine $_{\text {it }}$ & & $\begin{array}{l}-0.034 \\
(0.023)\end{array}$ \\
\hline Employer size $_{\text {it }}$ & & $\begin{array}{l}-0.000 \\
(0.000)\end{array}$ \\
\hline Stocks covered $_{\text {it }}$ & & $\begin{array}{r}0.004 \wedge \\
(0.002)\end{array}$ \\
\hline Market volatility $_{\mathrm{t}}$ & & $\begin{array}{l}0.017^{* * *} \\
(0.001)\end{array}$ \\
\hline Analyst-firm fixed effects & $\checkmark$ & $\checkmark$ \\
\hline Constant & $\begin{array}{l}0.475^{* * *} \\
(0.079)\end{array}$ & $\begin{array}{l}2.259 * * * \\
(0.277)\end{array}$ \\
\hline $\begin{array}{l}\text { F statistic } \\
\mathrm{R}^{2} \text {-within }\end{array}$ & $\begin{array}{l}731.935 \\
0.088\end{array}$ & $\begin{array}{l}319.500 \\
0.142\end{array}$ \\
\hline
\end{tabular}

Notes:

Dependent variable is the log of Forecasting Error, in basis points

Includes annual EPS forecasts between 2001 and 2013 (69,363 observations)

Heteroscedasticity-robust standard errors in parentheses

$\wedge \mathrm{p}<.1,{ }^{*} \mathrm{p}<0.05,{ }^{* *} \mathrm{p}<0.01,{ }^{* * *} \mathrm{p}<0.001$ 


\section{CHAPTER 6: A NATURAL EXPERIMENT TO ESTABLISH CAUSALITY}

Although analysts' coverage of publicly traded firms is important for financial markets and fits my theory's scope conditions, it also presents challenges for making causal claims. First, the process by which analysts select stocks is endogenous in that analysts are influenced by established patterns of collective attention. Several studies document the influence of employers and clients in shaping an analyst's coverage and intensity of coverage for particular stocks (for a review, see Mehran, and Stulz, 2007). Other research reveals that observed coverage contains positive information about analysts’ expectations regarding firm performance (i.e. Das, et al., 2006). Endogenous coverage decisions are not problematic per se, unless these processes systematically affect an analyst's accuracy or audience closure. For example, analysts may choose some of the same firms as their most accurate rivals in pursuit of a "halo effect". Such reverse causality would be in line with the dual nature of structure, as structure both guides social action and "tends to be reproduced by that social action” (Sewell, 1992). I consider these alternatives by examining the effect on a focal analyst's accuracy when audience closure with a stock changes due to the exogenous removal of competitors from the evaluation network.

To establish causality, I require some event that would randomly change audience closure for some, but not all of the stocks held by an analyst. The shock must be exogenously determined, meaning that accuracy should only be impacted through changes in audience closure. This scenario lends itself to a difference-in-differences (D-in-D) identification strategy, where observed changes in analysts' accuracy for affected stocks relative to unaffected stocks can be causally attributed to changes in audience closure (figure 6.1). 


\section{Figure 6.1: Loss of audience closure from an exogenous shock}

Firms

Analysts
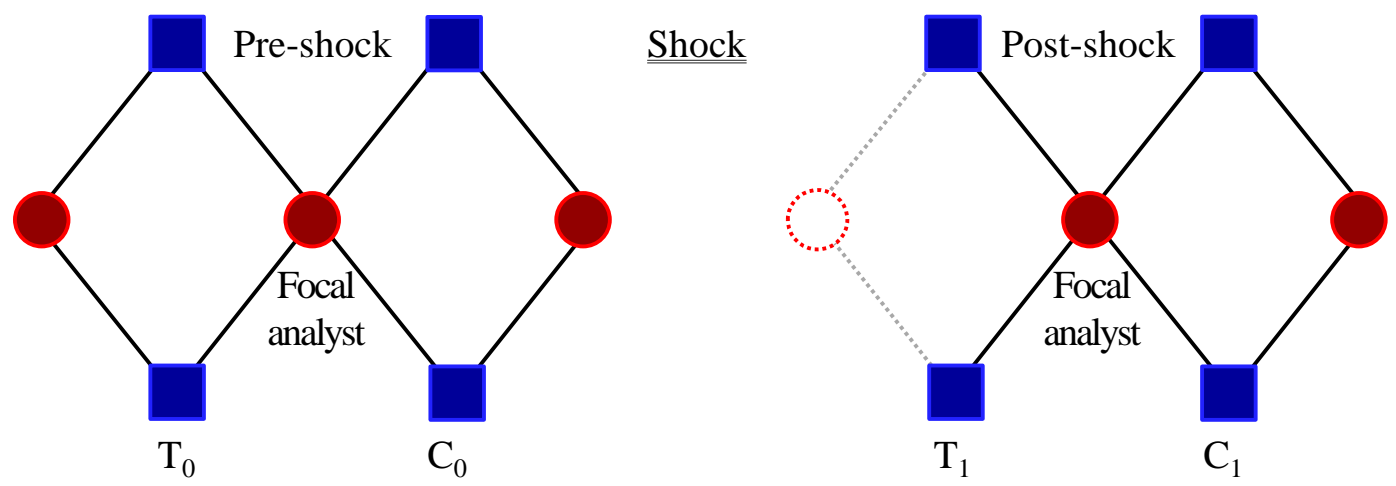

Assume that the focal analyst in figure 6.1 issues forecasts with accuracy $T_{0}$ and $C_{0}$ for two of the firms he covered in period 0, (before the shock). An exogenous shock removes one of the competing analysts, with whom the focal analyst co-covered firm $\mathrm{T}$ but not firm $\mathrm{C}$. The effect of the lost audience closure on the focal analyst's accuracy is given by $\left(T_{1}-T_{0}\right)-\left(C_{1}-C_{0}\right)$, the difference in differences estimator. Subtracting the change in accuracy in the control firm $\left(\mathrm{C}_{1}-\mathrm{C}_{0}\right)$ from the change in accuracy in the treatment firm $\left(\mathrm{T}_{1}-\mathrm{T}_{0}\right)$ removes any time trends common to both firms (Angrist, and Pischke, 2009).

My identification strategy investigates the exogenous loss of analysts who perished in the terrorist attacks of September 11, 2001. The 9/11 attacks have been used as an exogenous shock to investigate changes in rates of new business founding (Paruchuri, and Ingram, 2012) and by Kelly and Ljungqvist (2012) to examine information asymmetry in asset pricing models. 


\section{Sample}

From a published list of World Trade Center victims on 9/11, I identified 16 analysts with forecast estimates in the IBES tape. ${ }^{26}$ At the time of the attacks, these 16 analysts (12 from KBW and 4 from Sandler) collectively covered the equity of 182 firms with fiscal years ending on 31 December 2001. I focus on firms with the same fiscal year end to avoid the problem of nonoverlapping forecasting horizons (Call, et al., 2009). My sampling strategy proceeded as follows. I identified all analysts who issued at least one forecast between April $1^{\text {st }} 2001$ and September $10^{\text {th }} 2001$, and at least one forecast after the attacks but before the release of a firm's actual earnings (from September $17^{\text {th }} 2001$ until February $22^{\text {nd }} 2002$ ) for any of the stocks covered by the victims (i.e. the treatment group of stocks). ${ }^{27}$ To be included in the sample, a surviving analyst also had to have published pre and post 9-11 forecasts on at least one firm that had not been covered by an analyst who perished (i.e. the control group of stocks). Figure 6.2 illustrates the sampling strategy.

\footnotetext{
${ }^{26}$ Two brokerage firms, Keefe, Bruyette \& Woods (KBW) and Sandler O’Neil \& Partners (Sandler) each suffered over 60 casualties on that day.

${ }^{27}$ The New York Stock Exchange, the American Stock Exchange and NASDAQ remained closed until September 17.
} 
Figure 6.2: 9/11 sample selection, treatment and control groups (3,121 forecasts)

\author{
9/11 victims (16)
}

Treatment stocks (182)

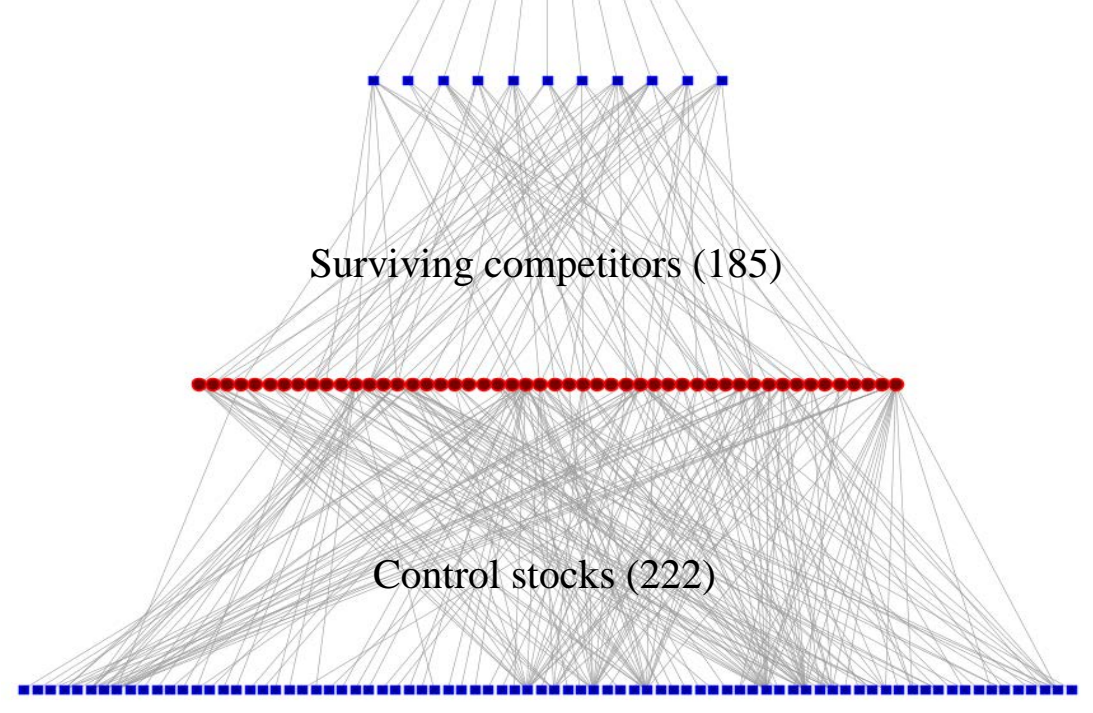

In figure 6.2, squares represent stocks and the middle row of circles represents the 185 surviving analysts who met the sampling conditions, each of whom made forecasts in the periods before and after 9/11 for at least one stock in each of the treatment and control groups. The top row of squares represents the 182 stocks in the treatment group (45\% of all sampled stocks), while the bottom row of squares represents the 222 stocks in the control group. ${ }^{28}$

If the theory's predictions are correct, I should observe an unexplained increase in forecasting error after 9/11 that cannot be accounted for by time trends or individual firm or analyst characteristics. In addition, changes in forecast error should be an increasing function of

\footnotetext{
${ }^{28}$ From the 182 stocks in the treatment group, 7 were covered by two analysts who perished, while the remaining 175 were covered by only one of the victims.
} 
"treatment intensity", which in this case is the percentage of frames of reference lost due to the sudden, exogenous removal of victims from the evaluation network. More formally,

H3: After 9/11, larger losses in audience closure led to higher forecast error.

Figure 6.3 illustrates the effect predicted in hypothesis three.

Figure 6.3: Predicted increase in forecast error due to lost audience closure

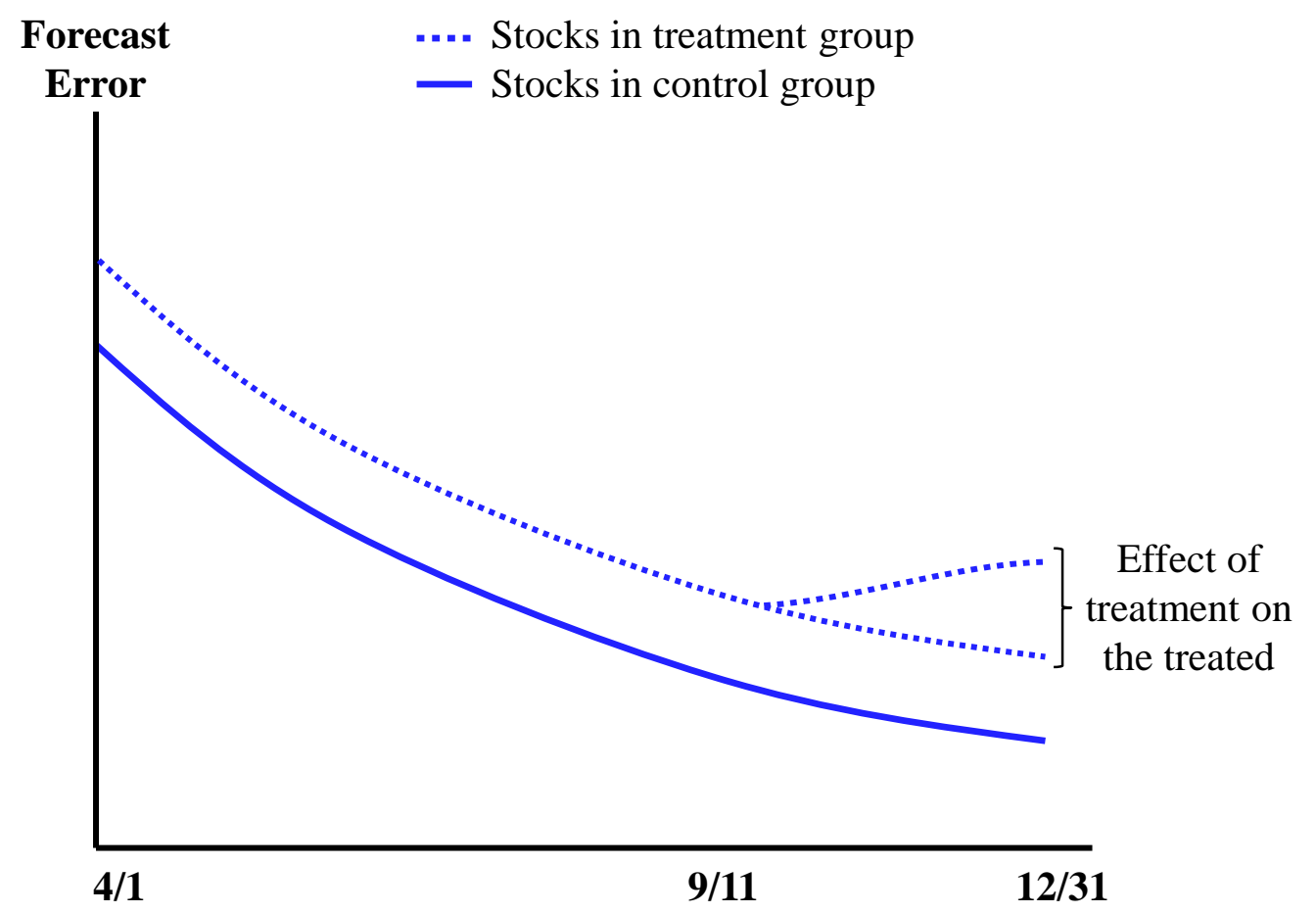

\section{Variables}

For stocks in both the treatment and in the control groups, I calculated the forecasting error, as previously described, of every forecast issued by sampled analysts after the end of the first quarter of 2001 (i.e. starting on 4/1/2001) until right before the last firm in the sample published actual earnings (on 2/22/2002). An analyst's accuracy should deteriorate more when 
lost frames of reference constituted a larger share of the total audience closure with a stock. I divided the number of lost frames of reference by the total audience closure between each pair formed by a surviving analyst and a stock to generate the variable $\% A C$ lost. The $\%$ AC lost variable captures the filtering capacity lost by an analyst on each stock due to the removal of victims from the evaluation network. The binary indicator Post 9/11 is equal to one for the period after 9/11 until the last sampled firm revealed actual annual earnings (from 09/17/2001 until 02/22/2002) and zero otherwise (from 04/01/2001 until 09/10/2001). I controlled for weekly changes in market volatility, cumulative stock returns and stock price. Forecast dispersion was updated monthly. I used average values for the period before and after 9/11 for the number of analysts covering a firm and the number of firms per analyst.

\section{Analysis}

Identification would be undermined if the event's trauma differentially affected surviving analysts and one compared changes in accuracy between analysts. The appropriate strategy is to compare changes in error on forecasts issued by the same analyst for stocks in the treatment group relative to stocks in the control group.

A differences-in-differences design can be conducted in a regression framework, offering at least three important advantages (Angrist, and Pischke, 2009). First, the researcher can easily estimate coefficients and standard errors. Second, covariates can be included to account for time-varying systematic differences that may alter the partial effect of change due to the treatment. A regression formulation also permits using a continuous variable, rather than a dummy variable, in order to measure treatment intensity. I estimate regressions with fixed 
effects for firm-analyst pairs to capture variation net of stock and analyst's average forecast error and to control for time-invariant unobserved heterogeneity.

I model the forecast error (FE) of analyst $i$ on stock $k$ using the formulation suggested by Hong and Kacperczyk (2010, see equation 3):

$$
F E_{i k t}=\alpha_{i}+\gamma_{k}+\omega V_{t}+\beta_{1} \text { LostAC }_{i k}+\beta_{2} \text { Post }_{i k}+\beta_{3}\left(\text { Post }_{i k} \times \text { LostAC }_{i k}\right)+\beta_{4} \text { Controls }_{i k t}+\varepsilon_{i k t} \text {, }
$$

where $\alpha, \gamma$ and $V$ respectively represent analyst fixed effects, firm fixed effects and weekly market volatility. The coefficient on the interaction term $\left(\beta_{3}\right.$ in equation (2)) tests the hypothesis that after 9/11, analyst $i$ 's forecasting error on stock $k$ increased as a function of lost frames of reference.

\section{Results}

Models 1 and 2 in table 6.1 strongly support hypothesis 3, and enable a causal interpretation of audience closure. The forecast error of surviving analysts increased as a function of the percentage of audience closure lost. 
Table 6.1: Effect on forecasting error of audience closure lost on 9/11

\begin{tabular}{|c|c|c|c|c|}
\hline & Model 1 & Model 2 & Model 3 & Model 4 \\
\hline Post 9/11 & $\begin{array}{l}-0.582^{* * *} \\
(0.049)\end{array}$ & $\begin{array}{l}-0.764^{* * *} \\
(0.078)\end{array}$ & $\begin{array}{l}-0.770^{* * *} \\
(0.076)\end{array}$ & \\
\hline Post $9 / 11 \times \%$ AC lost & $\begin{array}{l}0.290^{* *} \\
(0.102)\end{array}$ & $\begin{array}{l}0.304^{* *} \\
(0.099)\end{array}$ & & \\
\hline Post 9/11 × Treated stock & & & $\begin{array}{c}0.090 \\
(0.054)\end{array}$ & \\
\hline Post 7/01 & & & & $\begin{array}{l}-0.451^{* * *} \\
(0.038)\end{array}$ \\
\hline Post 01 July $\times \%$ AC lost & & & & $\begin{array}{l}-0.088 \\
(0.167)\end{array}$ \\
\hline$\%$ AC lost & $\begin{array}{l}-0.218 \\
(0.194)\end{array}$ & $\begin{array}{l}-0.303 \\
(0.216)\end{array}$ & & $\begin{array}{l}0.514 \\
(0.332)\end{array}$ \\
\hline Weekly closing price & $\begin{array}{l}-0.531^{* * *} \\
(0.111)\end{array}$ & $\begin{array}{l}-0.461^{* * *} \\
(0.124)\end{array}$ & $\begin{array}{l}-0.447^{* *} \\
(0.127)\end{array}$ & $\begin{array}{l}-0.569 * * * \\
(0.142)\end{array}$ \\
\hline Weekly stock returns & $\begin{array}{c}0.420 \\
(0.274)\end{array}$ & $\begin{array}{c}0.643^{*} \\
(0.237)\end{array}$ & $\begin{array}{l}0.641^{* *} \\
(0.235)\end{array}$ & $\begin{array}{l}-0.241 \\
(0.204)\end{array}$ \\
\hline Monthly dispersion & $\begin{array}{c}0.281^{*} \\
(0.104)\end{array}$ & $\begin{array}{c}0.278 * \\
(0.111)\end{array}$ & $\begin{array}{c}0.258^{*} \\
(0.108)\end{array}$ & $\begin{array}{l}1.731^{* *} \\
(0.617)\end{array}$ \\
\hline Weekly market volatility & & $\begin{array}{l}0.020^{* *} \\
(0.006)\end{array}$ & $\begin{array}{l}0.019 * * \\
(0.006)\end{array}$ & $\begin{array}{l}-0.007 \\
(0.004)\end{array}$ \\
\hline Stocks covered & & $\begin{array}{c}0.000 \\
(0.003)\end{array}$ & $\begin{array}{c}0.000 \\
(0.003)\end{array}$ & $\begin{array}{l}-0.010 * \\
(0.004)\end{array}$ \\
\hline No. of analysts & & $\begin{array}{l}-0.023^{*} \\
(0.011)\end{array}$ & $\begin{array}{l}-0.023 * \\
(0.010)\end{array}$ & $\begin{array}{l}-0.047^{* *} \\
(0.014)\end{array}$ \\
\hline Analyst-firm fixed effects & $\checkmark$ & $\checkmark$ & $\checkmark$ & $\checkmark$ \\
\hline Constant & $\begin{array}{l}5.349 * * * \\
(0.391)\end{array}$ & $\begin{array}{l}4.919 * * * \\
(0.500)\end{array}$ & $\begin{array}{l}4.854^{* * *} \\
(0.513)\end{array}$ & $\begin{array}{l}6.605^{* * *} \\
(0.618)\end{array}$ \\
\hline F statistic & 29.399 & 31.962 & 46.125 & 52.472 \\
\hline $\mathrm{R}^{2}$-within & 0.153 & 0.160 & 0.160 & 0.188 \\
\hline
\end{tabular}

Notes:

Dependent variable is the log of Forecasting Error, in basis points

Includes EPS forecasts issued after 4/1/01 for firms with fiscal year ending 12/31/01

1,562 analyst-firm fixed effects and 3,121 observations

Heteroscedasticity-robust standard errors clustered by week in parentheses

$\wedge \mathrm{p}<.1,{ }^{*} \mathrm{p}<0.05,{ }^{* *} \mathrm{p}<0.01,{ }^{* * *} \mathrm{p}<0.001$ 


\section{Alternative explanation and test of robustness}

An alternative interpretation of what might be driving the significance of the Post $9 / 11 \times$ $\%$ AC lost coefficient is that the accuracy of surviving analysts decreased for firms in the treatment group not because of the loss of audience closure but because of the loss of an information provider. Since over $90 \%$ of the firms in the treatment group lost a single covering analyst during the attacks, I test this alternative explanation by replacing the $\% A C$ lost variable with an indicator of whether a firm belonged to the treatment group (Affected stock $=1$ ) or not (Affected stock $=0)$. If results are driven by a decrease in the number of information providers rather than by the erosion of the filtering mechanism, the coefficient for the Affected stock variable should capture variation in forecasting error better than $\% A C$ lost. The alternative explanation lacks statistical support. The coefficient on the Post 9/11 $\times$ Treated stock variable (table 6.1, model 3) is not statistically significant and is smaller in magnitude than the coefficient on Post 9/11 × \% AC lost (table 6.1, model 2). This result provides further evidence that survivors' forecasting error increased as a function of lost frames of reference, and not simply due to the disappearance of an information provider from the affected firm's evaluation network.

An assumption of difference in differences models is the treatment and control groups have parallel trends before the treatment event. This means that in the absence of the 9/11 treatment event, the average change in forecasting error would have been the same for stocks in both the treatment and control groups. A robustness test of the parallel trends assumption is running a "placebo regression”, which requires counterfactually choosing a treatment time earlier than the actual treatment time. If analysts were equally accurate on both groups of stocks before 9/11, then resetting the treatment date to an earlier time should not produce significant results. I chose 7/01/2001 as the "placebo" shock and ran an identical model to models 2 in table 6.1. As 
illustrated in model 4, also in table 6.1, the placebo regression (reassuringly) does not indicate a loss of accuracy in the post 7/01/2001 period from audience closure lost after 9/11. ${ }^{29}$ The nonsignificant results of the placebo models increase confidence that the correct causal variable has been identified. The accuracy of surviving analysts was indeed affected by audience closure lost in $9 / 11$.

${ }^{29} 7 / 01 / 2001$ is the date that halves the number of pre 9/11 forecast estimates. I obtained substantively similar results, available from the author, when testing several plausible placebo dates. 


\section{CHAPTER 7: STOCK-SPECIFIC EXPERTISE}

Up to this point, I have referred to analysts as audiences evaluating producers, represented by publicly traded firms. I leverage the flexibility of the audience-producer interface by exploring the role of analysts as producers of stock intelligence, which is evaluated by an audience of institutional investors utilizing their services. According to extant research, a focused producer can learn subtle lessons from experience more rapidly than one who spreads attention over multiple activities (Negro, et al., 2010). Given the intense competition for institutional investor business, analysts tend to develop a high degree of specialization among the 10-20 stocks typically covered. Exceptional stock-specific expertise will depend on analysts’ ability to provide extraordinary (i.e. profitable) insights to their investment clients. In the competitive arena of equity research, where all competitors specialize, even a top-performing analyst is unlikely to provide consistently profitable intelligence on more than a small fraction of the analyst's total coverage portfolio. My theory suggests that analysts may gain informational depth -and therefore develop deeper expertise -when other analysts' frames of reference are highly relevant for comparing and calibrating insights about particular stocks. Therefore, exceptional audience closure relative to competitors can help identify the role of social learning in developing stock-specific expertise. I test this claim by analyzing the comments from institutional clients evaluating the services of analysts ranked in an annual poll conducted by the trade magazine Institutional Investor (I.I.). 


\section{The Institutional Investor annual poll}

Since 1972, I.I. has been conducting an annual poll among institutional investors to determine which sell-side analysts have been most helpful during the preceding year. ${ }^{30}$ Rankings are categorized into industry groups, such that the vast majority of analysts appear only under one sector (see Methodology section in each October edition of Institutional Investor). Respondents evaluate analysts on six dimensions: earnings forecasts, industry knowledge, overall service, accessibility and responsiveness, stock selection and quality of written work (Groysberg, 2010). The 2013 poll included responses from over 3,300 individuals at 989 firms, including more than 90 of the 100 biggest U.S. equity managers. These respondents managed an estimated \$10.47 trillion in U.S. equities (October 2013). The results of the poll determine the ranking of analysts in each industry and, in the last few decades, Wall street has come to view the I.I. rankings as a measure of analyst quality (Groysberg, 2010). ${ }^{31}$ Ranked analysts, who often command multi-million dollar salaries from their employers, have been found to be less prone to herding behavior and tend to issue more frequent, accurate and influential earnings forecasts than non-ranked analysts (Fang, and Yasuda, 2009;Groysberg, 2010).

\section{Investors' recognition of stock-specific expertise}

I.I. magazine follows each ranked position with a 600-1000 words description of noteworthy calls by the analyst during that year, including direct quotes from clients who found

\footnotetext{
${ }^{30}$ Institutional investors, which include hedge funds, mutual funds and pension funds, use analysts' research to inform their investment decisions. In doing so, they also generate brokerage revenue for analysts' employers. An institutional money manager typically allocates stock trades to the brokerage house employing the analyst who has provided the best information on that stock (Groysberg, 2010).

${ }^{31}$ Although other annual rankings of security analysts exist, such as those compiled by Greenwich Associates and the Wall Street Journal, the thorough methodology converted the II rankings into "a seal of approval of sorts" (Groysberg, 2010)
} 
the analysts' services helpful for investments in a particular industry. For example, Sanford C. Bernstein’s Charles Hintz has earned a spot for several years for his coverage of companies under the Brokers, Asset Managers and Exchanges sector. In the October 2012 issue, I.I. quoted clients praising Hintz for providing "interpretation and context that is extremely helpful in understanding the strengths and vulnerabilities of brokers and exchanges”. Such blanket statements of praise that do not mention specific companies do not provide evidence of whether analysts had exceptional insights or distinctive understanding about particular firms. In several cases, however, investors praise analysts for their expert coverage of specific firms. Although an analyst could be complimented for her work on any of the firms in her coverage universe, the firms on which the analyst provided exceptional insights should be more salient in the minds of the institutional investors responding to the I.I. survey. For example, technology analyst Richard Sherlund is "renowned for his coverage of Microsoft" (October 2004) and recognized for his “unparalleled knowledge of the company's product lines” (October 2000). When it comes to Microsoft, Sherlund has been described as being "better plugged in than anybody else" (October 1998). Investors themselves seem to recognize Sherlund's stock-specific prowess, openly stating that "Rick [Sherlund] is a giant in the field because of Microsoft" (October 1999). More than his work on other firms, Sherlund's particular expertise on Microsoft made him into an invaluable resource for investors.

I claim that analysts are more likely to develop expertise, as recognized by clients, on stocks where the analyst benefits from multiple shared frames of reference. I test the hypothesis that shared frames are a factor in predicting stock-specific expertise, by exploring with which firms clients tend to associate each ranked analyst. 
H4: Institutional clients are more likely to mention firms where the analyst benefits from a greater number of shared frames of reference.

I test whether audience closure with a stock affects the probability that institutional investors mention that stock when justifying their vote for a focal analyst.

\section{Data and sample}

To test hypothesis four, I focus solely on the subset of analysts appearing in the last four editions of the I.I. annual rankings. First, I matched the IBES universe with the list of I.I.-ranked analysts. The resulting dataset contained 13,011 observations for 261 analysts covering the equity of 1,755 firms between 2009 and 2013. I then obtained textual descriptions for all first, second and third place rankings. I used an algorithm that matched company names found in the textual descriptions with those in the analyst's coverage universe. Table 7.1 contains a number

of quotes from investors recognizing ranked analysts’ exceptional expertise on their coverage of specific companies. 
Table 7.1: Investors’ recognition of analyst's stock-specific expertise

\begin{tabular}{|c|c|}
\hline Quote from Institutional Investor magazine (mentioned firms in bold) & Analyst and year \\
\hline "great call downgrading TW Telecom, just before they lowered expectations." & M. McCormack (2009) \\
\hline "spectacular, high-conviction stock picking, especially where Allergan is concerned." & R. Gal (2009) \\
\hline "his Omnicare downgrade saved us an expensive loss." & G. Santangelo (2010) \\
\hline "great call on Ford...he was early, and he was right." & J. Murphy (2010) \\
\hline "HealthSpring was a great call for us, Raskin made us money on that stock." & J. Raskin (2010) \\
\hline [Post's] 'timely call on Amazon was a real moneymaker." & J. Post (2011) \\
\hline "His early call on LyondellBasell was highly successful." & J. Zekauskas (2011) \\
\hline "the first to recommend Oracle, now everyone is following him." & P. Winslow Jr. (2011) \\
\hline "His best call was on Monster, where he has been the most bullish and absolutely right." & K. Gajrawala (2012) \\
\hline "He was right in downgrading Accenture in the low \$60s." & R. Bourgeois (2012) \\
\hline
\end{tabular}

\section{Dependent variable}

As illustrated in table 7.1, company mentions are invariably positive, and represent public acknowledgment of an analyst's stock-specific expertise. Stock-specific expertise is captured by the variable Co-mention $i k t$, which was coded as 1 if company $k$ was mentioned in relation to analyst $i$ in the I.I. ranking for year $t$. Co-mention $i k t$ was coded as zero for every company the analyst covered that year but which was not mentioned. 


\section{Relative scores for measures that vary within stock-years}

An analyst’s portfolio contains firms of diverse financial performance, size, and geographic scope. Therefore, within-analyst comparisons of firm attributes requires transforming variables into a comparable scale. I implemented a generalized version of the scoring methodology pioneered by Hong and Kubik (2003) to produce relative scores for measures that vary across analysts within each stock-year observation. A score of 100 means that the analyst ranked first on the relevant variable, while a score of zero means that the analyst ranked last from the entire cohort of analysts covering stock $k$ in year $t$. The general formula is given by:

$$
\operatorname{Score}\left(X_{i k t}\right)=100-\left[\frac{\operatorname{Rank}\left(X_{i k t}\right)-1}{N\left(X_{i k t}\right)-1}\right] \times 100 \text {, }
$$

where $\boldsymbol{X}$ stands for each of the variables being scored and $\boldsymbol{N}$ denotes the total number of analysts in year $t$ covering stock $k$. Each variable $\boldsymbol{X}$ is ranked in descending order starting with the best performing analyst. I calculated the relative score of each analyst $i$ relative to all analysts covering stock $k$ in year $t$ for the following measures: audience closure, stock-specific experience, speed (i.e. timeliness), number of forecasts (i.e. attention) and negative forecasting error (i.e. accuracy). ${ }^{32}$ For ties in ranks, I assigned the midpoint of the places taken up. For example, out of the 30 analysts issuing forecasts for Citigroup in 2011, Meredith Whitney tied for $7^{\text {th }}$ place in accuracy with one other analyst. Therefore her assigned ranking is 7.5 , the midpoint of the $7^{\text {th }}$ and $8^{\text {th }}$ places. The calculation of the accuracy score for the observation defined by Meredith Whitney, Citigroup and the year 2011 is as follows:

\footnotetext{
${ }^{32}$ The unscored measures are calculated as in the earlier analysis of forecasting error.
} 


$$
\text { Score }\left(\text { Accuracy }_{\text {Whitney, Citigroup, } 2011}\right)=100-\left[\frac{7.5-1}{30-1}\right] \times 100=77.6
$$

In the same manner, I generated scores for attention, experience, speed and audience closure.

\section{Stock-level controls}

Investors in general are more likely to mention larger, better known firms. The variable

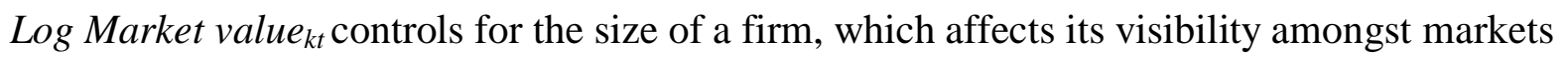
participants. A firm should be much more likely to come up when it performed exceptionally well because money managers would have had the opportunity to generate more profits on that stock. I controlled for this factor with the variable Cumulative returns ${ }_{k t}$, the annualized holding period returns for each stock $k$ in year $t$. When a company's valuation environment is characterized by a high degree of classificatory coherence, it is more difficult to earn exceptional returns because market participants are likely to have the same information. Following Zuckerman (2004) I control for stock $k$ 's classificatory coherence in year $t$ with the variable Coverage coherence $_{k t .}$ Leverage $_{k t}$ controls for the likelihood that firms using more debt than equity in their capital structure receive less focused attention from equity analysts. The amount of competition in covering a firm is held constant with the variable No. of analysts $k$, a count of the number of analysts covering firm $k$ in year $t$. Finally, given that institutional investors constitute the audience ranking and evaluating analysts’ performance, I control for the level and density of a stock’s institutional ownership respectively with the variables Institut.ownership $(\%)_{k t}$ and Institut.ownership (HHI) $)_{k t}$. Table 7.2 contains descriptive statistics and correlations for all variables in the analysis. 


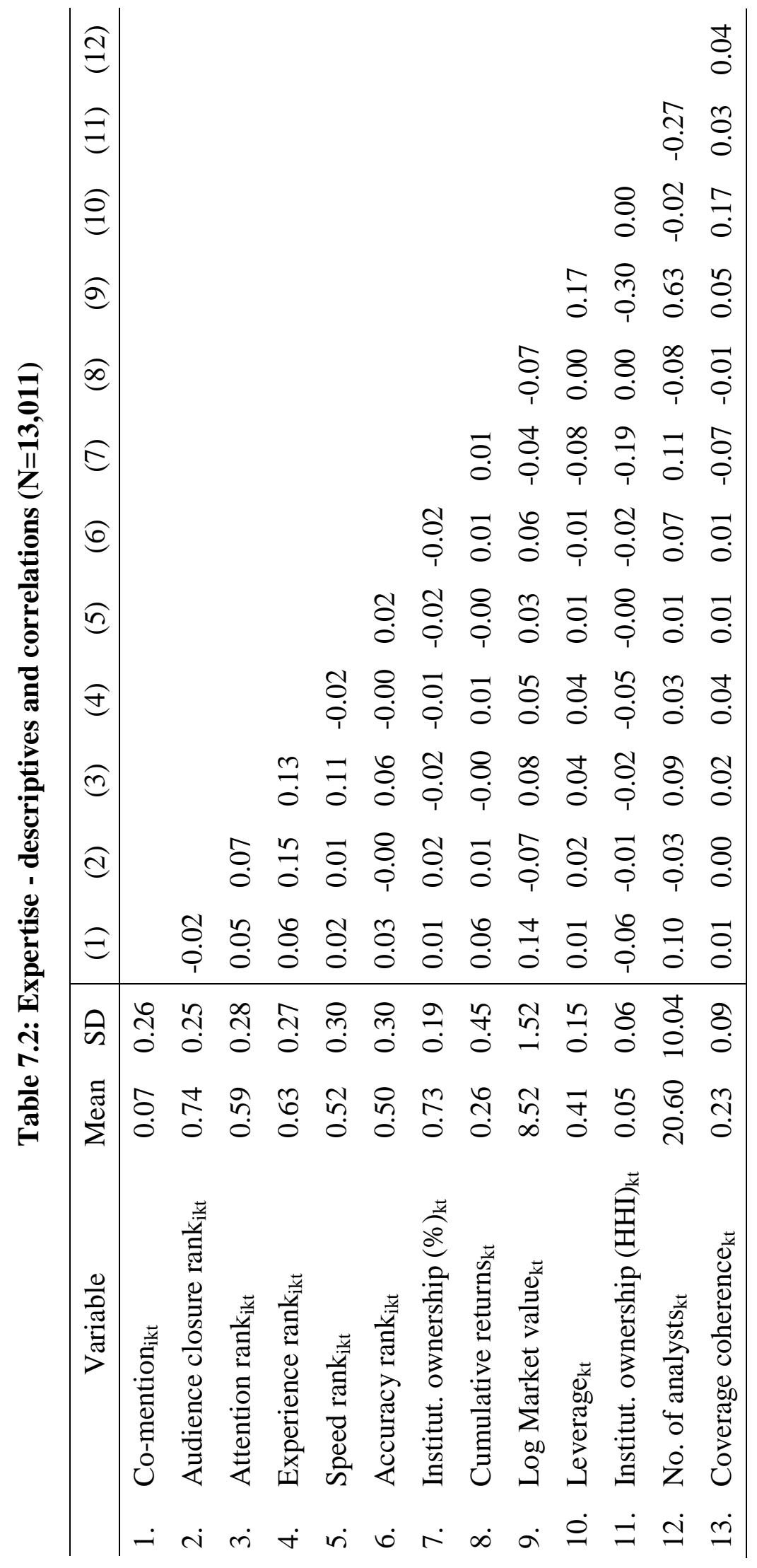




\section{Analysis}

The explicit purpose of this analysis is to determine which firms are most likely to contribute to recognition, net of individual characteristics. The question is not whether audience closure causally increases analyst's probability of being ranked by I.I. (all analysts in the sample are recognized industry specialists). Rather, the research question is which firms from an analyst's coverage portfolio most contribute to investors' recognition of expertise. Answering this question requires a model in which the likelihood of firm $k$ being mentioned in connection to analyst $i$ in year $t$ is estimated conditionally on the total number of firms being mentioned for analyst $i$ in year $t$. Imagine that a given analyst covered firms $\mathrm{A}, \mathrm{B}, \mathrm{C}$ and $\mathrm{D}$, and investors mentioned the analyst's work on firm's A and C. A conditional logit regression estimates the contribution of covariates on the probability that firms $\mathrm{A}$ and $\mathrm{C}$ were mentioned rather than firms B and D (Allison, 2009). The conditional (i.e. fixed effects) logistic model eliminates the individual analyst's parameters out of the likelihood function (Chamberlain, 1980). Table 7.3 contains parameter estimates for four models testing the hypothesis that analysts are more likely to have exceptional expertise on firms with high audience closure scores. 
Table 7.3: Conditional probability that firm $k$ is mentioned in connection to analyst $i$

\begin{tabular}{|c|c|c|c|c|}
\hline & Model 1 & Model 2 & Model 3 & Model 4 \\
\hline Audience closure rank $k_{\mathrm{ikt}}$ & $\begin{array}{l}0.819^{* * *} \\
(0.185)\end{array}$ & $\begin{array}{l}0.800^{* * * *} \\
(0.236)\end{array}$ & $\begin{array}{c}0.548^{* *} \\
(0.207)\end{array}$ & $\begin{array}{l}0.539^{* *} \\
(0.203)\end{array}$ \\
\hline Attention rank $\mathrm{ikt}_{\mathrm{ikt}}$ & $\begin{array}{l}0.543^{* * * *} \\
(0.142)\end{array}$ & & $\begin{array}{l}0.417^{* *} \\
(0.153)\end{array}$ & $\begin{array}{l}0.449^{* * *} \\
(0.157)\end{array}$ \\
\hline Experience rank $\mathrm{ikt}_{\mathrm{i} t}$ & $\begin{array}{l}1.161^{* * * *} \\
(0.189)\end{array}$ & & $\begin{array}{l}1.081^{* * * *} \\
(0.187)\end{array}$ & $\begin{array}{l}1.037^{* * * *} \\
(0.181)\end{array}$ \\
\hline Speed rank $\mathrm{ikt}_{\mathrm{i}}$ & $\begin{array}{c}0.340^{*} \\
(0.133)\end{array}$ & & $\begin{array}{c}0.288^{*} \\
(0.138)\end{array}$ & $\begin{array}{l}0.301^{*} \\
(0.140)\end{array}$ \\
\hline Accuracy rank $\mathrm{ikt}_{\mathrm{ikt}}$ & $\begin{array}{l}0.215^{*} \\
(0.104)\end{array}$ & & $\begin{array}{c}0.205 \\
(0.129)\end{array}$ & $\begin{array}{c}0.215^{\wedge} \\
(0.127)\end{array}$ \\
\hline Cumulative returns $_{\mathrm{kt}}$ & $\begin{array}{l}0.508^{2 *+*+} \\
(0.067)\end{array}$ & $\begin{array}{l}0.691^{* * * *} \\
(0.096)\end{array}$ & $\begin{array}{l}0.686^{* *+*} \\
(0.097)\end{array}$ & $\begin{array}{l}0.696^{6 *+*} \\
(0.118)\end{array}$ \\
\hline No. of analysts ${ }_{k t}$ & & $\begin{array}{l}-0.001 \\
(0.008)\end{array}$ & $\begin{array}{l}-0.002 \\
(0.008)\end{array}$ & $\begin{array}{l}-0.003 \\
(0.008)\end{array}$ \\
\hline Coverage coherence $_{\mathrm{kt}}$ & & $\begin{array}{l}-0.445 \\
(0.676)\end{array}$ & $\begin{array}{l}-0.642 \\
(0.722)\end{array}$ & $\begin{array}{l}-0.695 \\
(0.724)\end{array}$ \\
\hline Log Market value $_{\mathrm{kt}}$ & & $\begin{array}{l}0.409^{* * * *} \\
(0.060)\end{array}$ & $\begin{array}{l}0.397^{* * * *} \\
(0.059)\end{array}$ & $\begin{array}{l}0.395^{* * * *} \\
(0.061)\end{array}$ \\
\hline Leverage $_{\mathrm{kt}}$ & & $\begin{array}{l}-0.447^{*} \\
(0.179)\end{array}$ & $\begin{array}{l}-0.513^{* *} \\
(0.185)\end{array}$ & $\begin{array}{l}-0.532^{* *} \\
(0.179)\end{array}$ \\
\hline Institut. ownership (\%) $)_{\mathrm{kt}}$ & & $\begin{array}{l}1.103^{* * *} \\
(0.419)\end{array}$ & $\begin{array}{l}1.099^{* * *} \\
(0.416)\end{array}$ & $\begin{array}{c}1.104^{*} \\
(0.464)\end{array}$ \\
\hline Institut. ownership (HHI) $)_{\mathrm{kt}}$ & & $\begin{array}{l}-2.848^{* *} \\
(1.084)\end{array}$ & $\begin{array}{l}-2.770^{* *} \\
(1.091)\end{array}$ & $\begin{array}{l}-2.943^{*} \\
(1.209)\end{array}$ \\
\hline Analyst fixed effects & & $\checkmark$ & $\checkmark$ & $\checkmark$ \\
\hline Year fixed effects & & & & $\checkmark$ \\
\hline$\chi^{2}$ statistic & 179.8 & 689.6 & $1,584.1$ & $9,987.4$ \\
\hline Pseudo $\mathrm{R}^{2}$ & 0.028 & 0.057 & 0.067 & 0.070 \\
\hline
\end{tabular}

\section{Notes}

12,724 observations, 1,711 stocks and 244 analysts, 2009-2013

Standard errors (in parentheses) clustered by 25 employers

$\wedge \mathrm{p}<.1, * \mathrm{p}<0.05, * * \mathrm{p}<0.01, * * * \mathrm{p}<0.001$ 


\section{Results}

Analysts whose firms received no specific mentions (17 analysts out of 261) provide no information because the conditional probability of observing such outcomes is one regardless of the values of the parameter values (Gould, 2000). Observations for these analysts drop out of the estimation, reducing the sample size from 13,011 to 12,724. In addition to analyst fixed effects, the models in table 7.3 include several covariates. Model 1 controls for time varying analystfirm covariates, model 2 includes firm level controls, model 3 includes both analyst-firm and firm level controls and model 4 adds year fixed effects.

The positive effect of audience closure on the conditional likelihood of receiving a mention is robust to the inclusion of all sets of controls, providing strong support for hypothesis 4. More shared frames of reference help predict analysts’ stock-specific expertise. Figure 7.1 graphs the marginal effect of audience closure while keeping all other variables at their mean values. The probability of firm $k$ being mentioned in connection with analyst $i$ nearly doubles (from 3\% to 6\%) when the analyst's audience closure with that stock increases from the minimum to the maximum. 
Figure 7.1: Effect of audience closure on the probability that firm $k$ is mentioned*

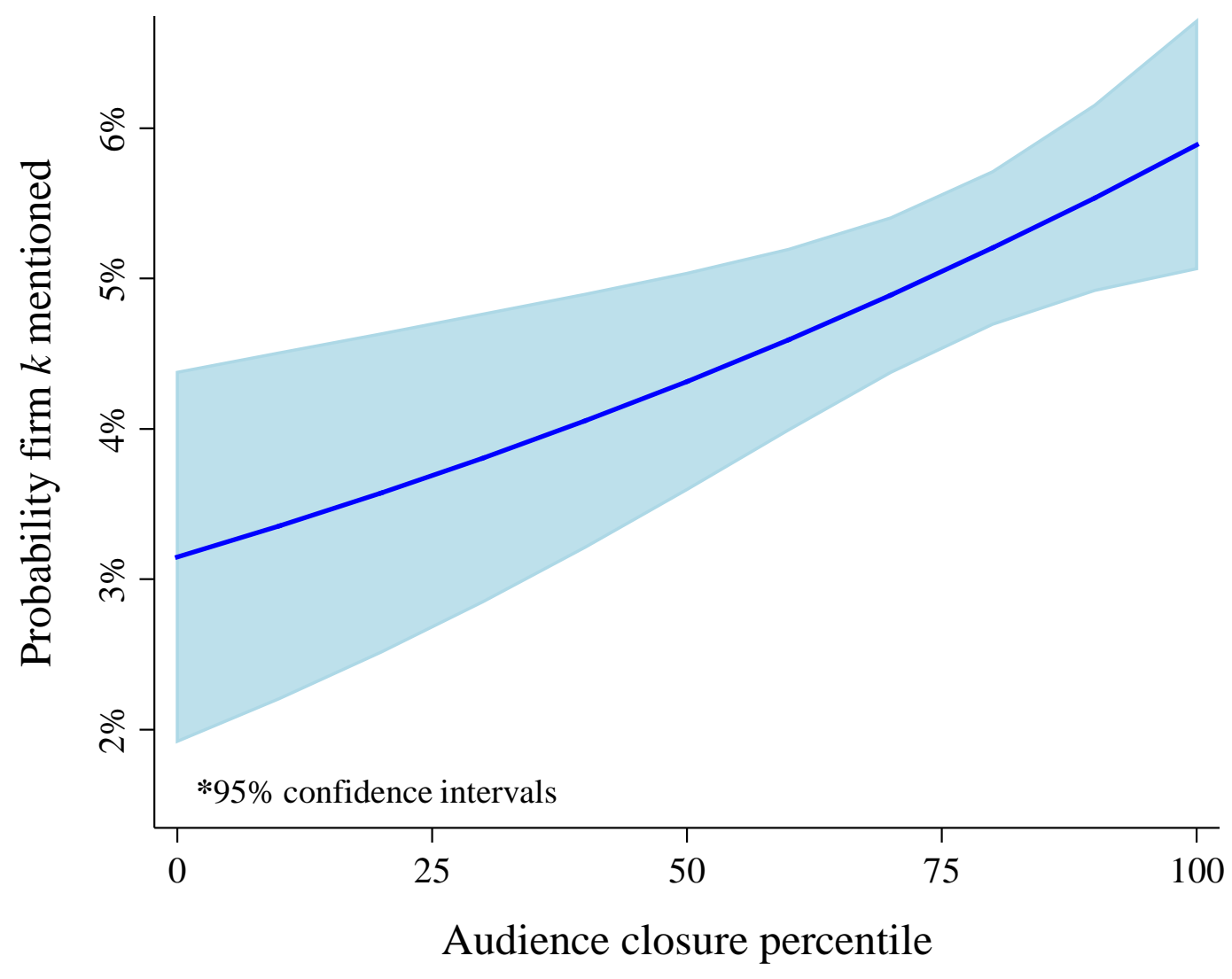




\section{CHAPTER 8: DISCUSSION AND CONCLUSION}

This research developed a theory of how the joint network of audiences and producers reveals a structural antecedent of social learning. The main thesis was that social learning advantages are partially determined by the structural characteristics of a system. I tested several implications of this thesis in the setting of security analysts covering the equity of publicly traded companies. Six complementary findings support the importance of positions endowed with a social learning advantage. First, a focal analysts’ ability to interpret information accurately on a focal stock improved in years when audience closure was higher. Second, more accurate forecasts were issued by analysts occupying positions of high audience closure in a focal stock's coverage network. Third, forecasts for stocks in a focal analyst's coverage portfolio occupying high audience closure positions tended to be more accurate. Fourth, the benefits of these network positions on forecasting accuracy fluctuated with environmental uncertainty. Fifth, an exogenous shock -the sudden death of analysts in the 9/11 attacks on the World Trade Centerhelped isolate the causal effect of audience closure on performance. The findings associated with the removal of peers due to an exogenous, random interruption in the evaluation network are relatively novel in network research (Greve, 2005). Sixth, besides conferring an accuracy advantage, top-ranked analysts’ particular expertise on high audience closure stocks was recognized by their institutional clients. Together, these findings contribute to several strands of research concerned with social learning and structural influences on performance.

\section{Contributions to theory}

This work provides a bridge between research on social learning and research on network structure. Much work has drawn on these two literatures, but to my knowledge this is the first 
study to propose and test a specific network characteristic that predicts performance advantages from social learning. Shared frames of reference constitute a novel yet intuitive construct to study structural influences that arise interdependently in joint networks of audiences and producers. I introduced audience closure as a measurement strategy to quantify shared frames of reference available from any position in an evaluation network. Decision makers trying to infer from others the value of a course of action have an advantage when located in network positions with more audience closure.

The theory of audience closure can shed light on the determination of competitive advantage in cluster theory, where relations of geographically proximate firms, consumers and suppliers define the cluster (Greve, 2009). Malloy (2005) provides evidence that geographically proximate analysts are more accurate than other analysts, especially when covered firms are located in small cities and remote areas. Future research can help increase our understanding of the relationships between geographic proximity and audience closure. For instance, among geographically proximate analysts, does audience closure help predict forecasting prowess, or is the effect of audience closure absorbed by geographic proximity? More generally, future research can examine flows of public information traveling along bipartite network ties from flows of private information and affective resources commonly studied in single-mode networks. Such work would extend past research on the dynamics of multiplex networks (e.g. Davis, and Greve, 1997;McPherson, et al., 2001;Sytch, and Tatarynowicz, 2014). In the analyst-stock interface, this would require data on friendships and other affective ties between analysts in order to understand how these ties both influence and are shaped by the bipartite coverage network, and how both networks interact to influence performance. 
The effects of environmental uncertainty in moderating network positions’ impact on accuracy represent an important boundary condition of social learning. Security analysts rely on each other as filters to improve their own forecasts, particularly in uncertain information environments. When the ratio of noise to useful information is high, the interpretative function becomes more valuable, increasing the accuracy advantage of analysts in high audience closure positions. In contrast, analysts receiving divergent signals with few shared frames of reference are more prone to "shooting in the dark". These findings complement research on complexity (e.g. Haunschild, and Ni Sullivan, 2002) and on how uncertainty affects networks (e.g., Beckman, et al., 2004) and social learning (Gaba, and Terlaak, 2013).

Past research has documented performance benefits from diversity of information sources (e.g., Beckman, and Haunschild, 2002). In the analyst context however, the benefits conferred by shared frames of reference is distinct and more consistent than those conferred by diverse information sources (compare coefficients for audience closure and degree centrality). Perhaps the benefits of audience closure may be limited to contexts where "information is plentiful but attention is scarce” (Simon, 1997;Hansen, and Haas, 2001). For example, the crucial challenge of physicians in Coleman et al.’s (1957) canonical study on innovation diffusion was described as "knowing how to sift the deluge of material that reaches him, and how to assess the value of it.” The information revolution precipitated by the internet means that contexts characterized by information overload are likely to become the norm rather than the exception. Seeking out network positions that align shared frames of reference can help decision makers filter through “an overwhelming horde of facts” (Burt, 1987). Together, these insights can guide organizations in their search for topic-specific experts and aid decision makers such as security analysts to specialize in those stocks where they have a structural advantage. 


\section{Managerial implications}

The activities of security analysts sustain markets by filtering information, and the finding that certain network positions enable better filters has important implications for directors of equity research departments and analysts themselves. Analysts can take into account audience closure when deciding which firms to cover, or how much effort to allocate given their structural advantages or disadvantages vis-à-vis competitors. Equity research directors can map the coverage networks of all analysts within their organization, and increase the audience closure of each analyst while at the same time reducing excessive overlap. Such a mapping would require regular updating, as an analyst's audience closure with a firm changes not only with changes in her own coverage, but also with changes in competitors' coverage. Beyond equity research, configurations that increase audience closure can enable producers to make more informed decisions when engaging alliance partners, entering new markets, or choosing a technological position in the competitive landscape (Stuart, and Podolny, 1996).

\section{Limitations and opportunities}

I have argued that positions high in audience closure enhance the benefits of observing others. However, further research is required to determine whether audience closure would be irrelevant or even detrimental to performance in environments that do not meet the theory’s scope conditions. For example, in environments where the actions of others are poorly visible or visible only in some contexts, positions of high audience closure could trigger information cascades or herding. In such situations, the performance advantage could instead accrue to those 
evaluating information from positions of brokerage. Further research is required to generate a precise typology of potential tradeoffs under different network structures.

Audience closure as defined in this article was meant to provide a general and accessible measure of frames of reference. This measurement strategy should be adapted for different research contexts. For example, simple counts may not be the right functional form if too many frames of reference overload the focal decision maker (Simon, 1956;March, and Simon, 1958;Cyert, and March, 1963). In this case, the impact of audience closure on accuracy may be concave rather than linear. Alternative versions of audience closure should undoubtedly fit the specific context in which they emerge. In its current form, audience closure gives equal weight to the number of sources of information (i.e. the number of analysts covering a firm) and to the depth of each source (the overlap in coverage between pairs of analysts). Future versions of audience closure could calibrate volume and depth depending on the theoretical requirements of the research setting. Finally, past performance, social status and relational dynamics could be incorporated to reflect weighted models of audience closure. ${ }^{33}$

This study raises other questions that require further research under more controlled conditions. For example, can actors in privileged network positions detect information cascades, thus deriving private value from value-destroying collective action? Are decisions to not follow

\footnotetext{
${ }^{33}$ Learning from competitors ought to increase over time, such that two analysts who cover the same stock for many years could be expected to develop more precise mental models to correctly interpret the actions and opinions of each other. On the other hand, this effect could decline sharply after a few cycles, given that individuals tend to quickly form opinions about each other and are unlikely to dynamically update their mental models. I investigated these countervailing ideas using a time-sensitive measure of audience closure. Co-coverage of a stock by two analysts in year $Y$ was modeled as an increasing function of the number of years $T$ since they started co-covering the stock. The weighted audience closure in year $Y$ decays at the rate of $(\mathrm{T}+1)^{-1.842}$, the rate for professional colleague relations estimated by Burt (2000). Empirical results were similar (same statistical significance and order of magnitude of coefficients) whether using either measure of audience closure. More research is required to untangle the relational dynamics of social learning.
} 
subsequently disappointing strategies more or less influenced by network position than following successful strategies learned from others?

\section{Conclusion}

This research began with the premise that certain network positions enable better social learning. Together, the findings support the claim that high audience closure provides such a social learning advantage in an evaluation network. The advantage is theoretically consistent with a network position's access to frames of reference, which in turn enhance a decision maker's ability to interpret the behavior of other evaluators. That this advantage emerges only under uncertainty reinforces a social learning explanation. Using a natural experiment, I tested the social learning mechanism against an agentic view of markets, demonstrating that decisionmakers rely on their network to filter and interpret information. Finally, I showed that topranked analysts tend to provide their most valuable services when audience closure with a stock is exceptionally high. Investment clients recognized such expertise by commenting on those stocks where the analyst was better positioned for social learning. The theory and findings inform how network positions matter for social learning and how social learning influences performance, two vital issues for research on competitive advantage and strategic decision making. 


\section{REFERENCES}

October 1998, Institutional Investor Magazine

October 2013 "Methodology: The best analysts of the year." Institutional Investor Magazine: 4988

Aldrich, H. E., and M. Ruef

2006 Organizations Evolving, Second ed. London ; Thousand Oaks, Calif.: SAGE Publications.

Allison, P. D.

2009 Fixed Effects Regression Models. Thousand Oaks, CA: SAGE Publications.

Amiram, D., et al.

2013 "Analysts’ Forecasts During Periods of High Market Uncertainty." Columbia Business School Research Paper No. 13-68

Angrist, J. D., and J.-S. Pischke 2009 Mostly Harmless Econometrics: An Empiricist's Companion. Princeton, NJ: Princeton University Press.

Aral, S., and M. Van Alstyne

2011 "The Diversity-Bandwidth Trade-off." American Journal of Sociology, 117: 90-171.

Avramov, D., et al.

2009 "Dispersion in analysts' earnings forecasts and credit rating." Journal of Financial Economics, 91: 83-101.

Bandura, A.

1977 Social Learning Theory. Englewood Cliffs, NJ: Prentice-Hall, Inc.

Banerjee, A. V.

1992 "A simple model of herd behavior." The Quarterly Journal of Economics: 797-817.

Bargh, J. A. 
1982 "Attention and automaticity in the processing of self-relevant information." Journal of Personality and Social Psychology, 43: 425.

Barker, R. G.

1998 "The market for information—evidence from finance directors, analysts and fund managers." Accounting and Business research, 29: 3-20.

Baum, J. A. C., and H. J. Korn 1996 "Competitive Dynamics of Interfirm Rivalry." Academy of Management Journal, 39: 255291.

1999 "Dynamics of dyadic competitive interaction." Strategic Management Journal, 20: 251.

Baum, J. A. C., et al. 2000 "Making the next move: How experiential and vicarious learning shape the locations of chains' acquisitions." Administrative Science Quarterly, 45: 766-801.

Beckman, C. M., and P. R. Haunschild 2002 "Network learning: The effects of partners' heterogeneity of experience on corporate acquisitions." Administrative Science Quarterly, 47: 92-124.

Beckman, C. M., et al.

2004 "Friends or strangers? Firm-specific uncertainty, market uncertainty, and network partner selection." Organization Science, 15: 259-275.

Belderbos, R., et al.

2011 "Generic and Specific Social Learning: Mechanisms in Foreign Entry Location Choice." Strategic Management Journal, 32: 1309-1330.

Berkman, H., et al. 2009 "Sell on the news: Differences of opinion, short-sales constraints, and returns around earnings announcements." Journal of Financial Economics, 92: 376-399.

Beunza, D., and R. Garud 2007 "Calculators, lemmings or frame-makers? The intermediary role of securities analysts." Sociological Review, 55: 13-39. 
Beunza, D., and D. Stark

2012 "From dissonance to resonance: cognitive interdependence in quantitative finance."

Economy and society, 41: 383-417.

Bikhchandani, S., et al.

1998 "Learning from the behavior of others: Conformity, fads, and informational cascades."

Journal of Economic Perspectives, 12: 151-170.

Boehmer, E., and E. K. Kelley

2009 "Institutional Investors and the Informational Efficiency of Prices." Review of Financial Studies, 22: 3563-3594.

Boldin, M., and B. Ding 2008 "User's Guide to Thomson Reuters Mutual Fund and Investment Company Common Stock Holdings Databases on WRDS." Wharton Research Data Services

Borgatti, S. P. 2006 "Identifying sets of key players in a social network." Computational \& Mathematical Organization Theory, 12: 21-34.

Borgatti, S. P., and M. G. Everett

1997 "Network analysis of 2-mode data." Social Networks, 19: 243-269.

Bowers, A., et al.

2013 "Competitive Parity, Status Disparity, and Mutual Forbearance: Securities Analysts'

Competition for Investor Attention." Academy of Management Journal

Breiger, R. L.

1974 "The duality of persons and groups." Social Forces, 53: 181-190.

Burt, R. S.

1987 "Social contagion and innovation: Cohesion versus structural equivalence." American Journal of Sociology: 1287-1335.

1992 Structural holes: the social structure of competition. Cambridge, Mass.: Harvard University Press. 
1997 "The contingent value of social capital." Administrative Science Quarterly, 42: 339-365.

2000 "Decay functions." Social Networks, 22: 1-28.

2005 Brokerage and Closure: An Introduction to Social Capital. New York: Oxford University Press.

2007 "Secondhand brokerage: Evidence on the importance of local structure for managers, bankers, and analysts." Academy of Management Journal, 50: 119-148.

2010 Neighbor Networks: Competitive Advantage Local and Personal. Oxford, UK: Oxford University Press.

Call, A. C., et al.

2009 "Are analysts' earnings forecasts more accurate when accompanied by cash flow forecasts?" Review of Accounting Studies, 14: 358-391.

Chamberlain, G.

1980 "Analysis of Covariance with Qualitative Data." Review of Economic Studies, 47: 225238.

Cialdini, R. B.

2009 Influence: The Psychology of Persuasion. New York: HarperCollins Publishers Inc.

Clark, H. H., and S. E. Brennan

1991 Grounding in Communication. Washington: Amer Psychological Assoc.

Clarke, J., et al.

2007 "The impact of all-star analyst job changes on their coverage choices and investment banking deal flow." Journal of Financial Economics, 84: 713-737.

Clement, M. B.

1999 "Analyst forecast accuracy: Do ability, resources, and portfolio complexity matter?" Journal of Accounting and Economics, 27: 285-303. 
Clement, M. B., and S. Y. Tse

2005 "Financial Analyst Characteristics and Herding Behavior in Forecasting." Journal of Finance, 60: 307-341.

Cohen, L., et al.

2010 "Sell-Side School Ties." Journal of Finance, 65: 1409-1437.

Cohen, L., and D. Lou

2012 "Complicated firms." Journal of Financial Economics, 104: 383-400.

Coleman, J. S., et al.

1957 "The diffusion of an innovation among physicians." Sociometry, 20: 253-270.

Cooper, R. A., et al.

2001 "Following the leader: a study of individual analysts' earnings forecasts." Journal of Financial Economics, 61: 383-416.

Cowen, A., et al.

2006 "Which types of analyst firms are more optimistic?" Journal of Accounting and Economics, 41: 119-146.

Cummings, J. N.

2004 "Work groups, structural diversity, and knowledge sharing in a global organization." Management Science, 50: 352-364.

Cummings, J. N., and R. Cross

2003 "Structural properties of work groups and their consequences for performance." Social Networks, 25: 197-210.

Cyert, R. M., and J. G. March

1963 A behavioral theory of the firm. Englewood Cliffs, NJ, USA: Prentice-Hall, INC.

Darr, E., et al.

1995 "The Acquisition, Transfer and Depreciation of Knowledge in Service Organizations: Productivity in Franchises." Management Science, 41: 147-160. 
Das, S., et al.

2006 "Analysts' Selective Coverage and Subsequent Performance of Newly Public Firms." Journal of Finance, 61: 1159-1185.

Davis, G. F., and H. R. Greve

1997 "Corporate elite networks and governance changes in the 1980s." American Journal of Sociology, 103: 1-37.

DiMaggio, P. J., and W. W. Powell

1983 "The iron cage revisited: Institutional isomorphism and collective rationality in organizational fields." American Sociological Review, 48: 147-160.

Doz, Y. L.

1996 "The Evolution of Cooperation in Strategic Alliances: Initial Conditions or Learning Processes?" Strategic Management Journal, 17: 55-83.

Emirbayer, M.

1997 "Manifesto for a relational sociology." American Journal of Sociology, 103: 281-317.

Evans, J. A.

2010 "Industry Induces Academic Science to Know Less about More." American Journal of Sociology, 116: 389-452.

Fang, L., and A. Yasuda 2009 "The Effectiveness of Reputation as a Disciplinary Mechanism in Sell-Side Research." Review of Financial Studies, 22: 3735-3777.

Ferrier, W. J.

2001 "Navigating the Competitive Landscape: The Drivers and Consequences of Competitive Aggressiveness." Academy of Management Journal, 44: 858-877.

Freeman, L. C.

1979 "Centrality in social networks conceptual clarification." Social Networks, 1: 215-239.

Gaba, V., and A. Terlaak 
2013 "Decomposing Uncertainty and Its Effects on Imitation in Firm Exit Decisions." Organization Science, 24: 1847-1869.

Gilbert, D. T., et al.

1995 "When comparisons arise." Journal of Personality and Social Psychology, 69: 227.

Gimeno, J.

2004 "Competition within and between Networks: The Contingent Effect of Competitive Embeddedness on Alliance Formation." Academy of Management Journal, 47: 820-842.

Giraldeau, L. A., et al. 2002 "Potential disadvantages of using socially acquired information." Philosophical Transactions of the Royal Society of London. Series B: Biological Sciences, 357: 1559-1566.

Goldstone, R. L., and M. A. Janssen 2005 "Computational models of collective behavior." Trends in Cognitive Sciences, 9: 424-430.

Gould, W.

2000 "Interpreting logistic regression in all its forms." Stata Technical Bulletin, 53: 19-29.

Greve, H. R. 1998 "Managerial cognition and the mimetic adoption of market positions: What you see is what you do." Strategic Management Journal, 19: 967-988.

2005 "Interorganizational learning and heterogeneous social structure." Organization Studies, 26: 1025-1047.

2009 "Bigger and Safer: the Diffusion of Competitive Advantage." Strategic Management Journal, 30: 1-23.

2011 "Fast and expensive: The diffusion of a disappointing innovation." Strategic Management Journal, 32: 949-968.

Grossman, S. J., and J. E. Stiglitz 1980 "On the impossibility of informationally efficient markets." The American economic review: 393-408. 
Groysberg, B.

2010 Chasing stars: the myth of talent and the portability of performance. Princeton, NJ:

Princeton University Press.

Gulati, R., and M. Gargiulo

1999 "Where do interorganizational networks come from?" American Journal of Sociology, 104:

1439-1493.

Gulati, R., and M. C. Higgins

2003 "Which ties matter when? The contingent effects of interorganizational partnerships on IPO success." Strategic Management Journal, 24: 127-144.

Hannan, M. T., et al.

2007 Logics of Organization Theory: Audiences, Codes, and Ecologies. Princeton, N.J.:

Princeton University Press.

Hansen, M. T., and M. R. Haas

2001 "Competing for attention in knowledge markets: Electronic document dissemination in a management consulting company." Administrative Science Quarterly, 46: 1-28.

Haunschild, P. R., and B. Ni Sullivan

2002 "Learning from complexity: Effects of prior accidents and incidents on airlines' learning." Administrative Science Quarterly, 47: 609-643.

Haveman, H. A.

1993 "Follow the leader: Mimetic isomorphism and entry into new markets." Administrative Science Quarterly, 38: 593-627.

Haveman, H. A., and L. Nonnemaker

2000 "Competition in multiple geographic markets: The impact on growth and market entry." Administrative Science Quarterly, 45: 233-267.

Hong, H., and M. Kacperczyk

2010 "Competition and bias." The Quarterly Journal of Economics, 125: 1683-1725. 
Hong, H., and J. D. Kubik

2003 "Analyzing the Analysts: Career Concerns and Biased Earnings Forecasts." Journal of

Finance, 58: 313-351.

Hong, H., et al.

2000 "Security analysts' career concerns and herding of earnings forecasts." The Rand journal of economics: 121-144.

Hsu, G., et al.

2009 "Multiple Category Memberships in Markets: An Integrative Theory and Two Empirical

Tests." American Sociological Review, 74: 150-169.

Ingram, P., and T. Simons

2002 "The Transfer of Experience in Groups of Organizations: Implications for Performance and Competition." MANAGEMENT SCIENCE, 48

Irvine, P. J.

2004 "Analysts' forecasts and brokerage-firm trading." The Accounting Review, 79: 125-149.

Jackson, A. R.

2005 "Trade Generation, Reputation, and Sell-Side Analysts." Journal of Finance, 60: 673-717.

Jegadeesh, N., and W. Kim

2010 "Do Analysts Herd? An Analysis of Recommendations and Market Reactions." Review of Financial Studies, 23: 901-937.

Johnson, T. C.

2004 "Forecast dispersion and the cross section of expected returns." Journal of Finance, 59:

1957-1978.

Kameda, T., and D. Nakanishi

2003 "Does social/cultural learning increase human adaptability?: Rogers's question revisited." Evolution and Human Behavior, 24: 242-260.

Kashima, Y., et al.

2007 "Grounding: Sharing Information in Social Interaction." In K. Fiedler (ed.), Social

Communication: 27-78. New York: Psychology Press. 
Kelly, B., and A. Ljungqvist

2012 "Testing asymmetric-information asset pricing models." Review of Financial Studies, 25:

1366-1413.

Kilduff, G. J., Elfenbein, H. A., \& Staw, B. M.

2010 "The psychology of rivalry: A relationally-dependent analysis of competition." Academy of Management Journal, 53: 943-969.

Latapy, M., et al.

2008 "Basic notions for the analysis of large two-mode networks." Social Networks, 30: 31-48.

Levinson, S. C.

2003 Space in Language and Cognition : Explorations in Cognitive Diversity. West Nyack, NY: Cambridge University Press.

Lewis, $\mathrm{M}$.

April 92008 "The Rise and Rise of Analyst Meredith Whitney."

Lind, P. G., et al.

2005 "Cycles and clustering in bipartite networks." Physical review E, 72: 056127.

Ljungqvist, A., et al.

2009a "Rewriting History." Journal of Finance, 64: 1935-1960.

Ljungqvist, A., et al.

2007 "Conflicts of interest in sell-side research and the moderating role of institutional investors." Journal of Financial Economics, 85: 420-456.

Ljungqvist, A., et al.

2009b "Scaling the Hierarchy: How and Why Investment Banks Compete for Syndicate Comanagement Appointments." Review of Financial Studies, 22: 3977-4007.

Loh, R. K., and G. M. Mian

2006 "Do accurate earnings forecasts facilitate superior investment recommendations?" Journal of Financial Economics, 80: 455-483. 
Loh, R. K., and R. M. Stulz

2011 "When Are Analyst Recommendation Changes Influential?" Review of Financial Studies, 24: 593-627.

Malloy, C. J.

2005 "The Geography of Equity Analysis." Journal of Finance, 60: 719-755.

March, J. G., and H. A. Simon

1958 Organizations. New York: Wiley.

McElreath, R., et al.

2005 "Applying evolutionary models to the laboratory study of social learning." Evolution and Human Behavior, 26: 483-508.

McNichols, M., and P. C. O'Brien

1997 "Self-selection and analyst coverage." Journal of Accounting Research, 35: 167-199.

McPherson, M., et al.

2001 "Birds of a feather: Homophily in social networks." Annual Review of Sociology, 27: 415444.

Mehran, H., and R. M. Stulz

2007 "The economics of conflicts of interest in financial institutions." Journal of Financial Economics, 85: 267-296.

Mesoudi, A.

2008 "An experimental simulation of the "copy-successful-individuals” cultural learning strategy: adaptive landscapes, producer-scrounger dynamics, and informational access costs." Evolution and Human Behavior, 29: 350-363.

Mikhail, M., et al.

1997 "Do security analysts improve their performance with experience?" Journal of Accounting Research, 36: 131-157.

Milgram, S., et al. 
1969 "Note on the Drawing Power of Crowds of Different Size " Journal of Personality and Social Psychology, 13: 79-82.

Mizruchi, M. S., and L. C. Fein

1999 "The social construction of organizational knowledge: A study of the uses of coercive, mimetic, and normative isomorphism." Administrative Science Quarterly, 44: 653-683.

Mola, S., and M. Guidolin

2009 "Affiliated mutual funds and analyst optimism." Journal of Financial Economics, 93: 108137.

Mouw, T.

2006 "Estimating the Causal Effect of Social Capital: A Review of Recent Research." Annual Review of Sociology, 32: 79-102.

Munshi, K.

2004 "Social learning in a heterogeneous population: technology diffusion in the Indian Green Revolution." Journal of Development Economics, 73: 185-213.

Negro, G., et al.

2010 "Categorical contrast and audience appeal: niche width and critical success in winemaking." Industrial and Corporate Change, 19: 1397-1425.

O'Brien, P. C.

1988 "Analysts' forecasts as earnings expectations." Journal of accounting and Economics, 10: 53-83.

Opsahl, T.

2011 "Triadic closure in two-mode networks: Redefining the global and local clustering coefficients." Social Networks

Paruchuri, S., and P. Ingram 2012 "Appetite for destruction: the impact of the September 11 attacks on business founding." Industrial and Corporate Change, 21: 127-149.

Pollock, T. G., et al. 
2008 "Market watch: Information and availability cascades among the media and investors in the US IPO market." Academy of Management Journal, 51: 335-358.

Porac, J. F., et al.

1995 "Rivalry and the Industry Model of Scottish Knitwear Producers." Administrative Science Quarterly, 40: 203-227.

Ramnath, S., et al.

2008 "The financial analyst forecasting literature: A taxonomy with suggestions for further research." International Journal of Forecasting, 24: 34-75.

Rao, H., et al.

2001 "Fool's gold: Social proof in the initiation and abandonment of coverage by Wall Street analysts." Administrative Science Quarterly, 46: 502-526.

Reagans, R., and E. W. Zuckerman

2001 "Networks, diversity, and productivity: The social capital of corporate R\&D teams." Organization Science, 12: 502-517.

Rendell, L., et al.

2010 "Why Copy Others? Insights from the Social Learning Strategies Tournament." Science, 328: 208-213.

Rogers, E. M.

1995 Diffusion of Innovations, fourth ed. New York: The Free Press.

Sampson, R. J., et al.

2002 "Assessing" neighborhood effects": Social processes and new directions in research." Annual Review of Sociology: 443-478.

Sewell, W. H. J.

1992 "A theory of structure: Duality, agency, and transformation." American Journal of Sociology: 1-29.

Simon, $\mathrm{H}$.

1956 "Rational choice and the structure of the environment." Psychological review, 63: 129. 
1997 "Designing Organizations for an Information-Rich World." In D. M. Lamberton (ed.), The Economics of Communication and Information: 187-203. Cheltenham, UK: Edward Elgar.

Smith, K. G., et al.

2001 "Competitive dynamics research: Critique and future directions." In M. Hitt, et al. (eds.), Handbook of strategic management: 315-361. London: Blackwell.

Srinivasan, R., et al.

2007 "Vicarious learning in new product introductions in the early years of a converging market." Management Science, 53: 16-28.

Stickel, S. E.

1992 "Reputation and performance among security analysts." Journal of Finance, 47: 1811-1836.

Strang, D., and N. B. Tuma

1993 "Spatial and temporal heterogeneity in diffusion." American Journal of Sociology, 99: 614639.

Stuart, T., E.

1998 "Network Positions and Propensities to Collaborate: An Investigation of Strategic Alliance Formation in a High-Technology Industry." Administrative Science Quarterly, 43: 668-698.

Stuart, T. E., and J. M. Podolny

1996 "Local search and the evolution of technological capabilities." Strategic Management Journal, 17: 21-38.

Sytch, M., and A. Tatarynowicz

2014 "Exploring the Locus of Invention: the Dynamics of Network Communities and Firms' Invention Productivity." Academy of Management Journal, 57: 249-279.

Terlaak, A., and Y. Gong

2008 "Vicarious Learning and Inferential Accuracy in Adoption Processes." Academy of Management Review, 33: 846-868.

Theiner, G., et al.

2010 "Recognizing group cognition." Cognitive Systems Research, 11: 378-395. 
Tsai, W., et al.

2011 "Seeing through the eyes of a rival: Competitor acumen based on rival-centric perceptions." Academy of Management Journal, 54: 761-778.

Tucci, C. L., and M. P. Lojo

1994 "Social Comparisons and Cooperative R\&D Ventures: The Double-Edged Sword of Communication." The International Center for Research on the Management of Technology. Cambridge: Sloan School of Management.

Wansleben, L.

2012 "Financial Analysts." In K. Knorr Cetina, and A. Preda (eds.), The Oxford Handbook of the Sociology of Finance: 250-271. Oxford, UK: Oxford University Press.

Washburn, M., and P. Bromiley

2014 "Managers and Analysts: An Examination of Mutual Influence." Academy of Management Journal, 57: 849-868.

Wasserman, S., and K. Faust

1994 Social network analysis : methods and applications. New York, NY: Cambridge University Press.

Watts, D. J., and P. S. Dodds

2007 "Influentials, networks, and public opinion formation." Journal of Consumer Research, 34: 441-458.

Williamson, O. E.

1985 The Economic Institutions of Capitalism. New York: Free Press.

Wisdom, T. N., and R. L. Goldstone

2011 "Innovation, Imitation, and Problem Solving in a Networked Group." Nonlinear DynamicsPsychology and Life Sciences, 15: 229.

Wisdom, T. N., et al.

2013 "Social Learning Strategies in Networked Groups." Cognitive science, 37: 1383-1425. 
Zhou, T., et al.

2010 "Solving the apparent diversity-accuracy dilemma of recommender systems." Proceedings of the National Academy of Sciences, 107: 4511-4515.

Zuckerman, E. W.

1999 "The Categorical Imperative: Securities Analysts and the Illegitimacy Discount." American Journal of Sociology, 104: 1398-1438.

2000 "Focusing the corporate product: Securities analysts and de-diversification." Administrative Science Quarterly, 45: 591-619.

2004 "Structural incoherence and stock market activity." American Sociological Review, 69: 405-432. 


\section{APPENDIX 1: CONSTRUCTING AUDIENCE CLOSURE}

The measurement of audience closure starts with a schedule representing the audience producer interface. This schedule can be expressed as a binary adjacency matrix $\boldsymbol{X}$ of dimensions $\left(K_{K} \times{ }_{I}\right)$, where ${ }_{K}$ is the total number of producers and ${ }_{I}$ the total number of evaluators under study at some period in time. Each $(k, i)^{\text {th }}$ entry in $\boldsymbol{X}$ is equal to one if producer $k$ is evaluated by audience $i$, and zero otherwise (Breiger, 1974). The $\boldsymbol{X}$ matrix has row totals that indicate the overall number of audiences evaluating each producer, while column totals indicate the overall number of producers evaluated by each audience.

The second step in constructing audience closure is to calculate overlap in producers for each pair of evaluators. Overlap is expressed by a matrix $\boldsymbol{Y}$ of dimension $\left({ }_{I} \times{ }_{I}\right)$, produced by matrixmultiplying the schedule in step 1 by its transpose; $\boldsymbol{X}^{\prime} \boldsymbol{X}=\boldsymbol{Y}$. Diagonal entries in $\boldsymbol{Y}\left(y_{i i}\right)$ denote the total number of producers associated with each focal evaluator $i$. Off-diagonal entries in $\boldsymbol{Y}\left(y_{i j}\right)$ denote the number of producers evaluated by both $i$ and $j(i \neq j)$. Higher values of $y_{i j}$ indicate stronger proximity between the two evaluators (Borgatti, and Everett, 1997). Depending on the context, stronger proximity may connote positive ties (e.g. number of alliances formed in the past by organizations $i$ and $j$ ), conflictive ties (e.g. number of outstanding lawsuits between $i$ and $j$ ) or competitive overlap (e.g. number of cities in which both $i$ and $j$ have a market presence).

The added value of the audience closure measures lies not in counting the direct links between audiences and producers, but in capturing the influence of alter evaluators through producers beyond the focal producer. This influence increases with the number of unique threestep paths spanning audience-producer pairs, as illustrated in figure 2.1. Audience closure for a focal evaluator $i$ and focal producer $k$ can be written by summing up the $y_{i j}$ entries across all other evaluators $j$ and adjusting the expression to exclude direct links: 


$$
A C_{i k}=\sum_{i \neq j}\left(y_{i j}-\sigma_{i k}\right) \sigma_{j k}
$$

The indicators $\sigma_{i k}$ and $\sigma_{i j}$ are equal to one if evaluators $i(j)$ are directly connected to focal producer $k$, and zero otherwise. The terms $\sigma_{i k}$ and $\sigma_{j k}$ ensure that audience closure between $i$ and $k$ increase only if $i$ and some $j$ share at least one additional producer $m(m \neq k) .{ }^{34} A C_{i k}$ captures opportunities available to focal evaluator $i$ for pairwise comparisons of $k$ with each $m$ shared with each alter evaluator $j$. From the point of view of a single evaluator $i$, audience closure is highest with the producer who enables the most direct comparisons with other producers. A peculiar characteristic of audience closure is that $A C_{i k}$ may be non-zero for some producer $k$ not evaluated by audience $i$. In such cases, audience closure between $i$ and $k$ can be thought of as latent. Although not leveraged in the current study, this property of audience closure could be a helpful factor for analysts deciding which stocks to add to their portfolio or as a guide to research on firms’ entry choices into new markets (e.g. Belderbos, et al., 2011).

\footnotetext{
${ }^{34}$ When both $i$ and $j$ are connected to $k, A C_{i k}=0$ if $y_{i j}<2$.
} 


\section{APPENDIX 2: AUDIENCE CLOSURE AND OTHER NETWORK MEASURES}

Most familiar network measures emerged from analyses of traditional, single-mode networks. In this appendix, I situate audience closure by providing a brief comparison to some of these measures as well as with measures developed specifically for bipartite networks.

\section{Reachability}

Reachability in traditional unimodal networks counts the number and lengths of paths between pairs of nodes. For example, nodes $i$ and $j$ are reachable by each other if connected by some path of length $p$. The powers of a socio-matrix $\boldsymbol{X}^{p}$ represent the number of paths of lengths "p" connecting two nodes (Wasserman, and Faust, 1994, pgs. 159-161). For example, elements of $\boldsymbol{X}^{3}$ count the number of 3-step paths between two pairs of nodes in a single mode network. In the purely mechanical sense, audience closure is a simple application to bipartite networks of 3step reachability.

\section{Centrality}

Audience closure is conceptually related to two familiar measures of centrality: betweenness centrality and degree centrality (Freeman, 1979). A node with high betweenness is along the shortest path between many pairs of nodes. High degree centrality means that a node has many "direct neighbors", or other nodes that can be reached in paths of length one. A recent extension of the concept of centrality are the "KPP-Neg” and "KPP-Pos” measures developed by Borgatti (2006). The general approach involves finding nodes that can reach as many remaining nodes as possible via direct links or short paths. 
Betweenness and degree centrality summarize an overall characteristic of each node, while the KPP-Neg and KPP-Pos measures identify sets of mutually influential nodes. In contrast to these measures, audience closure varies for each pair of nodes formed from opposite sides of the bipartite network. Similarly to measures of centrality, audience closure also increases as a node is connected to many other nodes via short paths. But unlike these measures, audience closure increases with additional alternative paths (i.e. redundancy) between pairs of nodes. Sensitivity to path redundancy is a desirable property because it captures a refined structural “mesh” beneficial for filtering complex information. For example, removing a "high betweenness” node causes many pairs of nodes to become fully disconnected or at least more distantly connected (Borgatti, 2006). The bipartite version of degree centrality in the current setting (i.e. the number of other analysts co-covering at least one stock with the focal analyst) is also insensitive to different paths when these are routed via the same competing analyst but different comparison stocks, or via the same comparison stock co-covered with different competitors. $^{35}$

\section{Clustering}

Latapy and colleagues (2008) and Lind et al. (2005) independently developed a clustering coefficient meant to capture overlap in bipartite networks. The measure (called redundancy coefficient and $C_{4}$, respectively) is defined as the fraction of pairs of neighbors of $i$ linked to a node other than $i$. In the analyst-stock setting, the bipartite clustering coefficient is obtained by dividing the number of stocks jointly covered by the focal analyst and her direct neighbors (i.e. the intersection of their sets) by the total number of unique stocks covered by the focal analyst

\footnotetext{
${ }^{35}$ In the first case, audience closure captures several alters' views of a single comparison stock (enabling the contextualizing process). In the second case, audience closure captures a single competitor across several stocks (enabling the untangling process).
} 
and her direct neighbors (i.e. the union of their sets). While the centrality measures are insensitive to redundancy, the clustering coefficient over-corrects this shortcoming, at least for the purposes of my social learning theory. A pair of analysts fully overlapping on the same few stocks will have a clustering coefficient of one (the maximum), and this number will be reduced by the entrance of another analyst with only partial overlap. This is anathema to the idea, captured by audience closure, that the third analyst may bring novel insights about co-covered stocks.

\section{Structural equivalence}

The concept of structural equivalence balances desirable properties from both centrality and clustering. Two nodes are structurally equivalent to the extent that they have identical relations with all others in the study population (Burt, 1987). In the network of analysts covering stocks, the bipartite version of structural equivalence proposed by Latapy et al. (2008) measures the tendency of a focal analyst's coverage universe to be included within the coverage universe of its direct neighbors. The measure captures tie redundancy very well, but only provides an analyst's "average” orientation to all of her stocks, vis-à-vis direct competitors. For example, analyst i's structural equivalence could not be statistically identified in a regression containing analyst fixed effects because the measure is the same for every stock $k$. By focusing on paths rather than node overlap, audience closure identifies each analyst's unique opportunities to learn about each stock. 


\section{Coverage coherence}

The building blocks of audience closure underlie Zuckerman's (2004)measure of a stock's coverage coherence. While audience closure is a dyadic property of each pair of nodes in opposite networks, coverage coherence provides an average for each node in only one of the two networks (in this case, the “average coverage similarity” of analysts following stock $k$ ). Coverage coherence is thus a weighted projection of a bipartite network into a one-mode structure, which introduces two major complications. First, many bipartite graphs can lead to the same projection (Latapy, et al., 2008). The construction of coverage coherence requires a number of steps to normalize and aggregate dyadic overlap, which obliterates information about an evaluator's unique position relative to shared producers. Second, projections of bipartite networks reduce the role of high degree nodes (e.g. firms with many covering analysts, as well as analysts covering many firms), which is a real distributional property of the network. As shown by Opsahl's (2011) analysis of a scientific collaboration network, the projection of a random version of the two mode network has over 350 times the level of clustering that is expected in corresponding classical random one-mode networks. If nodes in the bipartite network have a degree greater than two, triangles will be automatically formed in the one-mode projection, which will bias the one-mode clustering coefficient upwards (Opsahl, 2011).

There are many instances in the analyst context where the limitations of coverage coherence become apparent for my theoretical purposes. For example, coverage coherence provides no insights about patterns of coverage of "pure play” firms (i.e. those covered only by industry specialists). In contrast, audience closure helps identify better and worse positions for covering such a firm. As shown in the examination of expertise among I.I. ranked analysts, 
audience closure can also help identify stock-specific expertise for recognized industry specialists.

\section{Multimarket (multipoint) contact}

Multimarket contact appeared in Baum and Korn (1996) and was subsequently applied to the analyst context by Bowers and colleagues (2013) under the name of Multipoint contact (MPC). MPC captures "the extent to which an analyst covering a stock jointly with other analysts also covers other stocks jointly with those analysts” (Bowers, et al., 2013). Both audience closure and MPC have the advantage of uniquely relating each analyst-stock pair. Although the theoretical underpinning of MPC is drastically different from that of audience closure, their construction is similar. In particular, dividing audience closure by the product of the number of firms covered by analyst $i$ and the number of analysts covering firm $k$ yields MPC. However, there is no theoretical justification in my model of social learning to carry out this normalization. In addition, the empirical effect of dividing audience closure by the product of the number of firms covered by analyst $i$ and the number of analysts covering firm $k$ is unclear, since both measures are normally included as control variables in my regressions and in most studies on analyst forecasts and stock recommendations. 


\section{APPENDIX 3: PRODUCER CLOSURE EQUALS AUDIENCE CLOSURE}

Recall that audience closure has been defined as a function of $y_{i j}$, the number of producers shared by evaluators $i$ and $j$ :

$$
A C_{i k}=\sum_{i \neq j}\left(y_{i j}-\sigma_{i k}\right) \sigma_{j k}
$$

Let $w_{k m}$ represent the number of evaluators shared by the $k, m$ producer pair $(k \neq m)$. In other words $w_{k m}$ are the off-diagonal entries of $\boldsymbol{W}$, a square symmetric matrix of dimensions ${ }_{K} \times{ }_{K}$ (i.e. $\boldsymbol{W}=\boldsymbol{X} \boldsymbol{X}^{\prime}$ ). "Producer closure" between evaluator $\boldsymbol{i}$ and producer $k$ can be expressed as a function of overlap in evaluators:

$$
P C_{i k}=\sum_{k \neq m}\left(w_{k m}-\sigma_{i k}\right) \sigma_{i m}
$$

where $\sigma_{i k}$ and $\sigma_{i m}$ are equal to one if producers $k(m)$ are both evaluated by $i$ and zero otherwise. I claim that $A C_{i k}=P C_{i k}$ for any evaluator $i$ and producer $k$. Their equivalence is demonstrated below.

First, expand both expressions:

$$
\begin{aligned}
& A C_{i k}=\sum_{i \neq j}\left(y_{i j}-\sigma_{i k}\right) \sigma_{j k}=\sum_{j=1}^{J} y_{i j} \sigma_{j k}-\sum_{j=1}^{J} \sigma_{i k} \sigma_{j k}-y_{i i} \sigma_{i k}+\sigma_{i k}^{2} \\
& P C_{i k}=\sum_{k \neq m}\left(w_{k m}-\sigma_{i k}\right) \sigma_{i m}=\sum_{m=1}^{M} w_{k m} \sigma_{i m}-\sum_{m=1}^{M} \sigma_{i k} \sigma_{i m}-w_{k k} \sigma_{i k}+\sigma_{i k}^{2}
\end{aligned}
$$

Note that the number of evaluators for producer $k=w_{k k}=\sum_{j=1}^{J} \sigma_{j k}$

Similarly, the number of producers for evaluator $i=y_{i i}=\sum_{m=1}^{M} \sigma_{i m}$

Therefore, $\sum_{j=1}^{J} \sigma_{i k} \sigma_{j k}=w_{k k} \sigma_{i k}$, and $\sum_{m=1}^{M} \sigma_{i k} \sigma_{i m}=y_{i i} \sigma_{i k}$. 
Therefore it suffices to show that

$$
\sum_{j=1}^{J} y_{i j} \sigma_{j k}=\sum_{m=1}^{M} w_{k m} \sigma_{i m}
$$

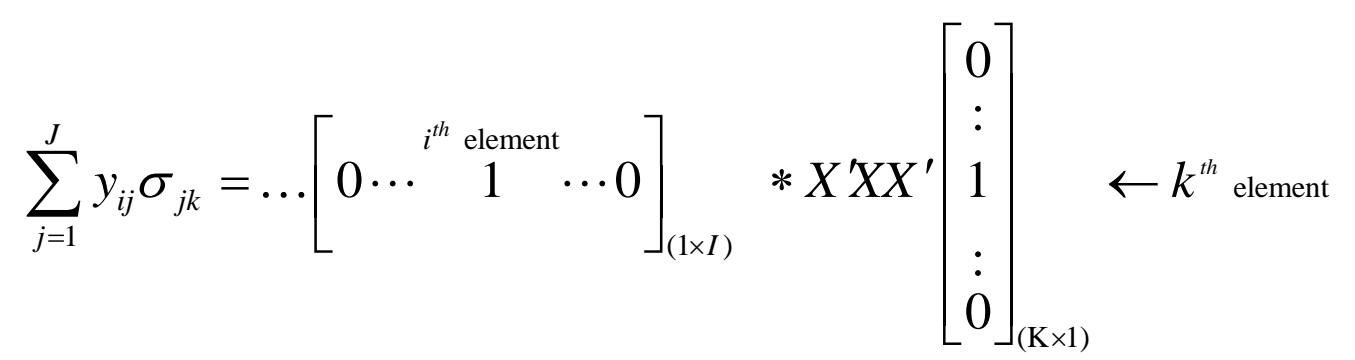

$\sum_{m=1}^{M} w_{k m} \sigma_{i m}=\ldots\left[\begin{array}{ccc}0 & k^{\text {th }} \text { element } & 1 \\ & \cdots & \cdots\end{array}\right]_{(1 \times K)} * X X^{\prime} X\left[\begin{array}{c}0 \\ \vdots \\ 1 \\ \vdots \\ 0\end{array}\right]_{(I \times 1)} \leftarrow i^{\text {th }}$ element

(1) and (2) are transposes of each other that evaluate to a scalar.

Therefore, $\sum_{j=1}^{J} y_{i j} \sigma_{j k}=\sum_{m=1}^{M} w_{k m} \sigma_{i m} \Rightarrow A C_{i k}=P C_{i k}$

$$
\text { Q.E.D. }
$$

This equivalence is visually obvious in figure 2.1: the number of unique three-step paths connecting Deb and the focal producer $\mathrm{p}_{\mathrm{F}}$ are of course equivalent to the number of three-step paths connecting $\mathrm{p}_{\mathrm{F}}$ to Deb. The empirical results also reflect that what could logically be thought of as "producer closure” is an alternative derivation of "audience closure”, as proven above. In table 5.1, I find that analysts in high audience closure positions provide the most accurate forecasts of any given firm's future earnings (model 3). At the same time, I also find that high audience closure helps predict the firms for which a given analyst issues the most accurate forecasts (model 4). 